\title{
Disaggregation of SMOS Soil Moisture in Southeastern Australia
}

\author{
3 Olivier Merlin, Christoph Rüdiger, Ahmad Al Bitar, Philippe Richaume, Jeffrey P. Walker, and Yann H. Kerr
}

4 Abstract-Disaggregation based on Physical And Theoretical 5 scale Change (DisPATCh) is an algorithm dedicated to the dis6 aggregation of soil moisture observations using high-resolution 7 soil temperature data. DisPATCh converts soil temperature fields 8 into soil moisture fields given a semi-empirical soil evaporative 9 efficiency model and a first-order Taylor series expansion around 10 the field-mean soil moisture. In this study, the disaggregation 11 approach is applied to soil moisture and ocean salinity (SMOS) 12 data over the $500 \mathrm{~km}$ by $100 \mathrm{~km}$ AACES (Australian Airborne 13 Calibration/validation Experiments for SMOS) area. The $40-\mathbf{k m}$ 14 resolution SMOS surface soil moisture pixels are disaggregated 15 at $\mathbf{1 - k m}$ resolution using the soil skin temperature derived from 16 moderate resolution imaging spectroradiometer (MODIS) data, 17 and subsequently compared with the AACES intensive ground 18 measurements aggregated at $\mathbf{1 - k m}$ resolution. The objective is to 19 test DisPATCh under various surface and atmospheric conditions. 20 It is found that the accuracy of disaggregation products varies 21 greatly according to season: while the correlation coefficient be22 tween disaggregated and in situ soil moisture is about 0.7 during 23 the summer AACES, it is approximately zero during the winter 24 AACES, consistent with a weaker coupling between evaporation 25 and surface soil moisture in temperate than in semi-arid climate. 26 Moreover, during the summer AACES, the correlation coefficient 27 between disaggregated and in situ soil moisture is increased from 280.70 to 0.85 , by separating the $1-\mathrm{km}$ pixels where MODIS temper29 ature is mainly controlled by soil evaporation, from those where 30 MODIS temperature is controlled by both soil evaporation and

31 vegetation transpiration. It is also found that the $5-\mathrm{km}$ resolution 32 atmospheric correction of the official MODIS temperature data 33 has a significant impact on DisPATCh output. An alternative at34 mospheric correction at $\mathbf{4 0}-\mathbf{k m}$ resolution increases the correlation 35 coefficient between disaggregated and in situ soil moisture from 360.72 to 0.82 during the summer AACES. Results indicate that

Manuscript received March 31, 2011; revised September 1, 2011; accepted October 30, 2011. The AACES participants are gratefully acknowledged for their participation in collecting this extensive data set. The Australian Airborne Calibration/validation Experiments for SMOS have been made possible through infrastructure (LE0453434) and research (DP0879212) funding from the Australian Research Council, and the collaboration of a large number of scientists from throughout Australia, United States and Europe. Initial setup and maintenance of the study catchments was funded by two research Grants (DP0343778, DP0557543) from the Australian Research Council and by the CRC for Catchment Hydrology. This work was funded by the CNES TOSCA (Terre solide, Océan, Surfaces Continentales et Atmosphère) program and the Centre National de la Recherche Scientifique.

O. Merlin is with the Centre d'Etudes Spatiales de la Biosphère (CESBIO), 31401 Toulouse, France (e-mail: olivier.merlin@ cesbio.cnes.fr).

C. Rüdiger (e-mail: chris.rudiger@monash.edu)

A. Al Bitar (e-mail: ahmad.albitar@cesbio.cnes.fr).

P. Richaume (e-mail: philippe.richaume@cesbio.cnes.fr).

J. P. Walker (e-mail: jeff.walker@monash.edu).

Y. H. Kerr (e-mail: yann.kerr@cesbio.cnes.fr).

Color versions of one or more of the figures in this paper are available online at http://ieeexplore.ieee.org.

Digital Object Identifier 10.1109/TGRS.2011.2175000
DisPATCh has a strong potential in low-vegetated semi-arid areas 37 where it can be used as a tool to evaluate SMOS data (by reducing 38 the mismatch in spatial extent between SMOS observations and 39 localized in situ measurements), and as a further step, to derive 40 a $1-\mathbf{k m}$ resolution soil moisture product adapted for large-scale 41 hydrological studies.

Index Terms-AACES, calibration/validation, disaggregation, 43 Disaggregation based on Physical And Theoretical scale Change 44 (DisPATCh), field campaign, moderate resolution imaging spectro- 45 radiometer (MODIS), soil moisture and ocean salinity (SMOS). 46

\section{INTRODUCTION}

$\mathbf{P}$ ASSIVE MICROWAVE remote sensing has the capability 48 to provide key elements of the terrestrial hydrological 49 cycle such as surface soil moisture [1], [2] and overland pre- 50 cipitation [3], [4]. Nevertheless, due to the large discrepancy 51 between the observation scale (several tens of $\mathrm{km}$ ) and the scale 52 of physical interactions with the land surface (one wavelength 53 or several $\mathrm{cm}$ ), the radiative transfer models applied to passive 54 microwave remote sensing data are only semiphysically based. 55 Consequently, the retrieval process of land surface parameters 56 from microwave brightness temperatures requires ancillary data 57 for calibration and validation purposes [5]. It also requires a 58 strategy to use such ancillary data since ground-based sampling 59 is often made over a small area/point, which constrasts with 60 the large integrated extent of spaceborne passive microwave 61 observations.

The soil moisture and ocean salinity (SMOS), [6]) satellite 63 was launched on November 2, 2009. Over land, the SMOS 64 mission aims at providing $\sim 5 \mathrm{~cm}$ surface soil moisture data 65 at a spatial resolution better than $50 \mathrm{~km}$ and a repeat cycle of 66 less than 3 days. The payload is a 2-D interferometer equipped 67 with 69 individual L-band antennas regularly spaced along Y- 68 shaped arms. This new concept allows observing all pixels in 69 the $1000 \mathrm{~km}$ wide field of view at a range of incidence angles. 70 It also allows reconstructing brightness temperatures on a fixed 71 sampling grid [7].

Since the SMOS launch, various field experiments (the 73 HOBE site in Denmark [8], the Mali site in Western Africa 74 [9], the SMOSMANIA site in Southwestern France [10] just 75 to name a few) have been undertaken to validate SMOS recon- 76 structed brightness temperatures and soil moisture retrievals. 77 The AACES (Australian Airborne Calibration/validation 78 Experiment for SMOS, [11]) is one of the most compre- 79 hensive campaigns worldwide dedicated to SMOS calibra- 80 tion/validation. A series of two experiments were undertaken 81 in 2010, AACES-1 in January-February (Austral summer) and 82 
83 AACES-2 in September (Austral winter). The data collected 84 in AACES include 1-km resolution airborne L-band brightness 85 temperature mapped over a $500 \mathrm{~km}$ by $100 \mathrm{~km}$ area, 20 days 86 of very intensive ground measurements and $205 \mathrm{~km}$ by $2 \mathrm{~km}$ 87 ground sampling areas.

88 Even though the AACES ground measurements are very 89 extensive, it is not feasible to cover the whole extent of a 90 SMOS pixel by ground sampling alone. This is the reason why 91 most validation strategies of spaceborne passive microwave 92 data using in situ measurements have been based on the as93 sumption that local observations are representative of a much 94 larger spatial extent (i.e., the size of a microwave pixel). In the 95 heterogeneous case where this assumption does not hold, up96 scaling approaches [12], [13] have been developed to relate the 97 available ground observations to satellite scale soil moisture. 98 Such approaches are very useful over sites which have been 99 monitored for a long time and where extensive measurements 100 have been made over a range of spatial scales. However, aggre101 gation rules are difficult to build over sites which have been set 102 up recently, or where no extensive field campaigns have been 103 undertaken.

104 This study develops a methodology to facilitate the cali105 bration and validation of SMOS data using localized ground 106 measurements, such as those collected during AACES. The 107 methodology combines upscaling (aggregation) and downscal108 ing (disaggregation) approaches to make remote sensing and 109 in situ observations match at an intermediate spatial resolution 110 of $1 \mathrm{~km}$. The key step in the procedure is a disaggregation 111 algorithm of passive microwave soil moisture using kilometric 112 optical data [14]-[16]. Disaggregating SMOS soil moisture can 113 solve the disparity of spatial scales between satellite and in situ 114 observations. However, the validation of spaceborne data by 115 means of a disaggregation approach requires the uncertainties 116 and potential error sources in downscaled data to be assessed. 117 Generally speaking, disaggregation is a compromise between 118 downscaling resolution and accuracy. The higher downscaling 119 resolution, the more disaggregated values are spatially repre120 sentative of ground observations, but typically have a lower 121 accuracy and vice versa [17]. In this context, a disaggrega122 tion algorithm named Disaggregation based on Physical And 123 Theoretical scale Change (DisPATCh) is applied to $40-\mathrm{km}$ 124 resolution SMOS soil moisture over the AACES area using 1$125 \mathrm{~km}$ resolution Moderate resolution Imaging Spectroradiometer 126 (MODIS) data. The objective is to test DisPATCh under various 127 surface and atmospheric conditions. Specifically, the impact 128 of climatic (evaporative demand), meteorologic (presence of 129 clouds), and vegetation (cover and water status) conditions on $1301-\mathrm{km}$ resolution disaggregated soil moisture is evaluated both 131 qualitatively by visual assessment of disaggregation images and 132 quantitatively by comparing DisPATCh output with AACES 133 intensive ground measurements.

134 The AACES, SMOS, and MODIS data used in this study 135 are first described. Next, the disaggregation methodology is 136 presented followed by a step-by-step description of the Dis137 PATCh algorithm. Results of the comparison between disag138 gregated SMOS soil moisture and in situ measurements are 139 then reported. To test DisPATCh under various surface and 140 atmospheric conditions, the algorithm is run during AACES-1 and AACES-2 in different modes, by including (or not) a 141 correction for vegetation and atmospheric effects. Finally, some 142 perspectives in the use of DisPATCh for validating SMOS data 143 using ground-based sampling are given.

\section{Data Collection And PReprocessing}

The AACES experiments were planned to provide ground 146 and airborne soil moisture data over an area of approximately 147 $500 \mathrm{~km}$ by $100 \mathrm{~km}$ during the two main seasons in the 148 Murrumbidgee river catchment, in southeastern Australia. The 149 first AACES campaign (AACES-1) was undertaken in summer 150 2010 from January 18 to February 21, and the second campaign 151 (AACES-2) was undertaken in the following Austral winter 152 from September 11 to September 24 [11]. Fig. 1 presents the 153 study area including the $205 \mathrm{~km}$ by $2 \mathrm{~km}$ ground sampling 154 focus areas. The background image is the MODIS 250-m res- 155 olution 16-day normalized difference vegetation index (NDVI) 156 product of February 2, 2010. The climate of the Murrumbidgee 157 catchment area ranges from semi-arid in the west to alpine in 158 the east, with a strong rainfall and potential evapotranspiration 159 gradient in the west-east direction. Land use is extensive graz- 160 ing in the west, cropping in the center, and mostly grazing/forest 161 in the east (refer to [11] for a detailed account of AACES). 162

\section{A. $H D A S$}

163

During both AACES-1 and AACES-2, a spatially enabled 164 platform (Hydraprobe Data Acquisition System, HDAS) was 165 used to collect extensive measurements of near-surface soil 166 moisture. HDAS is a handheld system combining a soil dielec- 167 tric sensor (Hydraprobe) and a pocket PC with GPS receiver, 168 allowing for direct storage of location and measurement within 169 the GIS software. HDAS measurements were calibrated using 170 the approach presented in [18] with a root mean square error 171 of point estimate of about $0.03 \mathrm{~m}^{3} / \mathrm{m}^{3}$. The sampling coverage 172 was two $5 \mathrm{~km}$ by $2 \mathrm{~km}$ farms per day during AACES- 1 and one 173 $5 \mathrm{~km}$ by $2 \mathrm{~km}$ farm per day during AACES-2. Within each farm, 174 a total of six adjacent $5 \mathrm{~km}$ long transects separated by $330 \mathrm{~m} 175$ were walked to cover each area of $10 \mathrm{~km}^{2}$, and three separate 176 HDAS measurements were made along transects every $50 \mathrm{~m} . \quad 177$

In this study, HDAS soil moisture data are aggregated at 178 $1-\mathrm{km}$ resolution by averaging all measurements made within 179 each pixel of the MODIS resolution grid. Out of concern for 180 spatial representativeness of in situ observations, only the 1-km 181 pixels whose ground sampling covers more than two third of 182 its surface area are kept for comparison with disaggregation 183 results. The 1-km average of HDAS measurements is denoted 184 $\left\langle\mathrm{SM}_{\mathrm{HDAS}}\right\rangle$ and the standard deviation of in situ measurements 185 (denoted $\sigma_{\mathrm{HDAS}}$ ) computed to estimate the subpixel variability 186 at $1-\mathrm{km}$ resolution.

\section{B. SMOS}

The version-4 SMOS level-2 soil moisture product is used. 189 This product (released on March 24, 2011) was produced from 190 the reprocessed level 1C data, and the version-4 level-2 soil 191 moisture algorithm. SMOS has a 6 am (ascending) and 6 pm 192 


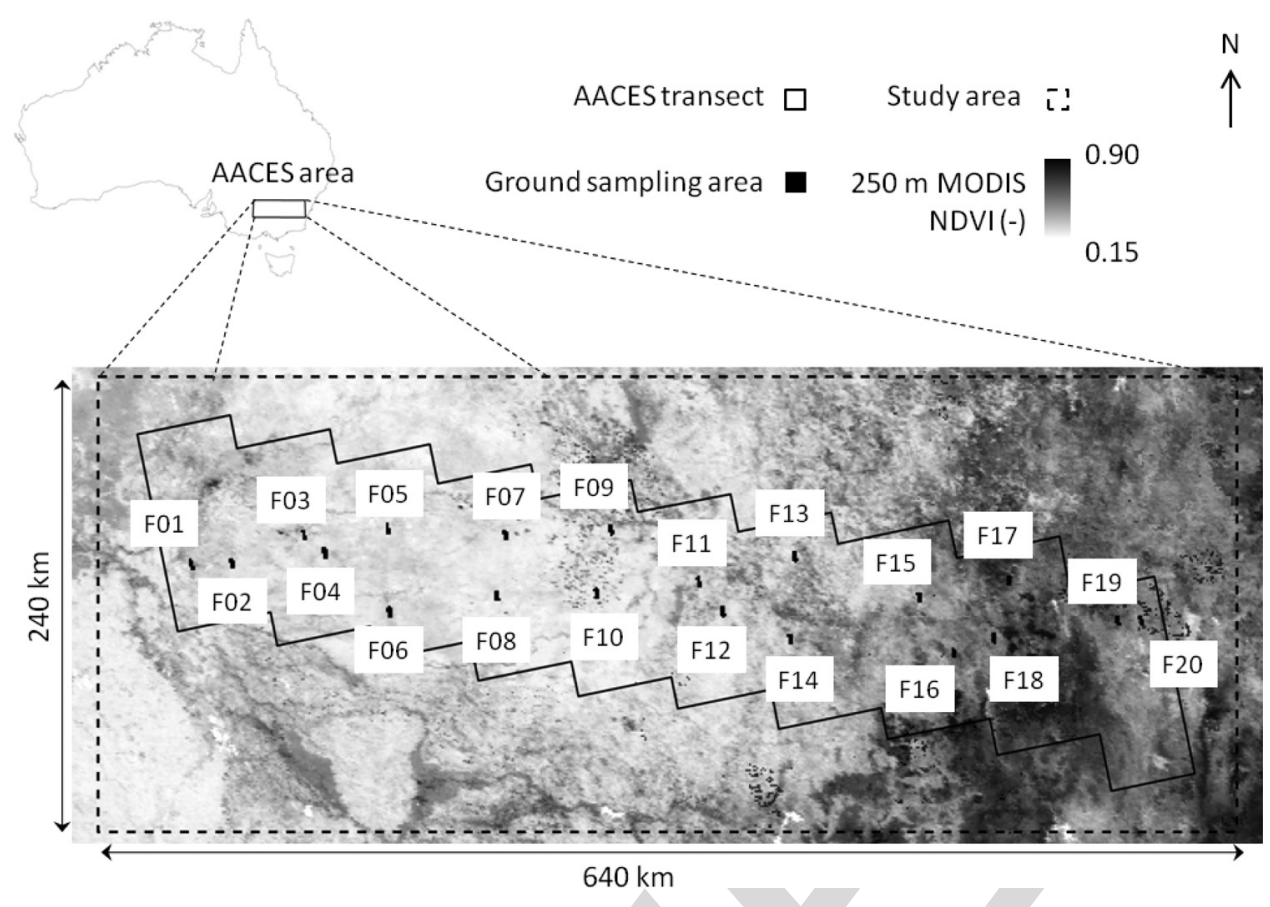

Fig. 1. Overview of the study area. During AACES, ten $100 \mathrm{~km}$ by $50 \mathrm{~km}$ patches were overflown by an airborne L-band radiometer. Within each patch, two $5 \mathrm{~km}$ by $2 \mathrm{~km}$ subareas were sampled to collect spatial soil moisture measurements. In this study, DisPATCh is run over a $640 \mathrm{by} 240 \mathrm{~km}$ area including the whole AACES area, and disaggregation results are evaluated over the ground sampling areas.

193 (descending) equator crossing time. The sampling grid of the 194 SMOS level-2 soil moisture product is called DGG or discrete 195 global grid [19], [20] and has a node separation of about $19615 \mathrm{~km}$. The DGG provides a discretization that is higher than 197 the SMOS natural pixel size, which is $40 \mathrm{~km}$ on average, 198 ranging from $30 \mathrm{~km}$ at boresight to $90 \mathrm{~km}$ at high incidence 199 angles. In this study, the disaggregation procedure takes advan200 tage of the oversampling of SMOS data to potentially reduce 201 (and provide an estimate of) random errors in disaggregated 202 SMOS data. Instead of using a single snapshot SMOS im203 age, DisPATCh uses four (overlapping) independent snapshots, 204 which are generated by: 1) sliding a 40-km resolution grid; and 2052 ) extracting the DGG nodes approximately centered on each $20640 \mathrm{~km}$ pixel. The extraction of SMOS DGG nodes is presented 207 in [21]. The DGG node(s) that fall(s) near the center of the $20840-\mathrm{km}$ resolution pixels with a $+/-10-\mathrm{km}$ tolerance are se209 lected. If more than one DGG is selected, the associated soil 210 moisture values are averaged to produce a single value for each $21140-\mathrm{km}$ resolution pixel. The $40-\mathrm{km}$ resolution grid that fits the 212 study area corresponds to what is termed here Resampling 1. 213 Similarly, Resampling 2, 3, and 4 are performed by sliding the 214 40-km resolution grid to coordinates $(+20 \mathrm{~km}, 0),(0,-20 \mathrm{~km})$, 215 and $(+20 \mathrm{~km},-20 \mathrm{~km})$, respectively. The four $40-\mathrm{km}$ resolu216 tion SMOS data sets are then used independently as input to 217 DisPATCh.

\section{C. MODIS}

The MODIS data used in this paper are composed of:

- Version-5 MODIS/Terra land surface temperature and emissivity daily level-3 global 1-km grid product (MOD11A1) and version-5 MODIS/Aqua land surface temperature and emissivity daily level-3 global 1-km grid 223 product (MYD11A1). The land surface temperature data 224 set is the main component of DisPATCh. It is used to 225 estimate $1-\mathrm{km}$ resolution soil evaporative efficiency at 226 $10 \mathrm{am}$ (Terra data) and $1 \mathrm{pm}$ (Aqua data) [22].

- Version-5 MODIS/Terra vegetation indices 16-day level-3 228 global 1-km grid product (MOD13A2). The NDVI data set 229 is used in DisPATCh to estimate the fractional vegetation 230 cover at 1-km resolution [23].

- Version-5 MODIS/Terra+Aqua albedo 16-day level-3 232 global 1-km grid product (MCD43B3). The surface albedo 233 data set is used in DisPATCh to estimate the vegetation 234 temperature at maximum water stress from the space land 235 surface temperature albedo [24]. The MCD43B3 product 236 provides $1-\mathrm{km}$ data describing both directional hemispher- 237 ical reflectance (black-sky albedo) at local solar noon 238 and bihemispherical reflectance (white-sky albedo). In this 239 study, surface albedo refers to the MODIS shortwave white 240 sky albedo.

- MODIS/Terra level-1B calibrated radiances swath 1-km 242 grid product (MOD021KM) and MODIS/Aqua level- 243 1B calibrated radiances swath $1-\mathrm{km}$ grid product 244 (MYD021KM). The radiance data set is used to derive 245 a land surface temperature data set that differs from the 246 official MOD11A1 and MYD11A1 products with respect 247 to atmospheric correction.

Products MOD11A1, MYD11A1, MOD13A2, and 249 MCD43B3 were downloaded through the NASA Warehouse 250 Inventory Search Tool (WIST http://wist.echo.nasa.gov/) and 251 products MOD021KM and MYD021KM were downloaded 252 through the NASA Level 1 and Atmosphere Archive and Dis- 253 tribution System (LAADS http://ladsweb.nascom.nasa.gov). 254 
TABLE I

Scale And OfFset VAlues Used to CONVERT TERra (AND AQUa) MODIS RADIANCE DATA TO PHYSICAL RADIANCE VALUES OVER THE AACES AREA

\begin{tabular}{|c||c|c|}
\hline Thermal band & Scale $\left(\mathrm{W} \mathrm{m}^{-2} \mathrm{sr}^{-1}\right)$ & Offset (-) \\
\hline \hline 31 & $8.4002 \cdot 10^{-4}\left(6.5081 \cdot 10^{-4}\right)$ & $1577(2036)$ \\
32 & $7.2970 \cdot 10^{-4}\left(5.7100 \cdot 10^{-4}\right)$ & $1658(2119)$ \\
\hline
\end{tabular}

255 All products were projected in UTM 55 South with a sampling 256 interval of $1000 \mathrm{~m}$ using the MODIS reprojection tool.

257 The level-1B calibrated radiance data $\left(R_{31}\right.$ and $R_{32}$ for bands 25831 and 32, respectively) were converted from digital number 259 (DN) to radiance in $\mathrm{W} \mathrm{m}^{-2} \mathrm{sr}^{-1}$ using the radiance scales and 260 offsets provided with each MODIS granule as listed in Table I

$$
R_{\lambda}=\text { Scale }_{\lambda} \times\left(\mathrm{DN}_{\lambda}-\text { Offset }_{\lambda}\right)
$$

261 The radiance values were then converted to brightness temper262 ature in $\mathrm{K}$ using the inverse of the Planck function [25]

$$
T b_{\lambda}=\frac{c_{2}}{\lambda \ln \left(1+\frac{c_{1}}{R_{\lambda} \lambda^{5}}\right)}
$$

263 with $c_{1}=1.19107 \times 10^{8} \quad \mu \mathrm{m}^{5} \quad \mathrm{~W} \mathrm{~m}^{-2} \quad \mathrm{sr}^{-1} \quad$ and $\quad c_{2}=$ $2641.43883 \times 10^{4} \mu \mathrm{m} \mathrm{K}$, for center wavelength of the given band 265 (11.0186 $\mu \mathrm{m}$ and $12.0325 \mu \mathrm{m}$ for 31 and 32 band, respectively).

\section{D. Overlapping HDAS, SMOS, and MODIS Data and}

\section{Generating an Input Data Set}

268 As indicated in Table II, HDAS soil moisture, SMOS soil 269 moisture, and cloud-free MODIS land surface temperature data 270 have overlapped on five days during AACES-1 (on January 27128 and 30 and February 15, 18, and 20) and on five days 272 during AACES-2 (on September 11, 13, 21, 22, and 24). On 273 each sampling day, two farms were sampled during AACES-1 274 (except on February 18 when three farms were sampled), and 275 one farm was sampled during AACES-2, so that disaggregation 276 results can be evaluated for ten date-farm units during AACES2771 and five date-farm units during AACES-2.

278 DisPATCh is applied to an input ensemble composed of the 279 different combinations of available SMOS (ascending orbit at $2806 \mathrm{am}$ and/or descending orbit at $6 \mathrm{pm}$ ) and MODIS (onboard 281 Terra platform at $10 \mathrm{am}$ and/or Aqua platform at $1 \mathrm{pm}$ ) data. To 282 increase the quantity of input data sets, the MODIS data col283 lected on the day before and the day after the SMOS overpass 284 date are also included. For SMOS data on day of year (DoY) 285 51, the clear sky MODIS data collected on DoY 54 are used. 286 Note that one implicitly assumes that no rainfall occurs between 287 MODIS and SMOS overpasses, and that the spatial variability 288 captured by MODIS is relatively similar to the actual variabil289 ity of surface soil moisture at the time of SMOS overpass. 290 Moreover, the SMOS data oversampling is used to generate 291 four (overlapping) 40-km resolution SMOS grids on which 292 DisPATCh is run independently, thus increasing the number 293 of downscaled data that could be used in the validation. It is 294 reminded that the spacing (about $15 \mathrm{~km}$ ) between neighboring 295 SMOS DGG nodes is smaller than the SMOS resolution (about
$40 \mathrm{~km}$ ). By combining the four SMOS grids, the two potential 296 SMOS data sets (two orbits in one day) and the six potential 297 MODIS data sets (three days including two overpasses each), 298 the maximum number of input data sets is 48 . The generation 299 of input data sets is shown in Fig. 2 and the number of daily 300 input data sets is indicated for each date-farm unit in Table II. 301

\section{Disagggregation Algorithm}

DisPATCh converts 1-km resolution MODIS-derived soil 303 temperature fields into $1-\mathrm{km}$ resolution surface soil moisture 304 fields given a semi-empirical soil evaporative efficiency model 305 [26] and a first-order Taylor series expansion around the 306 $40-\mathrm{km}$ resolution SMOS observation. DisPATCh is an im- 307 proved version of the algorithms in [16] and [27], and mainly 308 differs with regard to the representation of the vegetation water 309 status. In previous versions [16], [27], the soil temperature was 310 derived from MODIS land surface temperature by assuming 311 that vegetation was unstressed so that vegetation temperature 312 was uniformly set to the minimum surface temperature ob- 313 served within the SMOS pixel. In this study, the approach in 314 [28] is implemented to take into account vegetation water status 315 in the estimation of soil temperature.

\section{A. Disaggregation Methodology}

The disaggregation procedure decouples the soil evaporation 318 from the $0-5 \mathrm{~cm}$ soil layer and the vegetation transpiration 319 from the root-zone soil layer by separating MODIS surface 320 temperature into its soil and vegetation components as in the 321 triangle or trapezoidal method [28], [29]. MODIS-derived soil 322 temperature is then used to estimate soil evaporative efficiency, 323 which is known to be relatively constant during the day on clear 324 sky conditions. MODIS-derived soil evaporative efficiency is 325 finally used as a proxy for surface $(0-5 \mathrm{~cm})$ soil moisture 326 variability within the SMOS pixel. The link between surface 327 soil moisture and soil evaporative efficiency at different scales 328 is ensured by a downscaling relationship and a soil evapo- 329 rative efficiency model, as described below in more detail. 330 The originality of DisPATCh relies on a dynamical land cover 331 classification (based on the hourglass approach in [28]) that 332 takes into account the subpixel variability of the sensitivity of 333 soil evaporative efficiency to surface soil moisture.

1) Downscaling Relationship: The downscaling relation- 335 ship can be written as

$$
\begin{aligned}
\mathbf{S M}_{1 \mathrm{~km}}= & \mathbf{S M}_{\mathbf{S M O S}}+\frac{\partial \mathbf{S M}_{\mathbf{m o d}}}{\partial \mathbf{S E E}} \\
& \times\left(\mathrm{SEE}_{\text {MODIS }, 1 \mathrm{~km}}-\left\langle\mathrm{SEE}_{\text {MODIS }, 1 \mathrm{~km}}\right\rangle_{\mathbf{4 0} \mathrm{km}}\right)
\end{aligned}
$$

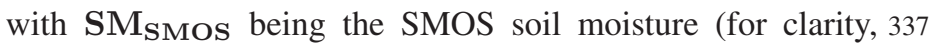
the variables defined at SMOS scale are written in bold), 338 SEE MODIS the MODIS-derived soil evaporative efficiency (ra- 339 tio of actual to potential evaporation), $\left\langle\mathrm{SEE}_{\mathrm{MODIS}}\right\rangle_{40} \mathrm{~km}$ its 340 average within a SMOS pixel and $\partial \mathbf{S} \mathbf{M}_{\text {mod }} / \partial \mathbf{S E E}$ the partial 341 derivative evaluated at SMOS scale of soil moisture with re- 342 spect to soil evaporative efficiency. Note that the linearity of (3) 343 implies that a possible bias in SMOS data would produce the 344 
TABLE II

List of OVERLAPPING HDAS, SMOS, AND MODIS (MOD11A1 AND MYD11A1) DATA DURING AACES-1 AND AACES-2. ONLY THE SMOS DATA Collected on the Same Day as Ground Sampling Have Been Considered. The MODIS Data Considered as InPut to DisPatCh Have Been Collected Within Plus or Minus One Day Either Side the Ground Sampling (and SMOS Overpass) Date. On Each Sampling Date, the Resultant Number of InPut Data Sets to DisPatCh Is Also Indicated

\begin{tabular}{|c|c|c|c|c|c|c|}
\hline Experiment & $\begin{array}{l}\text { Sampling } \\
\text { date }\end{array}$ & DoY & Farm & $\begin{array}{c}\text { SMOS } \\
\text { overpass time }\end{array}$ & $\begin{array}{c}\text { Cloud free } \\
\text { MODIS data (DoY) }\end{array}$ & $\begin{array}{c}\text { Number of input } \\
\text { data sets to DisPATCh }\end{array}$ \\
\hline \multirow[t]{10}{*}{ AACES-1 } & 28 January & 28 & F05 & $6 \mathrm{am}$ & Terra $(27,29) \&$ Aqua $(29)$ & 3 \\
\hline & 30 January & 30 & F07 & $6 \mathrm{am}$ & Terra $(29,30) \&$ Aqua $(29)$ & 12 \\
\hline & , & , & F08 & $6 \mathrm{am}$ & Terra $(29,30) \&$ Aqua $(29)$ & $9-12$ \\
\hline & 15 February & 46 & F15 & $6 \mathrm{am} \& 6 \mathrm{pm}$ & Terra (46) \& Aqua (47) & $8-14$ \\
\hline & , & , & F16 & $6 \mathrm{am} \& 6 \mathrm{pm}$ & Terra (46) \& Aqua (47) & $8-10$ \\
\hline & 18 February & 49 & F17 & 6 am \& $6 \mathrm{pm}$ & Terra $(48,50) \&$ Aqua $(48,49,50)$ & $30-38$ \\
\hline & , & , & F18 & $6 \mathrm{am} \& 6 \mathrm{pm}$ & Terra $(48,50) \&$ Aqua $(48,49,50)$ & $24-30$ \\
\hline & , & , & $\mathrm{F} 20$ & 6 am \& $6 \mathrm{pm}$ & Terra $(48,50) \&$ Aqua $(48,49,50)$ & $34-40$ \\
\hline & 20 February & 51 & F19 & $6 \mathrm{am} \& 6 \mathrm{pm}$ & Terra (54) \& Aqua (54) & $6-8$ \\
\hline & , & , & $\mathrm{F} 20$ & $6 \mathrm{am} \& 6 \mathrm{pm}$ & Terra (54) \& Aqua (54) & 16 \\
\hline \multirow[t]{5}{*}{ AACES-2 } & 11 September & 254 & F09 & $6 \mathrm{am} \& 6 \mathrm{pm}$ & Terra $(253,254) \&$ Aqua $(254)$ & $6-14$ \\
\hline & 13 September & 256 & F07 & 6 am \& $6 \mathrm{pm}$ & Terra (256) & 8 \\
\hline & 21 September & 264 & F13 & 6 am \& 6 pm & Terra (263) \& Aqua (264) & 16 \\
\hline & 22 September & 265 & F15 & 6 am \& $6 \mathrm{pm}$ & Terra $(265) \&$ Aqua $(264,266)$ & 16 \\
\hline & 24 September & 267 & F09 & $6 \mathrm{am} \& 6 \mathrm{pm}$ & Terra $(267) \&$ Aqua $(266,267,268)$ & $24-32$ \\
\hline
\end{tabular}

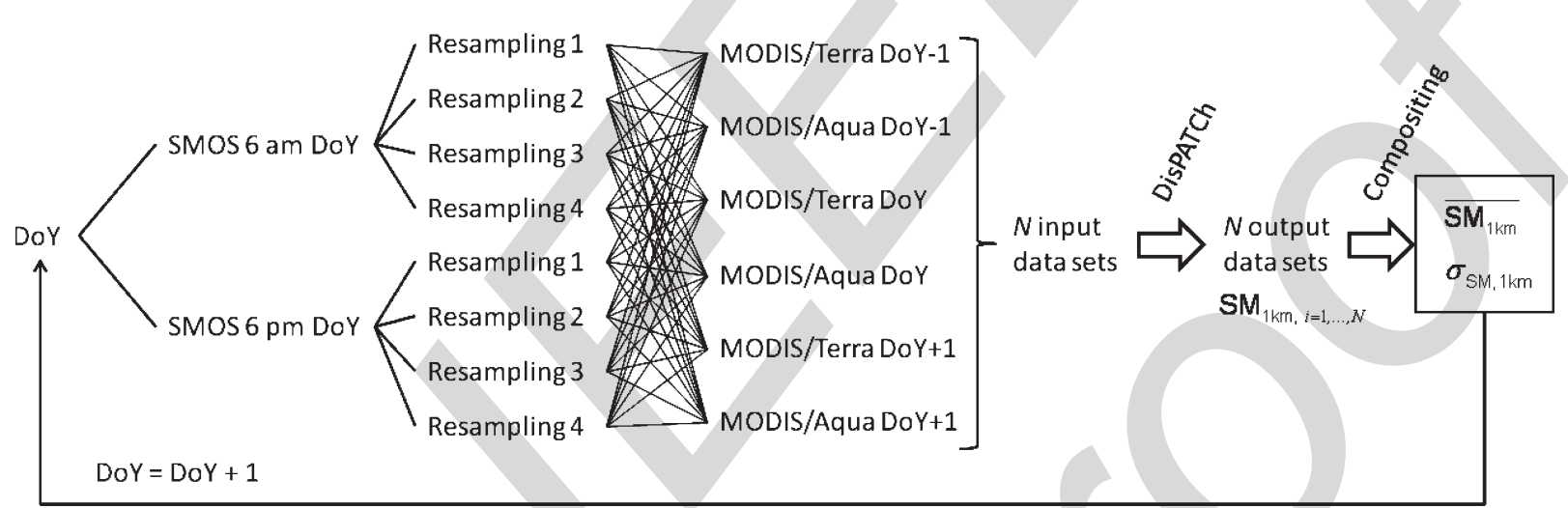

Fig. 2. Schematic diagram presenting the combination of SMOS and MODIS to generate an ensemble of input data to DisPATCh. The output data are composited at $1-\mathrm{km}$ resolution by computing the average $\left(\overline{\mathrm{SM}_{1} \mathrm{~km}}\right)$ and standard deviation $\left(\sigma_{\mathrm{SM}, 1 \mathrm{~km}}\right)$ of disaggregated SMOS soil moisture.

345 same bias in disaggregated data [30]. Consequently, although 346 the possible presence of a bias in SMOS data limits the accuracy 347 in the disaggregated soil moisture, it is not a limiting factor to 348 the applicability of DisPATCh. MODIS derived soil evaporative 349 efficiency is expressed as a linear function of soil temperature

$$
\mathrm{SEE}_{\mathrm{MODIS}, 1 \mathrm{~km}}=\frac{\mathbf{T}_{\mathbf{s}, \max }-T_{\mathrm{s}, 1 \mathrm{~km}}}{\mathbf{T}_{\mathbf{s}, \max }-\mathbf{T}_{\mathbf{s}, \min }}
$$

350 with $T_{\mathrm{S}}$ being the MODIS-derived soil skin temperature, $351 \mathbf{T}_{\mathbf{s}, \text { max }}$ the soil skin temperature at $\mathrm{SEE}=0$ and $\mathbf{T}_{\mathbf{s}, \text { min }}$ 352 the soil skin temperature at $\mathrm{SEE}=1$. The linearity of the 353 relationship between soil evaporative efficiency and surface 354 soil temperature was verified using the physically based dual 355 source energy budget model in [31] using a synthetic data set 356 composed of a range of surface soil moisture values and differ357 ent atmospheric conditions (results not shown). End-members $358 \mathbf{T}_{\mathbf{s}, \text { min }}$ and $\mathbf{T}_{\mathbf{s}, \max }$ are estimated from the polygons obtained by plotting MODIS surface temperature against MODIS NDVI 359 and MODIS albedo as in [24]. Derivation of soil temperature is 360 based on a linear decomposition of the surface temperature into 361 its soil and vegetation components as a good approximation of 362 the relationship with fourth power for temperatures [32], [33] 363 and consistent with the triangle method. MODIS-derived soil 364 skin temperature is expressed as

$$
T_{\mathrm{s}, 1 \mathrm{~km}}=\frac{T_{\mathrm{MODIS}}-f_{\mathrm{v}, 1 \mathrm{~km}} T_{\mathrm{v}, 1 \mathrm{~km}}}{1-f_{\mathrm{v}, 1 \mathrm{~km}}}
$$

with $T_{\text {MODIS }}$ being the $1-\mathrm{km}$ resolution MODIS land sur- 366 face temperature, $f_{\mathrm{v}}$ the MODIS-derived fractional vegetation 367 cover, and $T_{\mathrm{v}}$ the vegetation temperature. In this study, vegeta- 368 tion temperature is estimated using the approach proposed by 369 [28]. In (5), fractional vegetation cover is written as

$$
f_{\mathrm{v}, 1 \mathrm{~km}}=\frac{\mathrm{NDVI}_{\text {MODIS }}-\mathbf{N D V I}_{\mathbf{s}}}{\mathbf{N D V I}_{\mathbf{v}}-\mathbf{N D V I}_{\mathbf{s}}}
$$


371 with NDVI $\mathrm{M}_{\text {MODIS }}$ being the 1-km resolution MODIS NDVI, $372 \mathbf{N D V I}_{\mathbf{s}}$ the NDVI corresponding to bare soil, and $\mathbf{N D V I}_{\mathbf{v}}$ the 373 NDVI corresponding to full-cover vegetation. Minimum and 374 maximum NDVI values are set to 0.15 and 0.90 , respectively.

375 In [16], the accuracy and robustness of the disaggregation 376 methodology were tested using three different formulations of 377 soil evaporative efficiency [26], [34], [35]. Results based on the 378 NAFE'06 data set [36], which was collected over a $60 \mathrm{~km}$ by $37940 \mathrm{~km}$ area in the AACES area, indicated that the model in 380 [26] was better adapted for conditions where soil properties are 381 unknown at high resolution. Consequently, the partial derivative 382 in (3) is computed using the soil evaporative efficiency model 383 in [26]

$$
\mathrm{SEE}_{\bmod }=\frac{1}{2}-\frac{1}{2} \cos \left(\pi \cdot \mathrm{SM} / \mathbf{S M}_{\mathbf{p}}\right)
$$

384 with $\mathbf{S M}_{\mathbf{p}}$ being a soil parameter (in soil moisture unit). In 385 [26], $\mathbf{S M}_{\mathbf{p}}$ was set to the soil moisture at field capacity. In 386 DisPATCh, $\mathbf{S M}_{\mathbf{p}}$ is retrieved at $40-\mathrm{km}$ resolution from SMOS 387 and aggregated MODIS data [16]. By inverting (7), one obtains

$$
\mathrm{SM}_{\text {mod }}=\frac{\mathbf{S M}_{\mathbf{p}}}{\pi} \cos ^{-1}(1-2 \mathrm{SEE})
$$

388 2) Vegetation Temperature: Vegetation temperature in (5) is 389 estimated at 1-km resolution with the "hourglass" approach in 390 [28]. By plotting the diagonals in the quadrilateral in Fig. 3, 391 four areas are distinguished in the space defined by surface 392 temperature and fractional vegetation cover. In zone A, land 393 surface temperature is mainly controlled by soil evaporation 394 leading to optimal sensitivity to surface soil moisture. In zone $395 \mathrm{D}$, land surface temperature is mainly controlled by vegetation 396 transpiration with no sensitivity to surface soil moisture. In 397 zones B and C, land surface temperature is controlled by both 398 soil evaporation and vegetation transpiration with intermediate 399 (average) sensitivity to surface soil moisture. Based on this un400 derstanding, vegetation temperature is estimated in a different 401 manner in each zone.

402 For a given data point located in Zone A, vegetation temper403 ature is

$$
T_{\mathrm{v}, 1 \mathrm{~km}}=\left(\mathbf{T}_{\mathbf{v}, \text { min }}+\mathbf{T}_{\mathbf{v}, \text { max }}\right) / 2
$$

404 with $\mathbf{T}_{\mathbf{v}, \text { min }}$ and $\mathbf{T}_{\mathbf{v}, \text { max }}$ being the vegetation temperature 405 at minimum and maximum water stress, respectively. End406 members $\mathbf{T}_{\mathbf{v}, \text { min }}$ and $\mathbf{T}_{\mathbf{v}, \text { max }}$ are estimated from the poly407 gons obtained by plotting MODIS surface temperature against 408 MODIS NDVI and MODIS albedo as in [24].

409 For a given data point located in Zone B, vegetation temper410 ature is

$$
T_{\mathrm{v}, 1 \mathrm{~km}}=\left(T_{\mathrm{v}, \min , 1 \mathrm{~km}}+\mathbf{T}_{\mathbf{v}, \max }\right) / 2
$$

411 with $T_{\mathrm{v}, \mathrm{min}, 1 \mathrm{~km}}$ being the vegetation temperature associated 412 with $\mathrm{SEE}=0\left(T_{\mathrm{s}}=\mathbf{T}_{\mathbf{s}, \max }\right)$.

413 For a given data point located in Zone $\mathrm{C}$, vegetation temper414 ature is

$$
T_{\mathrm{v}, 1 \mathrm{~km}}=\left(\mathbf{T}_{\mathbf{v}, \min }+T_{\mathrm{v}, \max , 1 \mathrm{~km}}\right) / 2
$$
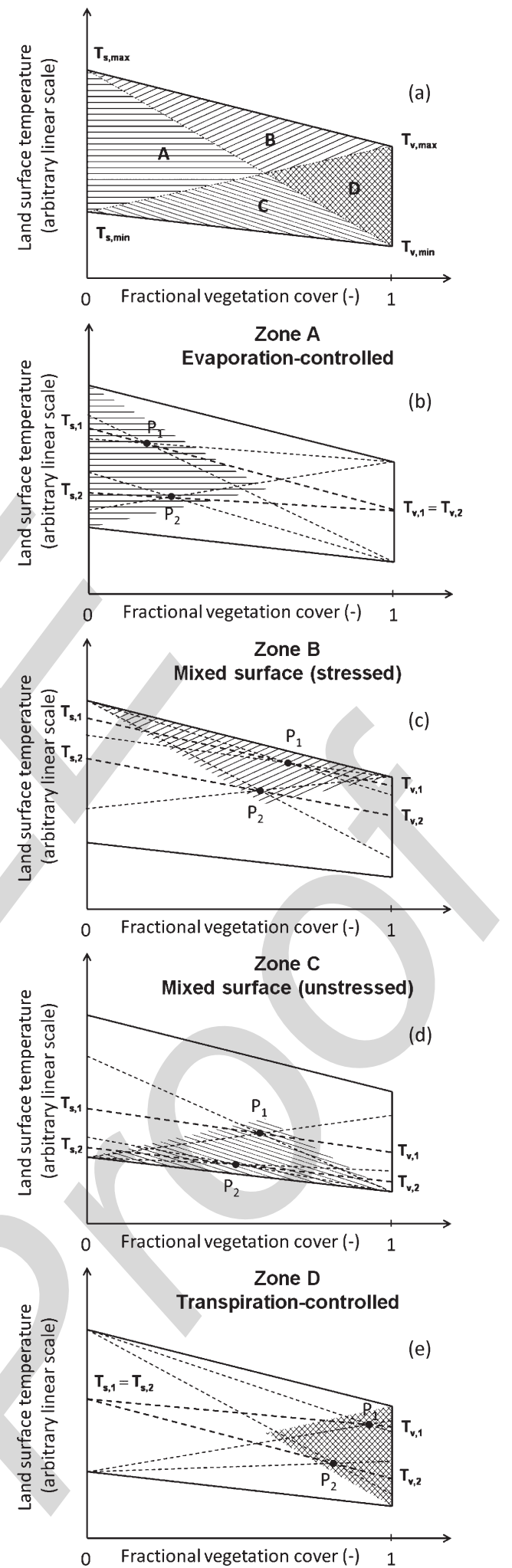

Fig. 3. Polygon defined in the land surface temperature-fractional vegetation cover space contains four distinct zones A, B, C, and D. In Zone A (soildominated area), the estimated vegetation temperature is constant leading to optimal sensitivity of estimated soil temperature to surface soil moisture. In Zone $\mathrm{D}$, the estimated soil temperature is constant with no sensitivity to surface soil moisture. In Zone B and C (mixed surface), surface temperature is both controlled by soil evaporation and vegetation transpiration with intermediate (average) sensitivity of estimated soil temperature to surface soil moisture. DisPATCh can be run in the Zone $\mathrm{A}+\mathrm{B}+\mathrm{C}$ mode or in the Zone A only mode. 

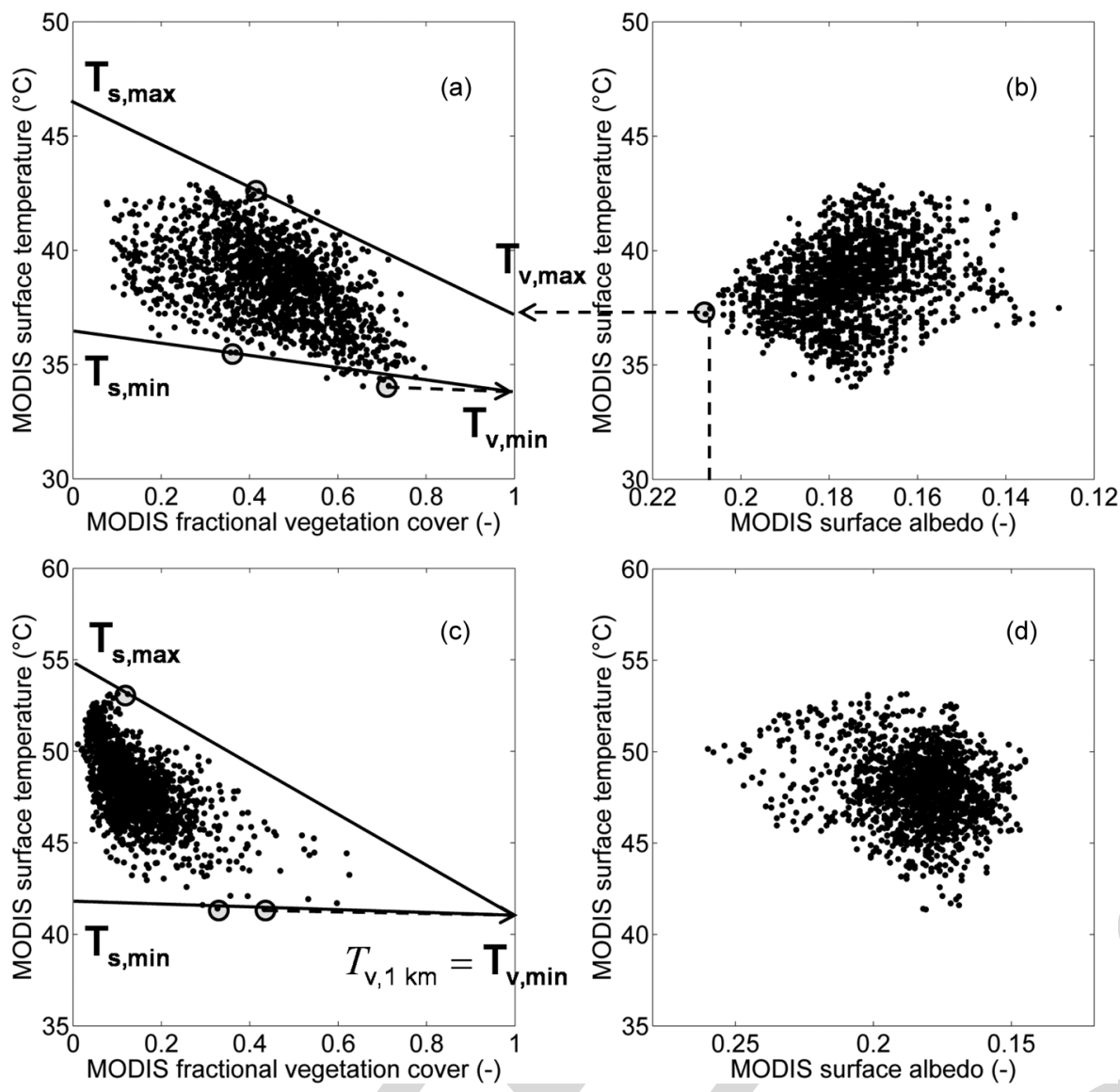

Fig. 4. Temperature end-members $\mathbf{T}_{\mathbf{s}, \mathbf{m i n}}, \mathbf{T}_{\mathbf{s}, \mathbf{m a x}}, \mathbf{T}_{\mathbf{v}, \mathbf{m i n}}$, and $\mathbf{T}_{\mathbf{v}, \mathbf{m a x}}$ are estimated from the surface temperature-fractional vegetation cover space and the surface temperature-surface albedo space within two given SMOS pixels. In (b), the pixel corresponding to the largest MODIS albedo has a fractional vegetation cover larger than 0.5 , so that $\mathbf{T}_{\mathbf{v} \text {, } \text { max }}$ is set to its surface temperature. In (d), the pixel corresponding to the largest MODIS albedo has a fractional vegetation cover lower than 0.5 , so that $\mathbf{T}_{\mathbf{v}, \max }$ is set to $\mathbf{T}_{\mathbf{v}, \text { min }}$.

415 with $T_{\mathrm{v}, \max , 1 \mathrm{~km}}$ being the vegetation temperature associated 416 with $\mathrm{SEE}=1\left(T_{\mathrm{S}}=\mathbf{T}_{\mathbf{s}, \mathbf{m i n}}\right)$.

417 For a given data point located in Zone D, vegetation temper418 ature is

$$
T_{\mathrm{v}, 1 \mathrm{~km}}=\left(T_{\mathrm{v}, \min , 1 \mathrm{~km}}+T_{\mathrm{s}, \max , 1 \mathrm{~km}}\right) / 2
$$

419 3) End-Members: End-members $\mathbf{T}_{\mathbf{s}, \min }, \mathbf{T}_{\mathbf{s}, \max }, \mathbf{T}_{\mathbf{v}, \min }$ 420 and $\mathbf{T}_{\mathbf{v} \text {, max }}$ are estimated by combining the spatial information 421 provided by the surface temperature-fractional vegetation cover 422 space and the surface temperature-albedo space plotted using 423 MODIS data collected in a 40-km resolution SMOS pixel. An 424 illustration is provided in Fig. 4 for two given SMOS pixels.
- $\mathbf{T}_{\mathbf{v}, \text { min }}$ : the vegetation temperature at minimum vegetation water stress is set to the minimum MODIS surface temperature in the SMOS pixel [see Fig. 4(a) and (c)].

- $\mathbf{T}_{\mathbf{v}, \text { max }}$ : the vegetation temperature at maximum vegetation water stress is set to the MODIS surface temperature of the pixel with the maximum value of MODIS albedo in the SMOS pixel [see Fig. 4(b)]. If the fractional vegetation cover of that pixel is lower than 0.5 [see Fig. 4(d)], the vegetation temperature at maximum vegetation water stress is alternatively set to $\mathbf{T}_{\mathbf{v}, \text { min }}$, meaning that vegetation is unstressed within the SMOS pixel. The condition based on fractional vegetation cover is lower than 0.5 aims to increase the robustness of the determination approach of
$\mathbf{T}_{\mathbf{v}, \text { max }}$, particularly in the SMOS pixels where all surface 438 conditions are not met.

- $\mathbf{T}_{\mathbf{s}, \text { min }}$ : the soil temperature at $\mathrm{SEE}=1$ is extrapolated 440 along the wet soil edge at $f_{\mathrm{v}}=0$. The wet soil edge 441 is defined as the line passing through $\left(1, \mathbf{T}_{\mathbf{v}, \text { min }}\right)$ and 442 through the data point such that all the data points with 443 $f_{\mathrm{v}}<0.5$ are located above the wet soil edge [see Fig. 4(a) 444 and (c)].

- $\mathbf{T}_{\mathbf{s}, \text { max }}$ : the soil temperature at $\mathrm{SEE}=0$ is extrapolated 446 along the dry soil edge at $f_{\mathrm{v}}=0$. The dry soil edge 447 is defined as the line passing through $\left(1, \mathbf{T}_{\mathbf{v}, \max }\right)$ and 448 through the data point such that all the data points with 449 $f_{\mathrm{v}}<0.5$ are located below the dry soil edge [see Fig. 4(a) 450 and (c)].

\section{B. Atmospheric Correction}

In MOD11A1 and MYD11A1 products, the land surface 453 temperature is derived from MODIS thermal radiances using 454 the split window algorithm [37]

$$
\begin{aligned}
T_{\text {MODIS }}= & C+\left(A_{1}+A_{2} \frac{1-\epsilon}{\epsilon}+A_{3} \frac{\Delta \epsilon}{\epsilon^{2}}\right) \frac{T b_{31}+T b_{32}}{2} \\
& +\left(B_{1}+B_{2} \frac{1-\epsilon}{\epsilon}+B_{3} \frac{\Delta \epsilon}{\epsilon^{2}}\right) \frac{T b_{31}-T b_{32}}{2}
\end{aligned}
$$


456 with $T b_{31}$ and $T b_{32}$ being the brightness temperatures mea457 sured in the MODIS bands 31 and 32, respectively, $\epsilon_{31}$ and $\epsilon_{32}$ 458 the surface emissivities estimated in the respective bands, and $459 A_{1}, A_{2}, A_{3}, B_{1}, B_{2}, B_{3}$, and $C$ regression coefficients. These 460 coefficients are available during algorithm execution via a look 461 up table stratified by subranges of near surface air temperature 462 and total column water vapor. These input field are obtained at 463 a 5-km resolution from the MODIS07_L2 product.

464 Given that regression coefficients in (13) are provided at $4655-\mathrm{km}$ resolution, the atmospheric corrections on the MODIS 466 land surface temperature product are actually made at 5-km 467 resolution. To test whether atmospheric corrections on MODIS 468 temperature have an impact on disaggregation results, a differ469 ent procedure is proposed to obtain another temperature data 470 set whose atmospheric corrections are operated at the scale 471 of a SMOS pixel, i.e., at $40-\mathrm{km}$ resolution (instead of $5-\mathrm{km}$ 472 resolution for the official MODIS temperature product). The 473 approach is to normalize the mean MODIS radiance-derived 474 brightness temperature at the SMOS resolution. Normalization 475 is done by adjusting the minimum and maximum mean MODIS 476 brightness temperature to the minimum and maximum value 477 of the official MODIS land surface temperature product within 478 the SMOS pixel, respectively. The new temperature noted $479 T_{\text {MODIS }}^{\text {unif. corr. (uniform atmospheric corrections) is written }}$

$$
\begin{aligned}
T_{\text {MODIS }}^{\text {unif. corr. }} & =T_{\text {MODIS,min }}+\left(T_{\text {MODIS,max }}-T_{\text {MODIS,min }}\right) \\
& \times \frac{T b_{31}+T b_{32}-\operatorname{Min}\left(T b_{31}+T b_{32}\right)}{\operatorname{Max}\left(T b_{31}+T b_{32}\right)-\operatorname{Min}\left(T b_{31}+T b_{32}\right)}
\end{aligned}
$$

480 with $T_{\text {MODIS, } m i n}$ and $T_{\text {MODIS, } m a x}$ being the minimum and 481 maximum MODIS land surface temperature within the SMOS 482 pixel, and $\operatorname{Min}()$ and $\operatorname{Max}()$ the function that returns the mini483 mum and maximum value within the SMOS pixel, respectively. 484 Note that the underlying assumptions of (14) are:

485 - near surface air temperature and column water vapor vary 486 at scales larger than $40 \mathrm{~km}$ (size of a SMOS pixel).

487 - surface emissivity is close to 1 .

\section{C. Algorithm}

489 The steps used in applying DisPATCh include: 1) select490 ing the SMOS pixels with at least 90\% (clear sky) MODIS491 retrieved land surface temperature coverage; 2) computing 492 soil evaporative efficiency over nominal MODIS pixels with 493 (4); 3) estimating soil evaporative efficiency over non-nominal 494 MODIS pixels; 4) retrieving parameter $\mathbf{S M}_{\mathbf{p}}$; 5) applying the 495 downscaling relationship of (3); 6) correcting disaggregated 496 soil moisture by the SMOS pixel weighting function; and 7) 497 compositing on a daily basis the disaggregation output en498 semble [21]. The input and output data and their link within 499 DisPATCh are summarized in Fig. 5.

500 1) Selecting Clear Sky SMOS Pixels: A threshold of $90 \%$ 501 cloud-free MODIS coverage is used to select the SMOS pix502 els to be disaggregated. In the official MODIS land surface 503 temperature product (MOD11A1 for Terra and MYD11A1 for 504 Aqua), the data affected by the presence of clouds are already 505 masked. Hence, selection of the $90 \%$ clear sky SMOS pixels is

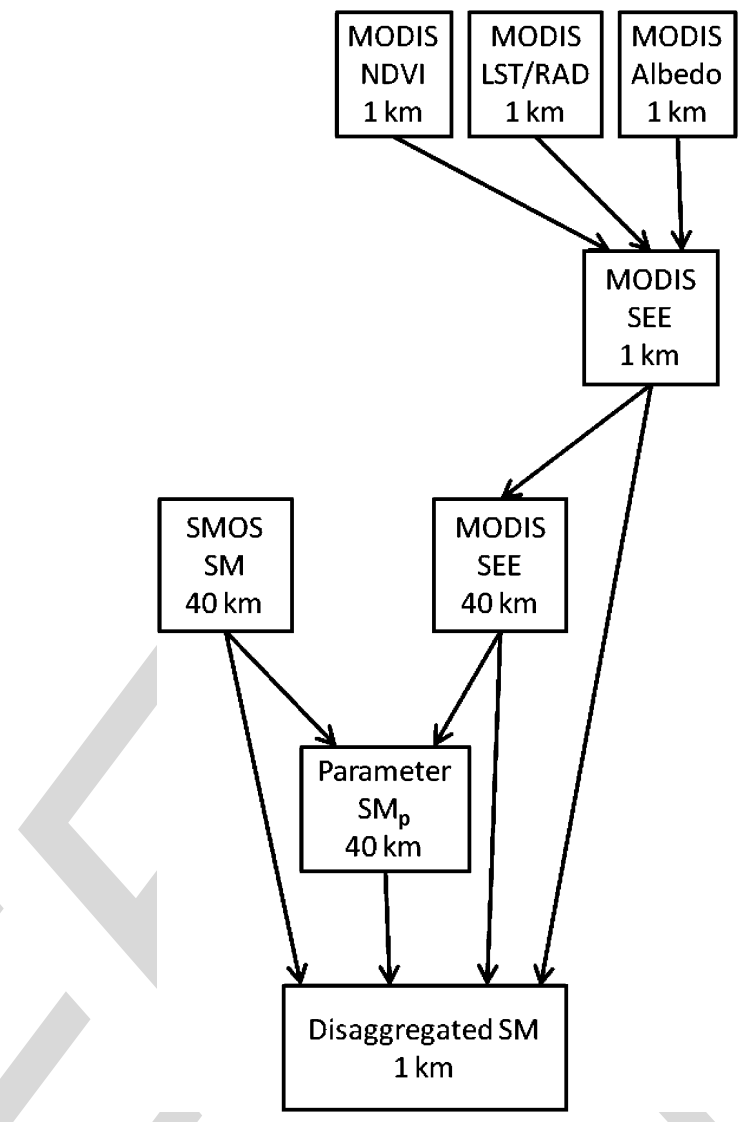

Fig. 5. Schematic diagram presenting the input and output data of DisPATCh.

directly based on the MODIS land surface temperature product 506 masking.

2) Non-Nominal Pixels: Nominal MODIS pixels are de- 508 fined as the $1-\mathrm{km}$ resolution pixels that do not include open 509 water and where land surface temperature is actually retrieved. 510 Open water pixels are flagged in the algorithm when MODIS 511 NDVI retrievals yield negative values. The soil evaporative 512 efficiency of open water pixels is set to 1 . The emerged pixels 513 where land surface temperature is not retrieved (due to the 514 presence of some clouds within the SMOS pixel) are processed 515 as pixels with mean surface conditions. In practice, the soil 516 evaporative efficiency of cloudy pixels (which represent less 517 than $10 \%$ of the surface area within the SMOS pixel) is set to 518 the mean soil evaporative efficiency calculated over the clear 519 sky MODIS pixels. Allocating a soil evaporative efficiency 520 value to non-nominal pixels allows DisPATCh to be run over a 521 wider range of SMOS pixels, including those partially covered 522 by clouds. However, non-nominal 1-km resolution pixels are 523 flagged and discarded from the disaggregation output ensemble. 524

3) Forested Areas: In this study, DisPATCh is applied to all 525 the SMOS pixels where the soil moisture retrieval is successful, 526 even those including forest class, as long as the $1 \mathrm{~km}$ MODIS 527 pixels are in Zone A, B or C (see Fig. 3). This choice is 528 relevant here because the AACES extensive data were almost 529 exclusively collected in agricultural areas (cropping/grazing), 530 so forests for this study are not an issue. In the case of a 531 mixed SMOS pixel including a significant fraction of forest, 532 DisPATCh should be applied to the surface area of the dominant 533 
534 class, thus excluding the surface area of the minority land cover 535 classes.

536 4) Calibration: The soil moisture parameter $\mathbf{S M}_{\mathbf{p}}$ used to 537 compute $\partial \mathbf{S} \mathbf{M}_{\mathbf{m o d}} / \partial \mathbf{S E E}$ in (3) is estimated by inverting the $538 \mathrm{SEE}$ model in (7) at SMOS resolution

$$
\mathbf{S M}_{\mathbf{p}}=\frac{\pi \cdot \mathbf{S M}_{\mathbf{S M O S}}}{\cos ^{-1}\left(1-2\left\langle\mathrm{SEE}_{\mathrm{MODIS}, 1 \mathrm{~km}}\right\rangle_{40 \mathrm{~km}}\right)}
$$

539 A value of $\mathbf{S M}_{\mathbf{p}}$ is obtained for each SMOS pixel and each 540 input data set. Note that the main assumption limiting validity 541 of the calibration approach is the soil evaporative efficiency 542 model [26] itself. The soil evaporative efficiency model in [26] 543 was chosen for its simplicity (one parameter) and its ability 544 to represent the general behavior of soil evaporative efficiency 545 over the full range of soil moisture: particularly the null deriva546 tive at zero and at maximum soil moisture, and an inflexion 547 point in between [38]. However, it has some inconsistencies. 548 In particular, [38] have indicated that 1) potential evaporation 549 is physically reached at soil saturation and not at field capac550 ity; therefore the model in [26] should be (strictly speaking) 551 parameterized by the soil moisture at saturation and not by the 552 soil moisture at field capacity, and 2) soil evaporative efficiency 553 varies with potential evaporation, meaning that the soil moisture 554 parameter (set to the soil moisture at field capacity in [26]) 555 should theoretically vary in time with atmospheric evaporative 556 demand. Consequently, the $\mathbf{S M}_{\mathbf{p}}$ retrieved from SMOS and 557 MODIS data using the model in [26] is definitely not the soil 558 moisture at field capacity as in [26], although it could be in part 559 related to it. In this study, $\mathbf{S M}_{\mathbf{p}}$ is therefore considered to be a 560 fitting parameter self-estimated by DisPATCh.

561 5) Weighting Function: A SMOS pixel WEighting Function 562 (WEF) is used to take into account the impact of soil mois563 ture distribution on the SMOS scale soil moisture as seen by 564 SMOS radiometer. A centrosymmetric analytical approxima565 tion MEAN_WEF is provided in [19], [20]

$$
\operatorname{MEAN} \_\operatorname{WEF}(\rho)=C_{\mathrm{MWEF} 2}+\mathrm{WEF}_{\mathrm{A}}\left(\frac{\rho}{C_{\mathrm{MWEF} 1}} \cdot \frac{\pi}{C_{\mathrm{WEF} 1}}\right)
$$

566 with $\rho$ being the distance from the SMOS pixel center, and $567 C_{\mathrm{MWEF} 1}=40 \mathrm{~km}, C_{\mathrm{MWEF} 2}=0.027, C_{\mathrm{WEF} 1}=73.30$ and

$$
\mathrm{WEF}_{\mathrm{A}}\left(\rho^{\prime}\right)=\frac{\left[\operatorname{sinc}\left(C_{\mathrm{WEF} 1} \cdot \rho^{\prime}\right)\right]^{C_{\mathrm{WEF} 2}}}{1+C_{\mathrm{WEF} 3} \cdot \rho^{\prime} C_{\mathrm{WEF} 4}}
$$

568 with $\rho^{\prime}$ being the distance in the director cosines coordinates, $569 \operatorname{sinc}(x)=\sin (x) / x$, and $C_{\mathrm{WEF} 2}=1.4936, C_{\mathrm{WEF} 3}=524.5$ 570 and $C_{\mathrm{WEF} 4}=2.103$.

571 A correction is applied to disaggregated soil moisture in (3)

$$
\underset{\mathrm{SM}_{1 \mathrm{~km}}^{\text {wef corr. }}=\mathrm{SM}_{1 \mathrm{~km}}+\frac{\sum \operatorname{MEAN} \_\mathrm{WEF}(\rho) \cdot \mathrm{SM}_{1 \mathrm{~km}}(\rho)}{\sum \operatorname{MEAN}_{-} \mathbf{W E F}(\rho)}}{-\mathbf{S M}_{\mathbf{S M O S}}}
$$

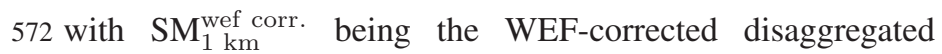
573 soil moisture. Mathematically speaking, one should replace $574 \mathbf{S M}_{\text {SMos }}$ with $\sum$ MEAN_WEF $\cdot \mathrm{SM}_{1 \mathrm{~km}} / \sum \mathrm{MEAN}$ _WEF 575 in (3) and (15) and run an iteration loop until convergence of $\mathrm{SM}_{1 \mathrm{~km}}^{\text {wef corr. }}$ values. However, the impact of the WEF on 576 disaggregated soil moisture is expected to be low so that the 577 simple correction in (18) is considered to be sufficient for the 578 purpose of the study.

6) Disaggregation Output: The downscaling relationship in 580 (3) is applied to each input data set, and the disaggregated soil 581 moisture data ensemble is averaged on each $1-\mathrm{km}$ resolution 582 pixel within the study area. Averaging is a way to reduce 583 random uncertainties in the disaggregation output. In [17], [27], 584 disaggregated soil moisture was averaged in space (aggregated) 585 at the expense of downscaling resolution. Herein, temporal 586 averaging [30] is preferred to keep an optimal downscaling 587 resolution. Note that a condition to average disaggregated soil 588 moisture in time is the availability of thermal infrared data 589 at high temporal frequency. Another significant advantage of 590 applying DisPATCh to an input ensemble is to provide an 591 estimate of the uncertainty in 1-km resolution disaggregated 592 soil moisture, e.g., by computing the standard deviation within 593 the output ensemble.

\section{ApPlication}

To test DisPATCh under various surface and atmospheric 596 conditions, the algorithm is run during AACES-1 and AACES- 597 2 in different modes, by including (or not) a correction for 598 vegetation and atmospheric effects. In each case, disaggregated 599 SMOS soil moisture and HDAS measurements are compared 600 at $1-\mathrm{km}$ resolution for all date-farm units with overlapping 601 HDAS/SMOS/MODIS data.

\section{A. Null Hypothesis}

In this study, the null hypothesis is defined as the application 604 of DisPATCh with parameter $\mathbf{S M}_{\mathbf{p}}$ set to zero in (8). Hence, 605 the downscaling relationship in (3) becomes

$$
\mathrm{SM}_{1 \mathrm{~km}}=\mathrm{SM}_{\mathrm{SMOS}}
$$

meaning that no 1-km information is used. Defining a null 607 hypothesis is useful to test whether DisPATCh is able to re- 608 produce the subpixel variability within the $\sim 10 \mathrm{~km}^{2}$ sam- 609 pling farms with better skill than simply assuming a uniform 610 moisture condition. Statistical results in terms of root mean 611 square difference, mean difference, correlation coefficient, and 612 slope of the linear regression between the SMOS soil moisture 613 disaggregated with (19) and in situ measurements are listed in 614 Table III. One observes that the root mean square difference 615 is generally explained by a (negative) bias in SMOS data and 616 that none of the correlations evaluated at $1-\mathrm{km}$ resolution for 617 each farm separately is statistically significant (all calculated p- 618 values are larger than 0.10). Thus, the rationale for developing 619 DisPATCh is to improve the correlation at fine scale between 620 SMOS and ground soil moisture and to reduce the bias in 621 disaggregated SMOS data in the specific case where the bias 622 in SMOS data at the farm scale is due to the heterogeneity of 623 soil moisture within the SMOS pixel. 
TABLE III

DisPatch Is Run With No 1-km Information ( $\mathbf{S M}_{\mathbf{p}}$ Set to Zero) and Statistical Results Are Listed in Terms of Root Mean SQuare

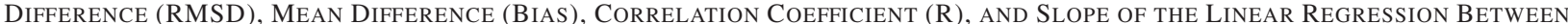
1-km Resolution Disaggregated SMOS Soll Moisture and 1-km Aggregated In Situ Measurements. The Mean

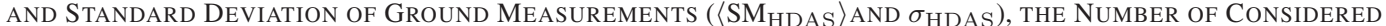
1-km Pixels, and Statistical Significance (p-Value) ARe Also Listed for Each Date-Farm Unit

\begin{tabular}{|c|c|c|c|c|c|c|c|c|}
\hline DoY/Farm & $\begin{array}{c}\left\langle\mathrm{SM}_{\mathrm{HDAS}}\right\rangle \\
\left(\mathrm{m}^{3} / \mathrm{m}^{3}\right)\end{array}$ & $\begin{array}{c}\sigma_{\mathrm{HDAS}} \\
\left(\mathrm{m}^{3} / \mathrm{m}^{3}\right)\end{array}$ & $\begin{array}{l}\text { Number of } \\
1 \mathrm{~km} \text { pixels }\end{array}$ & $\begin{array}{l}\text { RMSD } \\
\left(\mathrm{m}^{3} / \mathrm{m}^{3}\right)\end{array}$ & $\begin{array}{c}\text { Bias } \\
\left(\mathrm{m}^{3} / \mathrm{m}^{3}\right)\end{array}$ & $\begin{array}{l}\mathrm{R}^{\dagger} \\
(-)\end{array}$ & $\begin{array}{c}\text { Slope }^{\dagger} \\
(-)\end{array}$ & $\begin{array}{c}\text { p-value } \\
(-)\end{array}$ \\
\hline 28/F05 & 0.04 & 0.02 & 7 & 0.04 & -0.04 & - & - & 1.0 \\
\hline 30/F07 & 0.02 & 0.03 & 8 & 0.02 & -0.02 & - & - & 1.0 \\
\hline 30/F08 & 0.03 & 0.02 & 7 & 0.02 & -0.02 & - & - & 0.69 \\
\hline 46/F15 & 0.29 & 0.05 & 8 & 0.04 & 0.03 & - & - & 0.91 \\
\hline 46/F16 & 0.34 & 0.06 & 8 & 0.09 & -0.08 & - & - & 1.0 \\
\hline 49/F 17 & 0.21 & 0.06 & 8 & 0.04 & -0.04 & - & - & 0.66 \\
\hline 49/F18 & 0.25 & 0.07 & 6 & 0.08 & -0.08 & - & - & 0.42 \\
\hline $49 / \mathrm{F} 20$ & 0.20 & 0.09 & 4 & 0.02 & -0.007 & - & - & 0.87 \\
\hline $51 / \mathrm{F} 19$ & 0.24 & 0.08 & 6 & 0.13 & -0.13 & - & - & 0.77 \\
\hline $51 / \mathrm{F} 20$ & 0.20 & 0.10 & 6 & 0.09 & -0.08 & - & - & 0.79 \\
\hline AACES- 1 mean $\ddagger$ & - & - & - & - & - & - & - & $>0.10$ \\
\hline 254/F09 & 0.33 & 0.07 & 9 & 0.13 & -0.13 & - & - & 0.13 \\
\hline 256/F07 & 0.36 & 0.10 & 8 & 0.19 & -0.18 & - & - & 0.15 \\
\hline 264/F13 & 0.30 & 0.07 & 8 & 0.18 & -0.17 & - & - & 1.0 \\
\hline $265 / \mathrm{F} 15$ & 0.25 & 0.06 & 7 & 0.05 & -0.05 & - & - & 1.0 \\
\hline 267/F09 & 0.21 & 0.07 & 9 & 0.14 & -0.14 & - & - & 0.43 \\
\hline AACES- 2 mean & - & - & - & - & - & - & - & $>0.10$ \\
\hline
\end{tabular}

\section{B. Visual Assessment of Disaggregation Images}

626 As an example, DisPATCh is applied on DoY 49 over a 120 $627 \mathrm{~km}$ by $80 \mathrm{~km}$ subarea including the farms F16, F17, F18, F19, 628 and F20. The images of 1-km resolution disaggregated SMOS 629 soil moisture are presented in Fig. 6. DisPATCh is run with $630 \mathbf{S M}_{\mathbf{p}}$ set to zero (null hypothesis) and in four distinct modes 631 corresponding to the combinations of the "LST" (the official 632 MODIS land surface temperature product is used) and "RAD" 633 [the land surface temperature is derived from MODIS radiances 634 using (14)] modes and the "Zone $A+B+C$ " (the vegetation635 transpiration dominated $1-\mathrm{km}$ pixels are discarded) and "Zone 636 A only" (only the soil evaporation-dominated 1-km pixels are 637 selected) modes.

638 In Fig. 6, the SMOS DGG nodes where level-2 soil moisture 639 is successfully retrieved are overlaid on the image correspond640 ing to the null hypothesis (resampled SMOS data with no 1-km 641 information) for 6 am and 6 pm overpass times separately. The 642 gaps in SMOS data in the lower middle part of the images 643 are due to topography flagging over the Australian Alps. In 644 the version-4 SMOS level-2 processor, soil moisture is not 645 retrieved at the DGG nodes where the topography effects on 646 simulated brightness temperatures exceed a certain threshold, 647 so as to prevent large errors in soil moisture values. The appar648 ent resolution of the null hypothesis image is $20 \mathrm{~km}$ because 649 it is generated from the composition of four $40-\mathrm{km}$ resolution 650 resampled SMOS snapshot images, whose resampling grids are separated by $20 \mathrm{~km}$ (the SMOS level-2 data resampling strategy 651 was described in Section II-B.).

Note that the disaggregation products in the Zone $\mathrm{A}+\mathrm{B}+\mathrm{C} 653$ mode cover an area larger than the area sampled by SMOS 654 data, because the SMOS resolution (about $40 \mathrm{~km}$ ) is larger 655 than the SMOS product sampling length (about $15 \mathrm{~km}$ ), but 656 does not provide disaggregated values at a distance larger than 657 $20 \mathrm{~km}$ from the successful retrieval nodes. Concerning the Zone 658 A only mode, disaggregation products do not cover an area 659 larger than the SMOS sampling area because the Australian 660 Alps are surrounded by forests where the fraction of bare soil is 661 less than elsewhere in the area, and which correspond to Zone 662 $\mathrm{B}$ or $\mathrm{C}$ in the hourglass in Fig. 3.

When looking at the images obtained in the Zone $A+B+C 664$ mode in Fig. 6, one observes that the spatial structures of 665 1-km disaggregated SMOS soil moisture encompass, but does 666 not seem to be correlated with, the SMOS data sampling 667 length. However, a "boxy artifact" is still apparent at 20-km 668 resolution, which is the separation length of the SMOS data 669 resampling grids as explained in Section II-B. The notion of 670 "boxy artifact" was introduced by [39] to analyze the quality of 671 a disaggregation approach. The less apparent the low-resolution 672 boxes, the better the disaggregation skill of the algorithm to 673 spatially connect high-resolution disaggregated values between 674 neighboring low-resolution pixels, and thus to derive a realistic 675 high-resolution soil moisture field. When comparing the images 676 obtained in the Zone $\mathrm{A}+\mathrm{B}+\mathrm{C}$ mode with those obtained in the 677 


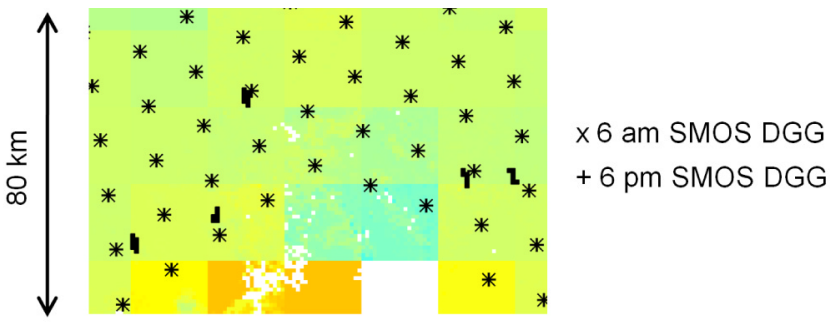

LST
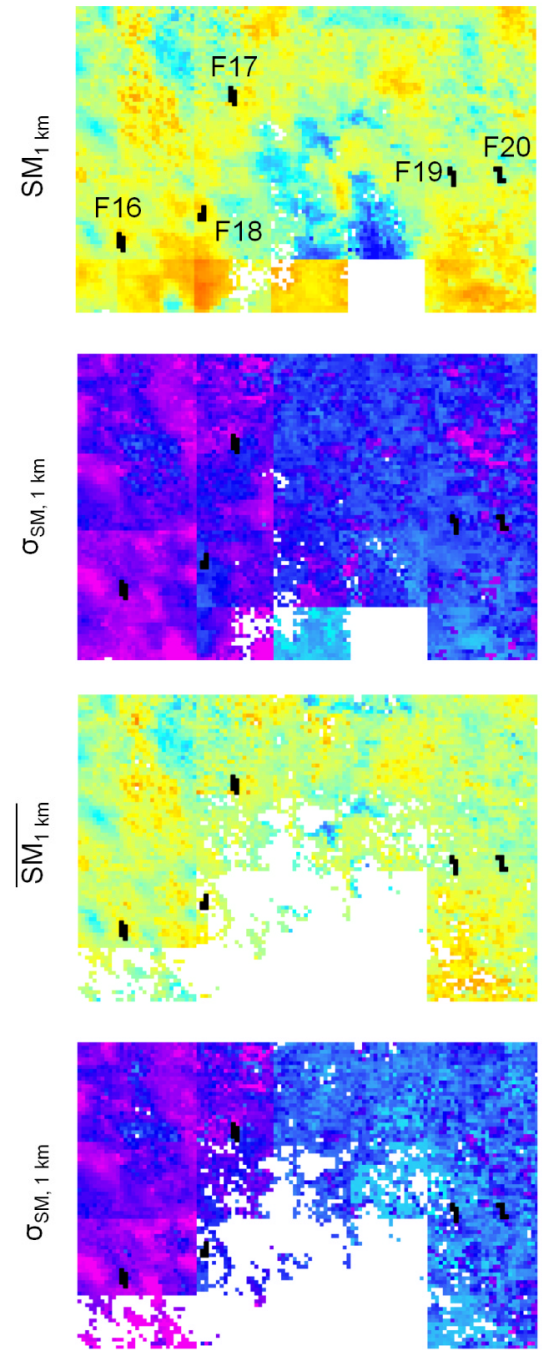

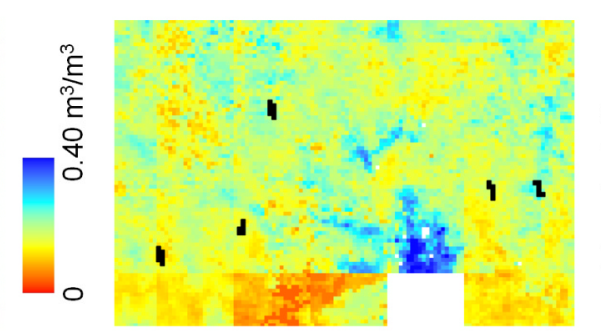

0
+
0
+
+
0
0
0
$N$
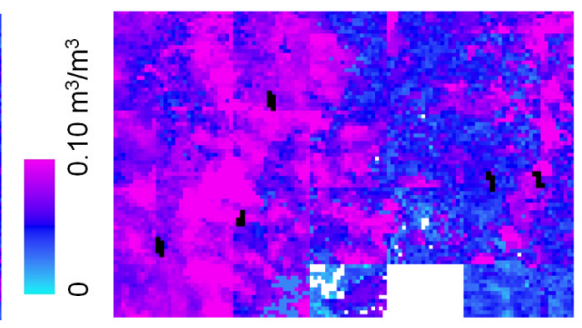

\section{0
+
0
+
+
0
0
0
$N$}
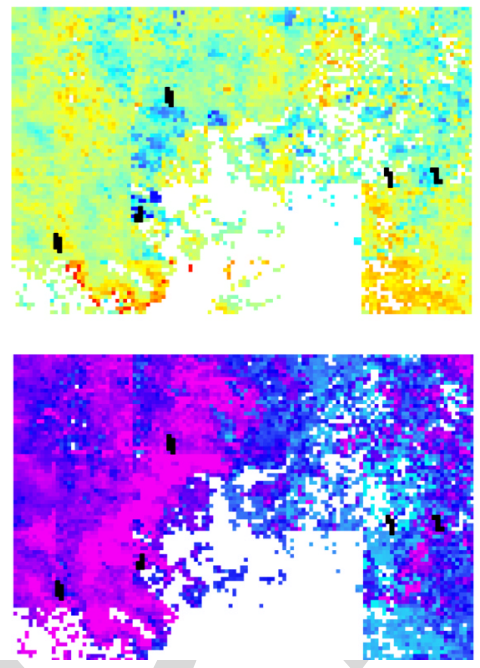
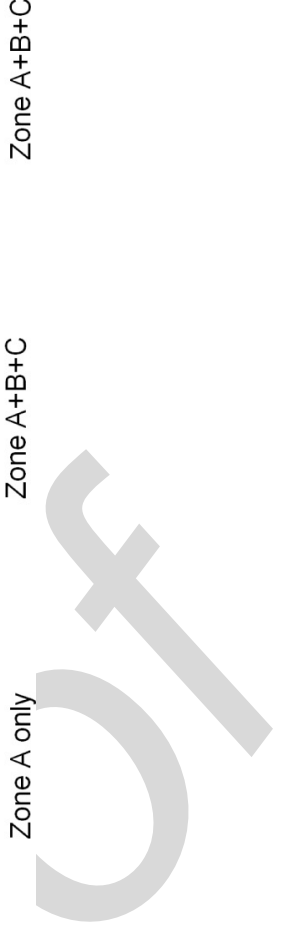

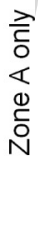

Fig. 6. Images of disaggregation results over a $120 \mathrm{~km}$ by $80 \mathrm{~km}$ subarea on DoY 49 . The disaggregated soil moisture $\left(\overline{\mathrm{SM}_{1} \mathrm{~km}}\right)$ and its estimated uncertainty $\left(\sigma_{\mathrm{SM}, 1 \mathrm{~km}}\right)$ are compared in the LST and RAD modes and in the Zone A+B+C and Zone A only modes. Sampling farms are overlaid on all images. SMOS DGG nodes are overlaid on the image corresponding to the null hypothesis (no 1-km resolution information) presented at top.

678 Zone A only mode, one observes that the $20-\mathrm{km}$ resolution boxy 679 artifact is less apparent in the Zone A only mode, consistent 680 with the better sensitivity of MODIS-derived SEE with soil681 dominated pixels (Zone A) than with mixed-surface (Zone B 682 and C) pixels. In Fig. 6, the images obtained in the LST and 683 RAD mode highlight different spatial structures. In general, 684 there are less data gaps in the RAD than in the LST mode. 685 However, ground validation data are required to assess their 686 relative quality/accuracy.

687 As an assessment of the uncertainty in composited soil mois688 ture disaggregation, the standard deviation within the disaggre689 gation output ensemble is also reported for each disaggregation product in Fig. 6. The same observations can be made as with 690 the soil moisture images: spatial structures are more visible, and 691 the boxy artifact is less apparent in the RAD than in the LST 692 mode. In general, the estimated uncertainty in disaggregated 693 products is larger in the RAD than in the LST mode, regardless 694 of the Zone $(\mathrm{A}+\mathrm{B}+\mathrm{C}$ or $\mathrm{A}$ only) mode.

\section{SMOS Weighting Function}

696

To evaluate the impact of the SMOS instrument weighting 697 function on disaggregation results, DisPATCh is run with (and 698 without) the WEF correction in (18). The expected effect of the 699 


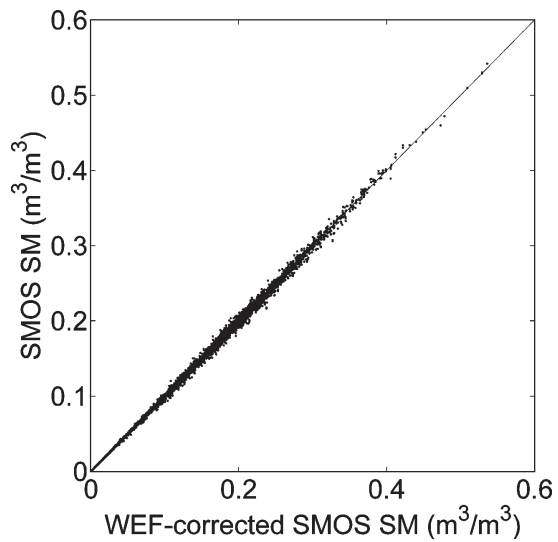

Fig. 7. Uncorrected versus WEF-corrected SMOS soil moisture for the entire data set.

$700 \mathrm{WEF}$ is a bias at $40 \mathrm{~km}$ resolution on disaggregated soil mois701 ture. Fig. 7 plots the uncorrected against WEF-corrected SMOS 702 soil moisture for the entire data set including both AACES-1 703 and AACES-2 experiments. The WEF correction has very 704 little impact on disaggregated soil moisture with a maximum 705 difference between uncorrected and WEF-corrected SMOS soil 706 moisture of $0.02 \mathrm{~m}^{3} / \mathrm{m}^{3}$, a mean difference of approximately 707 zero, and a standard deviation of $0.003 \mathrm{~m}^{3} / \mathrm{m}^{3}$. Although the 708 difference is small with this data set, WEF-corrected products 709 are expected to be more realistic. Therefore, the correction in 710 (18) is used in all the DisPATCh runs that follow.

\section{D. Quantitative Comparison With In Situ Measurements}

712 Fig. 8 presents the scatterplots of $1-\mathrm{km}$ resolution disaggre713 gated SMOS soil moisture versus 1-km resolution aggregated 714 in situ measurements for the ten date-farm units during 715 AACES-1. On each graph are plotted the soil moisture dis716 aggregated in the Zone $\mathrm{A}+\mathrm{B}+\mathrm{C}$ mode (empty squares) and 717 the soil moisture disaggregated in the Zone A only mode 718 (black squares). At the beginning of AACES-1, conditions are 719 very dry so that SMOS retrievals are close to zero and the 720 variability of in situ measurements is low (about $0.02 \mathrm{~m}^{3} / \mathrm{m}^{3}$ ). 721 In such conditions, no useful information is expected from the 722 application of DisPATCh, and the statistical results in terms of 723 spatial correlation are not meaningful for DoY 28/F05, DoY 724 30/F07 and DoY 30/F08. While wetter conditions occur after 725 DoY 30, cloud cover prevents DisPATCh to be run (MODIS 726 data are unavailable) until DoY 46. On DoY 46, the average 727 and standard deviation of in situ soil moisture measurements is $7280.32 \mathrm{~m}^{3} / \mathrm{m}^{3}$ and $0.06 \mathrm{~m}^{3} / \mathrm{m}^{3}$, respectively. The spatial variabil729 ity of $1-\mathrm{km}$ soil moisture is nicely captured by DisPATCh no730 tably in the RAD mode. On DoY 49, the disaggregated SMOS 731 soil moisture is still correlated with the in situ measurements 732 made in three farms (F17, F18, and F20). On the last ground 733 sampling day, disaggregation results are significantly correlated 734 with in situ measurements in F19, but not in F20. The poor 735 results obtained with DoY 51/F20 is probably due to the time 736 gap (3 days) between ground sampling date (DoY 51) and 737 MODIS overpass day (DoY 54).

738 Statistical results in terms of root mean square difference, 739 mean difference, correlation coefficient, and slope of the linear regression between the SMOS soil moisture disaggregated in 740 the Zone $\mathrm{A}+\mathrm{B}+\mathrm{C}$ mode and aggregated in situ measurements 741 are listed in Table IV. Statistical significance (p-value) is also 742 reported for each date-farm unit to select statistically significant 743 (p-value $<0.10$ ) results. Although the disaggregation of SMOS 744 data on extensively dry DoY 30 does not provide any additional 745 information (soil is uniformly dry), the observed correlation 746 between disaggregated (LST mode) and in situ soil moisture 747 is statistically significant, and the correlation coefficient value 748 is negative $(-0.70$ and -0.95 at F07 and F08, respectively). 749 One plausible explanation is the opposite effect of soil temper- 750 ature on HDAS soil moisture measurements and on MODIS- 751 derived soil evaporative efficiency: a slight undercorrection of 752 the temperature-corrected hydraprobe measurements at high 753 temperature [18] results in a slight increase of soil moisture 754 estimate with soil temperature, while an increase of soil temper- 755 ature makes soil evaporative efficiency decrease. Nevertheless, 756 the possible impact of soil temperature on HDAS measurements 757 is very low with a slope of the linear regression between 758 disaggregated SMOS and in situ soil moisture calculated as 759 -0.08 and -0.03 for F07 and F08, respectively. When selecting 760 statistically significant results $(\mathrm{p}$-value $<0.10$ ) and discarding 761 data for DoY 30, the mean correlation coefficient and slope in 762 RAD mode are 0.75 and 0.58 , respectively.

Fig. 9 presents the scatterplots of 1-km resolution disaggre- 764 gated SMOS soil moisture versus 1-km resolution aggregated in 765 situ measurements for the five date-farm units during AACES- 766 2. On each graph are plotted the soil moisture disaggregated in 767 the Zone $\mathrm{A}+\mathrm{B}+\mathrm{C}$ mode (empty squares) and the soil moisture 768 disaggregated in the Zone A only mode (black squares). The 769 surface conditions of AACES-2 were relatively wet with a mean 770 soil moisture value estimated as $0.29 \mathrm{~m}^{3} / \mathrm{m}^{3}$. The disaggre- 771 gated SMOS soil moisture does not correlate well with in situ 772 measurements with a p-value larger than 0.10 for all sampling 773 days, except for DoY 256/F07 in LST mode (see Table IV). The 774 negative correlation coefficient $(-0.73)$ obtained on DoY 256 is 775 discussed when comparing the Zone $\mathrm{A}+\mathrm{B}+\mathrm{C}$ and Zone A only 776 modes in Section IV-F. In general, statistical results in Table IV 777 indicate that DisPATCh does not succeed in representing the 778 variability of soil moisture at 1-km resolution during AACES- 779 2. In fact, DisPATCh is based on the tight coupling that occurs 780 between soil moisture and evaporation under high evaporative 781 demand conditions [40]. This coupling seems to be weak in 782 September over the study area so that the disaggregation results 783 at $1-\mathrm{km}$ resolution are not reliable.

784

For DoY 264/F13, however, an interesting feature is ob- 785 served on the graph corresponding to the RAD and Zone A 786 only modes. When removing the (three) black squares with 787 the largest errorbars, the correlation coefficient and the slope 788 of the linear regression between disaggregated and in situ 789 observations becomes 0.9 and 0.7 , respectively. This suggests 790 that: 1) the standard deviation within the disaggregation output 791 ensemble can be a good estimate of the uncertainty in the 792 composited disaggregation product; and 2) the applicability of 793 DisPATCh is greatly dependent on the quality of MODIS land 794 surface temperature. Note that in this study, a choice was made 795 to maximize the number of data points used in the comparison 796 with in situ measurements. Consequently, all the cloud-free 797 

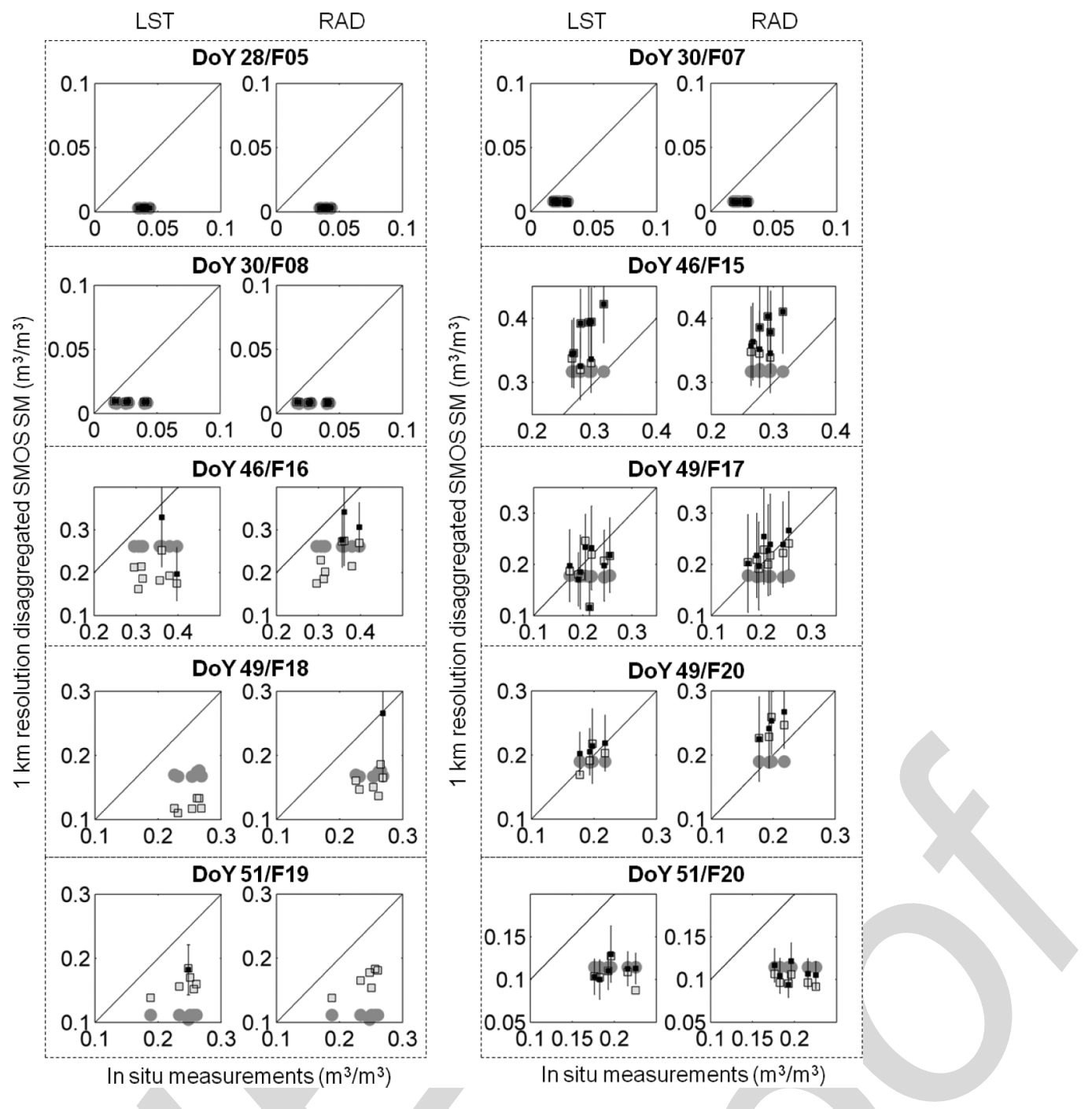

Fig. 8. Scatterplots of 1-km resolution disaggregated SMOS soil moisture versus 1-km resolution aggregated in situ measurements for each of the ten date-farm data sets during AACES-1. The filled circles correspond to disaggregation with no 1-km information, empty squares to Zone $\mathrm{A}+\mathrm{B}+\mathrm{C}$ mode and black squares to Zone A only mode. For the Zone A only mode, the uncertainty in disaggregated soil moisture is represented by vertical errorbars.

798 MODIS land surface temperature data were used regardless 799 of the MODIS land surface temperature quality index. Further 800 research should be conducted to assess whether selecting the 801 MODIS pixel with the best MODIS land surface temperature 802 quality index would improve the disaggregation results. This 803 would be possible using the AACES airborne data, which cover 804 a much larger area than in situ measurements.

\section{E. Atmospheric Corrections}

806 The impact of atmospheric corrections on DisPATCh output 807 is analyzed by comparing the disaggregation results obtained 808 in the LST and RAD mode. Quantitative comparison between 809 LST and RAD modes is provided in Table IV in terms of root 810 mean square difference, mean difference, correlation coeffi811 cient, and slope of the linear regression between disaggregated 812 SMOS soil moisture and aggregated in situ measurements. 813 Correlation coefficient and slope values are reported only if 814 the p-value (statistical significance) is lower than 0.10. It is 815 apparent that statistical results are better in the RAD than in the LST mode. When including all dates, the mean bias is 816 decreased from $-0.05 \mathrm{~m}^{3} / \mathrm{m}^{3}$ in LST mode to $-0.03 \mathrm{~m}^{3} / \mathrm{m}^{3} 817$ in RAD mode during AACES-1. When selecting statistically 818 significant results $(\mathrm{p}$-value $<0.10)$ and discarding data for 819 DoY 30, the mean correlation coefficient and slope is 0.75 and 820 0.58 in RAD mode, and 0.65 and 1.5 in LST mode, respectively. 821 Note that the improvement is very significant for DoY 46/F16 822 with a correlation coefficient and slope increasing from about 823 zero to 0.7 and 0.8 , respectively.

The fact that the results obtained in RAD mode are superior 825 to those obtained in LST mode indicates that the atmospheric 826 corrections of the official MODIS land surface temperature 827 add significant uncertainties in the disaggregation products. 828 One rationale may be that the information used in atmospheric 829 corrections (notably air temperature and water vapor profile 830 data) are subjected to large uncertainties at $5-\mathrm{km}$ resolution. 831 As DisPATCh is based on the spatial variations of MODIS 832 temperature relative to the $40 \mathrm{~km}$ scale mean, the atmospheric 833 corrections on the land surface temperature data are not nec- 834 essary at $5 \mathrm{~km}$ (as it is done in the MODIS temperature 835 
TABLE IV

DisPatCh Is Run in the Zone A+B+C Mode and Statistical Results Are Listed in Terms of Root Mean Square Difference (RMSD), Mean Difference (Bias), Correlation Coefficient (R), and Slope of the Linear Regression Between 1-km Resolution Disaggregated SMOS Soil Moisture and 1-km Aggregated IN Situ Measurements. The Results Obtained Using THE Radiance-Derived Land SuRface Temperature Data (RAD Mode) and Using The OfFicial MODIS LAND Surface Temperature Data (LSt Mode in Parenthesis) Are Compared. The Mean and Standard Deviation of Ground MEASUREMENTS ( $\langle$ SM HDAS $\rangle$ AND $\sigma$ HDAS $)$, THE NUMBER OF CONSIDERED 1-km PIXELS and Statistical Significance (P-Value) Are Also Listed for Each Date-Farm Unit

\begin{tabular}{|c|c|c|c|c|c|c|c|c|}
\hline DoY/Farm & $\begin{array}{c}\left\langle\mathrm{SM}_{\mathrm{HDAS}}\right\rangle \\
\left(\mathrm{m}^{3} / \mathrm{m}^{3}\right)\end{array}$ & $\begin{array}{c}\sigma_{\mathrm{HDAS}} \\
\left(\mathrm{m}^{3} / \mathrm{m}^{3}\right)\end{array}$ & $\begin{array}{l}\text { Number of } \\
1 \mathrm{~km} \text { pixels }\end{array}$ & $\begin{array}{l}\text { RMSD } \\
\left(\mathrm{m}^{3} / \mathrm{m}^{3}\right)\end{array}$ & $\begin{array}{c}\text { Bias } \\
\left(\mathrm{m}^{3} / \mathrm{m}^{3}\right)\end{array}$ & $\begin{array}{l}\mathrm{R}^{\dagger} \\
(-)\end{array}$ & $\begin{array}{c}\text { Slope }^{\dagger} \\
(-)\end{array}$ & $\begin{array}{c}\text { p-value } \\
(-)\end{array}$ \\
\hline 28/F05 & 0.04 & 0.02 & $7(7)$ & $0.04(0.04)$ & $-0.04(-0.04)$ & $-(-)$ & $-(-)$ & $0.72(0.80)$ \\
\hline 30/F07 & 0.02 & 0.03 & $8(8)$ & $0.02(0.02)$ & $-0.02(-0.02)$ & $-(-0.70)$ & $-(-0.08)$ & $0.20(0.05)$ \\
\hline $30 / \mathrm{F} 08$ & 0.03 & 0.02 & $7(7)$ & $0.02(0.02)$ & $-0.02(-0.02)$ & $-(-0.95)$ & $-(-0.03)$ & $0.11(0.001)$ \\
\hline $46 / \mathrm{F} 15$ & 0.29 & 0.05 & $8(8)$ & $0.09(0.09)$ & $0.09(0.08)$ & $-(0.65)$ & $-(1.5)$ & $0.12(0.08)$ \\
\hline $46 /$ F 16 & 0.34 & 0.06 & $8(8)$ & $0.12(0.15)$ & $-0.11(-0.14)$ & $0.72(-)$ & $0.76(-)$ & $0.04(0.95)$ \\
\hline 49/F17 & 0.21 & 0.06 & $8(8)$ & $0.02(0.04)$ & $0.00(-0.02)$ & $0.70(-)$ & $0.42(-)$ & $0.05(0.54)$ \\
\hline 49/F18 & 0.25 & 0.07 & $6(6)$ & $0.10(0.13)$ & $-0.09(-0.13)$ & $-(-)$ & $-(-)$ & $0.60(0.20)$ \\
\hline 49/F20 & 0.20 & 0.09 & $4(4)$ & $0.05(0.01)$ & $0.04(0.00)$ & $-(-)$ & $-(-)$ & $0.41(0.32)$ \\
\hline $51 /$ F19 & 0.24 & 0.08 & $6(6)$ & $0.07(0.08)$ & $-0.07(-0.08)$ & $0.84(-)$ & $0.56(-)$ & $0.04(0.19)$ \\
\hline $51 /$ F 20 & 0.20 & 0.10 & $6(6)$ & $0.10(0.09)$ & $-0.10(-0.09)$ & $-(-)$ & $-(-)$ & $0.17(0.51)$ \\
\hline AACES- 1 mean ${ }^{\ddagger}$ & $0.26(0.29)$ & $0.07(0.05)$ & $7(8)$ & $0.07(0.09)$ & $-0.06(-0.08)$ & $0.75(0.65)$ & $0.58(1.5)$ & $0.04(0.08)$ \\
\hline 254/F09 & 0.33 & 0.07 & $9(9)$ & $0.18(0.14)$ & $-0.16(-0.11)$ & $-(-)$ & $-(-)$ & $0.17(0.74)$ \\
\hline $256 / \mathrm{F} 07$ & 0.36 & 0.10 & $8(9)$ & $0.12(0.19)$ & $-0.10(-0.18)$ & $-(-0.73)$ & $-(-0.47)$ & $0.12(0.04)$ \\
\hline $264 / \mathrm{F} 13$ & 0.30 & 0.07 & $8(8)$ & $0.16(0.19)$ & $-0.14(-0.16)$ & $-(-)$ & $-(-$ & $0.59(0.47)$ \\
\hline $265 / \mathrm{F} 15$ & 0.25 & 0.06 & $7(7)$ & $0.16(0.18)$ & $0.01(0.03)$ & $-(-)$ & $-(-)$ & $0.32(0.34)$ \\
\hline 267/F09 & 0.21 & 0.07 & $9(9)$ & $0.16(0.15)$ & $-0.15(-0.15)$ & $-(-)$ & $-(-)$ & $0.90(0.86)$ \\
\hline AACES- 2 mean $\ddagger$ & 0.36 & 0.10 & $-(9)$ & $-(0.19)$ & $-(-0.18)$ & $-(-0.73)$ & $-(-0.47)$ & $>0.10(0.04)$ \\
\hline
\end{tabular}

$\ddagger$ the mean values computed for AACES-1 and AACES-2 include only statistically significant ( $\mathrm{p}$-value $<0.10)$ results and discard extensive dry days DoY 28-30.

836 algorithm). An atmospheric correction at $40-\mathrm{km}$ resolution is 837 sufficient and provides even better disaggregation results that 838 applying an atmospheric correction at $5-\mathrm{km}$ resolution.

\section{F. Vegetation Cover}

840 The impact of vegetation cover on DisPATCh output during 841 AACES-1 is analyzed by comparing the disaggregation results 842 obtained in the Zone $\mathrm{A}+\mathrm{B}+\mathrm{C}$ and Zone A only mode. Quan843 titative comparison between Zone $\mathrm{A}+\mathrm{B}+\mathrm{C}$ and Zone $\mathrm{A}$ only 844 modes is provided in Tables IV and $\mathrm{V}$ in terms of root mean 845 square difference, mean difference, correlation coefficient, and 846 slope of the linear regression between disaggregated SMOS soil 847 moisture and aggregated in situ measurements. It is apparent 848 that statistical results are generally better in the Zone A only 849 than in the Zone $\mathrm{A}+\mathrm{B}+\mathrm{C}$ mode for both LST and RAD modes. 850 In the RAD mode for instance, the mean correlation coefficient 851 is increased from 0.75 in the Zone $A+B+C$ mode (Table IV) to 8520.89 in the Zone A only mode (Table V). Also the mean slope 853 is closer to 1 as it switches from 0.58 in the Zone $A+B+C$ mode 854 (Table IV) to 0.91 in the Zone A only mode (Table V). Con855 sequently, results are consistent with the hourglass approach in 856 Fig. 3 that predicts a lower sensitivity of MODIS-derived soil 857 temperature to soil moisture in Zone B and C, Zone A having the highest potential for estimating soil moisture variability 858 from MODIS temperature.

On DoY 256, the negative correlation appearing in Zone 860 $\mathrm{A}+\mathrm{B}+\mathrm{C}$ mode (Table IV) is not significant in Zone A only mode 861 (Table V), suggesting that the contradictory result obtained on 862 DoY 256 is probably an artifact due to the small sample size. 863

Note that one drawback of the Zone A only mode is the larger 864 amount of data gaps in the soil moisture images. Therefore, 865 the use of both modes is a compromise between application 866 coverage and accuracy in the disaggregation output.

867

\section{G. Distinguishing Between SMOS and DisPATCh Errors}

868

By solving the extent mismatch between 40-km resolution 869 remote sensing observation and localized in situ measurements, 870 DisPATCh could be used as a tool to help improve the validation 871 strategies of SMOS data in low-vegetated semi-arid regions. It 872 also would reduce the coverage requirements identified by [41] 873 for airborne validation campaigns. However, such a validation 874 approach requires separating the different error sources that 875 may be attributed to SMOS soil moisture and to DisPATCh. 876 One solution is to estimate the errors attributed to DisPATCh 877 and then deduce the errors attributed to SMOS soil moisture. To 878 estimate the errors that are associated with the disaggregation 879 


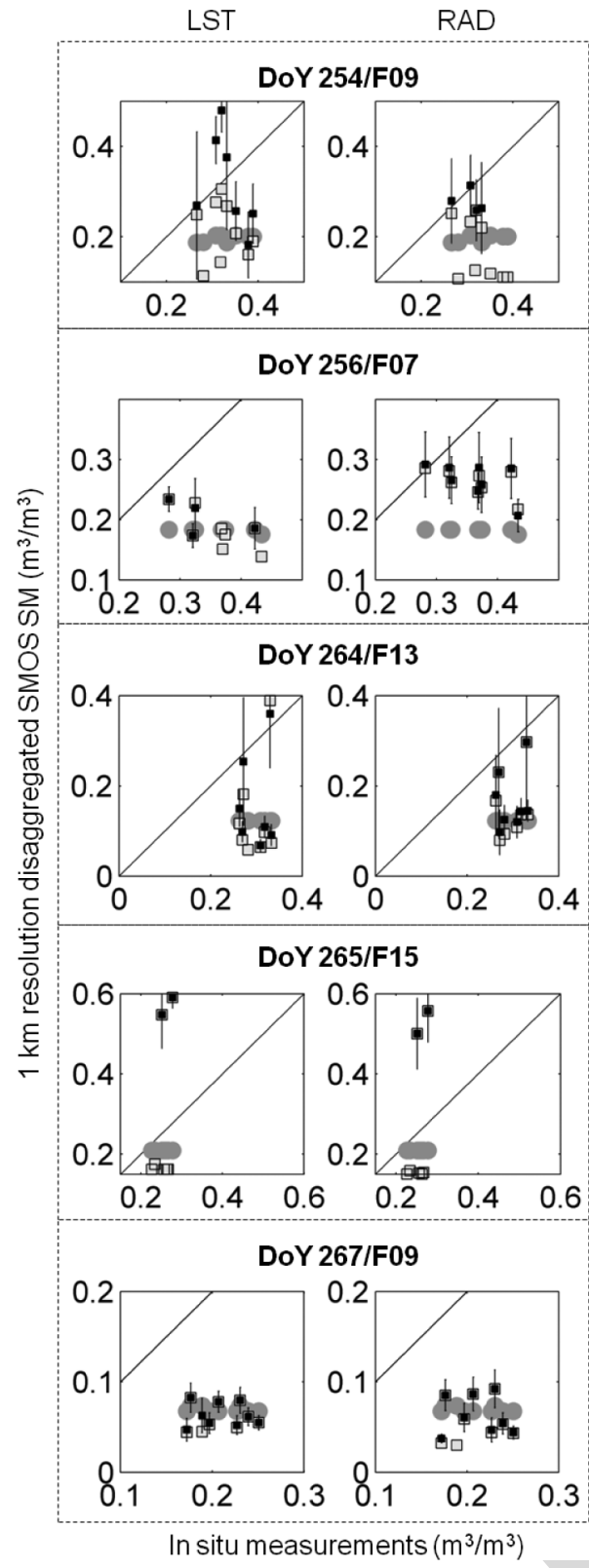

Fig. 9. Scatterplots of 1-km resolution disaggregated SMOS soil moisture versus 1-km resolution aggregated in situ measurements for each of the five datefarm data sets during AACES-2. The filled circles correspond to disaggregation with no $1-\mathrm{km}$ information, empty squares to Zone $\mathrm{A}+\mathrm{B}+\mathrm{C}$ mode and black squares to Zone A only mode. For the Zone A only mode, the uncertainty in disaggregated soil moisture is represented by vertical errorbars.

880 methodology, it is suggested to analyze the spatial correla881 tion between $1-\mathrm{km}$ disaggregated SMOS soil moisture and 882 in situ measurements. If the correlation is significant, then the 883 disaggregation product is likely to be sufficiently accurate for 884 validating SMOS data.

885 Note that the errors in DisPATCh are in part coupled with 886 the errors in SMOS soil moisture, particularly because SMOS 887 is an input to DisPATCh. However, any uncertainties in SMOS 888 soil moisture should not impact the disaggregation results at a 889 distance shorter than the SMOS data sampling length $(15 \mathrm{~km})$. 890 This is the reason why such a validation strategy should be 891 conducted with ground measurements made within a distance 892 radius of $15 \mathrm{~km}$.
In this study case, five date-farm units including DoY 893 46/F15, DoY 46/F16, DoY 49/F17, DoY 49/F18, and DoY 894 49/F20 indicate a significant correlation between disaggregated 895 SMOS soil moisture and in situ measurements. For these units, 896 the root mean square error in disaggregated SMOS soil mois- 897 ture is mainly explained by a bias in disaggregated soil moisture 898 (see Table IV). However, no conclusion can be drawn from 899 these data because: 1) the bias is sometimes positive (DoY 900 46/F15, DoY 49/F20), and sometimes negative (DoY 46/F16, 901 DoY 49/F17, DoY 49/F18); and 2) the comparison is made only 902 once for each farm, which does not allow analyzing the tempo- 903 ral behavior. Such a validation approach could be undertaken 904 in the near future using the OzNet (http://www.oznet.org.au/, 905 [42]) soil moisture monitoring network, providing continuous 906 measurements at 68 sites within the Murrumbidgee catchment 907 area.

\section{H. Subpixel Variability and Assimilation Perspectives}

DisPATCh is successively run in LST or RAD mode and in 910 Zone $\mathrm{A}+\mathrm{B}+\mathrm{C}$ or Zone A only mode during AACES-1. Fig. 10911 plots for each case the estimated uncertainty in disaggregated 912 soil moisture (computed as the standard deviation of the disag- 913 gregation output ensemble) against the subpixel variability of 914 $1-\mathrm{km}$ resolution in situ measurements (computed as the stan- 915 dard deviation of the in situ measurements made within 916 1-km pixels). The data corresponding to DoY 51 are plotted 917 separately because of the time gap between HDAS/SMOS 918 (DoY 51) and MODIS (DoY 54) collection time. It is interest- 919 ing to observe that the estimated uncertainty in disaggregated 920 soil moisture is closely related to the observed subpixel vari- 921 ability of in situ measurements. Hence, $\sigma_{\mathrm{SM}, 1 \mathrm{~km}}$ could be used 922 as a proxy for representing the soil moisture variability at scales 923 finer than 1-km resolution. Concerning the data on DoY 51, the 924 linear regression is clearly off the 1:1 line. This is consistent 925 with a decrease of the spatial variability in soil moisture during 926 a dry down period [43]. In particular, the spatial variability 927 in soil moisture is expected to be lower on DoY 54 than on 928 DoY 51.

The correlation between the estimated uncertainty in disag- 930 gregated soil moisture and the subpixel soil moisture variability 931 makes an additional link between DisPATCh output and assim- 932 ilation schemes into hydrological models. A number of optimal 933 assimilation methodologies have been developed to combine 934 model predictions with remote sensing observations. However, 935 any so-called optimal assimilation technique stops being opti- 936 mal if the uncertainty in remotely sensed data is unknown or 937 estimated with a large uncertainty. In the perspective of assim- 938 ilating disaggregated SMOS data into land surface models, one 939 should keep in mind that the error information on observable 940 variables is as crucial as the observations themselves, e.g., [44]. 941

\section{Summary AND CONCLUSION}

DisPATCh is an algorithm dedicated to the disaggregation of 943 soil moisture observations using high-resolution soil tempera- 944 ture data. It converts soil temperature fields into soil moisture 945 fields given a semi-empirical soil evaporative efficiency model 946 
TABLE V

DispatCh Is Run in the Zone A Only Mode, and Statistical Results Are Listed in Terms of Root Mean SQuare Difference (RMSD), Mean Difference (Bias), Correlation Coefficient (R), and Slope of the Linear Regression Between 1-km Resolution Disaggregated SMOS SoIl Moisture and 1-km AgGRegated IN Situ MEasurements. The Results ObTained Using the Radiance-Derived Land Surface Temperature Data (RAD Mode) and Using the OfFicial MODIS Land Surface Temperature Data (LSt Mode in Parenthesis) Are Compared. The Mean and Standard DeViation of Ground MEASUREMENTS ( $\left\langle\mathrm{SM}_{\text {HDAS }}\right\rangle$ AND $\sigma$ HDAS $)$, THE NUMBER OF CONSIDERED 1-km PiXels and Statistical Significance (P-VAlue) Are Also Listed for Each Date-Farm Unit

\begin{tabular}{|c|c|c|c|c|c|c|c|c|}
\hline DoY/Farm & $\begin{array}{c}\left\langle\mathrm{SM}_{\mathrm{HDAS}}\right\rangle \\
\left(\mathrm{m}^{3} / \mathrm{m}^{3}\right)\end{array}$ & $\begin{array}{c}\sigma_{\mathrm{HDAS}} \\
\left(\mathrm{m}^{3} / \mathrm{m}^{3}\right)\end{array}$ & $\begin{array}{l}\text { Number of } \\
1 \mathrm{~km} \text { pixels }\end{array}$ & $\begin{array}{l}\text { RMSD* } \\
\left(\mathrm{m}^{3} / \mathrm{m}^{3}\right)\end{array}$ & $\begin{array}{c}\text { Bias* } \\
\left(\mathrm{m}^{3} / \mathrm{m}^{3}\right)\end{array}$ & $\begin{array}{l}\mathrm{R}^{\dagger} \\
(-)\end{array}$ & $\begin{array}{c}\text { Slope }^{\dagger} \\
(-)\end{array}$ & $\begin{array}{c}\text { p-value } \\
(-)\end{array}$ \\
\hline $28 / \mathrm{F} 05$ & 0.04 & 0.02 & $7(7)$ & $0.04(0.04)$ & $-0.04(-0.04)$ & $-(-)$ & $-(-)$ & $0.72(0.80)$ \\
\hline $30 / \mathrm{F} 07$ & 0.02 & 0.03 & $8(8)$ & $0.02(0.02)$ & $-0.02(-0.02)$ & $-(-0.70)$ & $-(-0.08)$ & $0.20(0.05)$ \\
\hline $30 / \mathrm{F} 08$ & 0.03 & 0.02 & $7(7)$ & $0.02(0.02)$ & $-0.02(-0.02)$ & $-(-0.95)$ & $-(-0.03)$ & $0.11(0.001)$ \\
\hline $46 / F 15$ & 0.29 & 0.05 & $8(8)$ & $0.09(0.09)$ & $0.09(0.08)$ & $-(0.66)$ & - (1.4) & $0.13(0.07)$ \\
\hline $46 / \mathrm{F} 16$ & 0.34 & 0.06 & $3(2)$ & $0.07(0.14)$ & $-0.06(-0.12)$ & $-(-)$ & $-(-)$ & $0.96(-)$ \\
\hline 49/F17 & 0.21 & 0.06 & $8(8)$ & $0.02(0.04)$ & $0.02(-0.02)$ & $0.79(-)$ & $0.71(-)$ & $0.02(0.64)$ \\
\hline 49/F18 & 0.25 & 0.07 & $1(0)$ & $-(-)$ & $-(-)$ & $-(-)$ & $-(-)$ & $0.20(0.20)$ \\
\hline $49 / \mathrm{F} 20$ & 0.20 & 0.09 & $4(4)$ & $0.05(0.02)$ & $0.05(0.01)$ & $0.98(0.92)$ & $1.1(0.42)$ & $0.02(0.08)$ \\
\hline $51 / \mathrm{F} 19$ & 0.24 & 0.08 & $0(1)$ & $-(-)$ & $-(-)$ & $-(-)$ & $-(-)$ & $0.19(0.19)$ \\
\hline $51 /$ F 20 & 0.20 & 0.10 & $6(6)$ & $0.09(0.09)$ & $-0.09(-0.09)$ & $-(-)$ & $-(-)$ & $0.70(0.45)$ \\
\hline AACES-1 mean & $0.21(0.25)$ & $0.08(0.07)$ & $6(6)$ & $0.04(0.06)$ & $0.04(0.05)$ & $0.89(0.79)$ & $0.91(0.91)$ & $0.02(0.08)$ \\
\hline 254/F09 & 0.33 & 0.07 & $4(7)$ & $0.05(0.12)$ & $-0.03(-0.02)$ & $-(-)$ & $-(-)$ & $0.70(0.30)$ \\
\hline $256 / \mathrm{F} 07$ & 0.36 & 0.10 & $8(4)$ & $0.12(0.15)$ & $-0.10(-0.13)$ & $-(-)$ & $-(-)$ & $0.13(0.43)$ \\
\hline 264/F13 & 0.30 & 0.07 & $8(7)$ & $0.14(0.17)$ & $-0.13(-0.14)$ & $-(-)$ & $-(-)$ & $0.64(0.86)$ \\
\hline $265 / \mathrm{F} 15$ & 0.25 & 0.06 & $2(2)$ & $0.26(0.30)$ & $0.26(0.30)$ & $-(-)$ & $-(-)$ & $-(-)$ \\
\hline 267/F09 & 0.21 & 0.07 & $8(9)$ & $0.15(0.15)$ & $-0.15(-0.15)$ & $-(-)$ & $-(-)$ & $0.77(0.85)$ \\
\hline AACES- 2 mean & - & - & $-(-)$ & $-(-)$ & $-(-)$ & $-(-)$ & $-(-)$ & $>0.10(>0.10)$ \\
\hline
\end{tabular}

$\ddagger$ the mean values computed for AACES- 1 and AACES-2 include only statistically significant $(p$-value $<0.10)$ results and discard extensive dry days DoY 28-30.

947 and a first-order Taylor series expansion around the field-mean 948 soil moisture. In this study, the disaggregation approach is ap949 plied to 40-km resolution version-4 SMOS level-2 soil moisture 950 using 1-km resolution MODIS data. The objective is to test 951 DisPATCh under different surface and atmospheric conditions 952 using the very intensive ground measurements collected in 953 southeastern Australia during the 2010 summer and winter 954 AACES campaigns. Those measurements are aggregated at 955 the downscaling resolution $(1 \mathrm{~km})$ and subsequently compared 956 to the disaggregated SMOS soil moisture. Over the study 957 area, climatic (evaporative demand), meteorologic (presence 958 of clouds), and vegetation (cover and water status) conditions 959 are strong constraints on disaggregation results. The quality 960 of disaggregation products varies greatly according to season: 961 while the correlation coefficient between disaggregated and 962 in situ soil moisture is 0.7 during the summer AACES, it 963 is about zero during the winter AACES, consistent with a 964 weaker coupling between evaporation and surface moisture 965 in temperate than in semi-arid climate. Moreover, vegetation 966 cover prevents the soil temperature to be retrieved from thermal 967 infrared data and the vegetation water stress may increase the 968 remotely sensed land surface temperature independent of near969 surface soil moisture. By separating the 1-km pixels where 970 MODIS temperature is mainly controlled by soil evaporation, from those where MODIS temperature is controlled by both 971 soil evaporation and vegetation transpiration, the correlation 972 coefficient between disaggregated and in situ soil moisture is 973 increased from 0.70 to 0.85 during the summer AACES cam- 974 paign. Also, cloud cover totally obscures the surface during rain 975 events, and on clear sky days, the water vapor in the atmosphere 976 significantly affects the quality of land surface temperature 977 data. It is found that the 5-km resolution atmospheric correction 978 of the official MODIS temperature data has significant impact 979 on DisPATCh output. An alternative atmospheric correction at 980 40-km resolution increases the correlation coefficient between 981 disaggregated and in situ soil moisture from 0.72 to 0.82 during 982 the summer AACES.

983

The above limitations must be kept in mind when using 984 DisPATCh as a tool for validating SMOS soil moisture. Over 985 semi-arid areas, disaggregation can solve the extent mismatch 986 between the 40-km resolution SMOS data and localized in situ 987 measurements. However, the validation of SMOS using Dis- 988 PATCh requires separation of the errors associated with SMOS 989 data and the errors associated with DisPATCh. As SMOS data 990 are an input to DisPATCh, the errors in DisPATCh are also 991 linked to the uncertainty in SMOS soil moisture. Nevertheless, 992 one way to identify the error sources specifically attributed 993 to DisPATCh is to analyze the spatial correlation between 994 


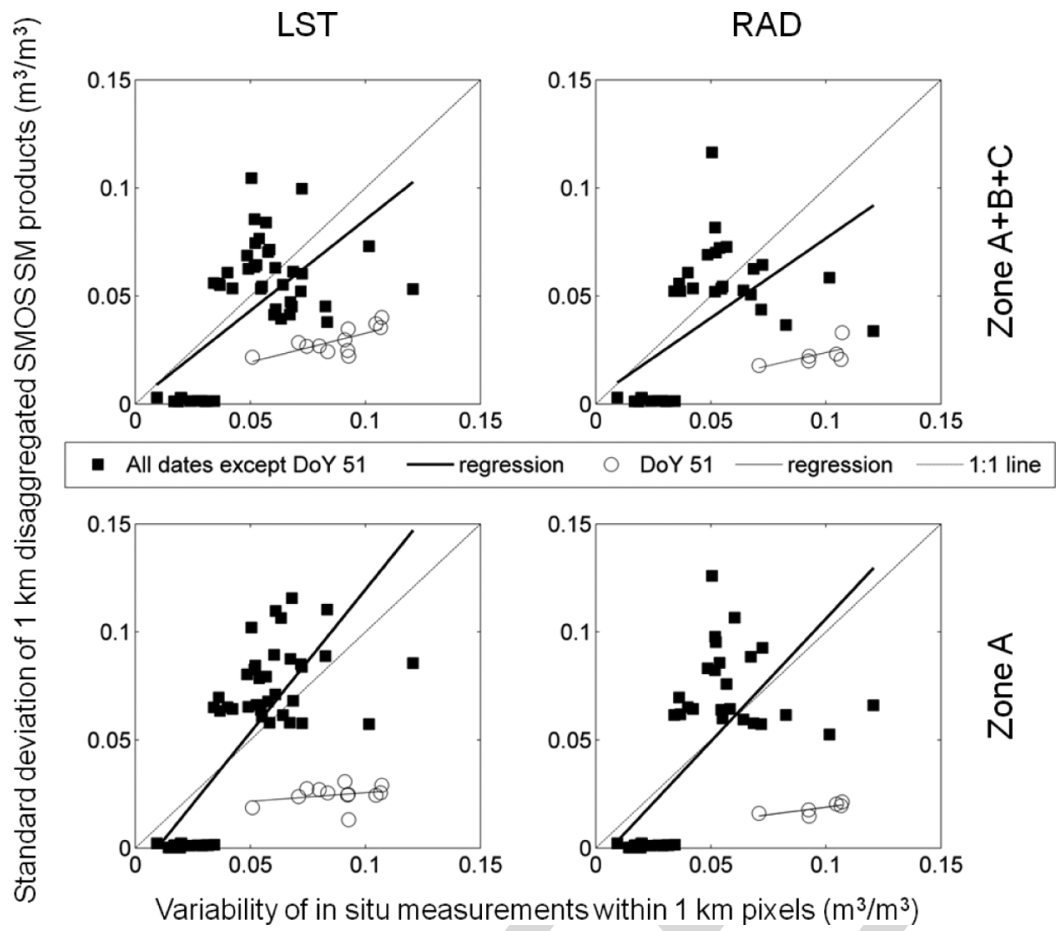

Fig. 10. Estimated uncertainty in disaggregated soil moisture $\left(\sigma_{\mathrm{SM}}, 1 \mathrm{~km}\right)$ versus subpixel variability of $1 \mathrm{~km}$ resolution in situ measurements for DisPATCh run in LST or RAD mode and Zone $\mathrm{A}+\mathrm{B}+\mathrm{C}$ or Zone A only mode.

995 disaggregated SMOS data and the in situ measurements made 996 at a distance larger than the downscaling resolution $(1 \mathrm{~km}$ with 997 MODIS data) and smaller than the SMOS data sampling length $998(15 \mathrm{~km})$.

999 Based on the results obtained using the AACES in situ 1000 measurements, several improvements of DisPATCh can be 1001 suggested:

1002

1003

1004

1005

1006

1007

1008

1009

1010

1011

1012

1013

1014

1015

1016

1017

1018

1019

1020

1021

1022

1023

1024

1025

1026
- Use of the MODIS land surface temperature quality index to select the SMOS pixels with the highest MODIS data quality.

- Correcting the MODIS land surface temperature for topography and illumination effects [45]. Within a 40-km SMOS resolution pixel, the elevation range may be very significant and thus induce a variability in land surface temperature that is not attributed to surface soil moisture.

- Use of ancillary air temperature data to constrain the estimation of end-members. The unstressed vegetation temperature $\mathbf{T}_{\mathbf{v}, \text { min }}$ could be set to the air temperature instead of the minimum MODIS land surface temperature. This would make the estimation of $\mathbf{T}_{\mathbf{v}, \mathbf{m i n}}$ less dependent on the representativeness of the surface conditions met within the SMOS pixel [24].

- Accounting for the dependency of soil evaporative efficiency to potential evaporation, by replacing the model in [26] with the model in [38].

- Estimating an optimal downscaling resolution for each season: as the sensitivity of soil evaporative efficiency to soil moisture is lower in the winter months than in the summer months, aggregating DisPATCh output may improve the quality of disaggregation products at the expense of spatial resolution [17].
A robust disaggregation methodology of SMOS soil moisture 1027 at $1-\mathrm{km}$ resolution, which would provide both disaggregated 1028 soil moisture and its uncertainty at $1-\mathrm{km}$ resolution is a crucial 1029 step toward the application of SMOS data to hydrological 1030 studies.

\section{REFERENCES}

[1] E. G. Njoku and L. Li, "Retrieval of land surface parameters using passive 1033 microwave measurements at 6-18 GHz," IEEE Trans. Geosci. Remote 1034 Sens., vol. 37, no. 1, pp. 79-93, Jan. 1999.

1035

[2] C. S. Draper, J. P. Walker, P. J. Steinle, R. A. M. D. Jeu, and 1036 T. R. H. Holmes, "An evaluation of AMSR-E derived soil moisture 1037 over Australia," Remote Sens. Environ., vol. 113, no. 4, pp. 703-710, 1038 Apr. 2009. doi:10.1016/j.rse.2008.11.011.

1039

[3] C. Kummerow, W. S. Olson, and L. Giglio, "A simplified scheme for 1040 obtaining precipitation and vertical hydrometeor profiles from passive 1041 microwave sensors," IEEE Trans. Geosci. Remote Sens., vol. 34, no. 5, 1042 pp. 1213-1232, Sep. 1996.

1043

[4] M. Grecu and E. N. Anagnostou, "Overland precipitation estimation from 1044 TRMM passive microwave observations," J. Appl. Meteor., vol. 40, no. 8, 1045 pp. 1367-1380, Aug. 2001.

1046

[5] T. J. Jackson, M. H. Cosh, R. Bindlish, P. J. Starks, D. D. Bosch, 1047 M. Seyfried, D. C. Goodrich, M. S. Moran, and J. Du, "Validation of 1048 advanced microwave scanning radiometer soil moisture products," IEEE 1049 Trans. Geosci. Remote Sens., vol. 48, no. 12, pp. 4256-4272, Dec. 2010. 1050 doi:10.1109/TGRS.2010.2051035.

1051

[6] Y. H. Kerr, P. Waldteufel, J.-P. Wigneron, S. Delwart, F. Cabot, 1052 J. Boutin, M. J. Escorihuela, J. Font, N. Reul, C. Gruhier, S. E. Juglea, 1053 M. R. Drinkwater, A. Hahne, M. Martin-Neira, and S. Mecklenburg, 1054 "The SMOS mission: New tool for monitoring key elements of the 1055 global water cycle," Proc. IEEE, vol. 98, no. 5, pp. 666-687, May 2010. 1056 doi:10.1109/JPROC.2010.2043032.

1057

[7] P. Matos, A. Gutiérrez, and F. Moreira, SMOS L1 Processor Discrete 1058 Global Grids Document, vol. SMOS-DMS-TN-5200. Lisboa, Portugal: 1059 DEIMOS Engenharia, 2004, V1.4.

1060

[8] S. Bircher, J. E. Balling, N. Skou, and Y. Kerr, "SMOS validation by 1061 means of an airborne campaign in the Skjern river catchment, Western 1062 Denmark," IEEE Trans. Geosci. Remote Sens., 2011, to be published. 1063 AQ1

[9] C. Gruhier, P. de Rosnay, S. Hasenauer, T. Holmes, R. de Jeu, 1064 Y. Kerr, E. Mougin, E. Njoku, F. Timouk, W. Wagner, and M. Zribi 1065 
1066 (2010, Jan.). Soil moisture active and passive microwave products: 1067 Intercomparison and evaluation over a Sahelian site. Hydrol. Earth Syst. 1068 Sci. [Online]. 14(1), pp. 141-156. Available: www.hydrol-earth-syst1069 sci.net/14/141/2010/

1070 [10] J.-C. Calvet, N. Fritz, F. Froissard, D. Suquia, A. Petitpa, and B. Piguet, 1071 "In situ soil moisture observations for the CAL/VAL of SMOS: The 1072 SMOSMANIA network," in Proc. IGARSS, Barcelona, Spain, 2007, 1073 pp. 1196-1199.

1074 [11] S. Peischl, J. P. Walker, M. Allahmoradi, D. Barrett, R. Gurney, Y. Kerr, 1075 E. Kim, J. Le Marshall, C. Rüdiger, D. Ryu, and N. Ye, "Towards vali1076 dation of SMOS using airborne and ground data over the Murrumbidgee 1077 catchment," in Proc. MODSIM, Cairns, Australia, 2009, pp. 3733-3739.

1078 [12] M. H. Cosh, T. J. Jackson, S. M. Moran, and R. Bindlish, "Temporal 1079 persistence and stability of surface soil moisture in a semi-arid water1080 shed," Remote Sens. Environ., vol. 112, no. 2, pp. 304-313, Feb. 2008. 1081 doi:10.1016/j.rse.2007.07.001.

1082 [13] P. de Rosnay, C. Gruhier, F. Timouk, F. Baup, E. Mougin, P. Hiernaux, 1083 L. Kergoat, and V. Le Dantec, "Multi-scale soil moisture measurements 1084 at the Gourma meso-scale site in Mali," J. Hydrol., vol. 375, no. 1/2, 1085 pp. 241-252, Aug. 2009. doi:10.1016/j.jhydrol.2009.01.015.

1086 [14] N. S. Chauhan, S. Miller, and P. Ardanuy, "Spaceborne soil moisture esti1087 mation at high resolution: A microwave-optical/IR synergistic approach," 1088 Int. J. Remote Sens., vol. 24, no. 22, pp. 4599-4622, Nov. 2003.

1089 [15] M. Piles, A. Camps, M. Vall-llossera, I. Corbella, R. Panciera, C. Rüdiger, 1090 Y. H. Kerr, and J. P. Walker, "Downscaling SMOS-derived soil moisture 1091 using MODIS visible/infrared data," IEEE Trans. Geosci. Remote Sens., 1092 vol. 49, no. 9, pp. 3156-3166, Sep. 2011

1093 [16] O. Merlin, A. Al Bitar, J. P. Walker, and Y. Kerr, "An improved algorithm 1094 for disaggregating microwave-derived soil moisture based on red, near1095 infrared and thermal-infrared data," Remote Sens. Environ., vol. 114, 1096 no. 10, pp. 2305-2316, Oct. 2010. doi:10.1016/j.rse.2010.05.007.

1097 [17] O. Merlin, A. Al Bitar, J. P. Walker, and Y. Kerr, "A sequential model 1098 for disaggregating near-surface soil moisture observations using multi1099 resolution thermal sensors," Remote Sens. Environ., vol. 113, no. 10, 1100 pp. 2275-2284, Oct. 2009. doi:10.1016/j.rse.2009.06.012.

1101 [18] O. Merlin, J. Walker, R. Panciera, R. Young, J. Kalma, and 1102 E. Kim, "Soil moisture measurement in heterogeneous terrain," in Proc. 1103 MODSIM-International Congress Modelling Simulation Modelling 1104 Simulation Society Australia New Zealand, Dec. 2007, pp. 2604-2610.

1105 [19] Y. H. Kerr, P. Waldteufel, P. Richaume, P. Ferrazzoli, and J.-P. Wigneron, 1106 SMOS Level 2 Processor Soil Moisture Algorithm Theoretical Basis 1107 Document (ATBD), vol. SO-TN-ESL-SM-GS-0001. Toulouse, France: 1108 CESBIO, May 2011, V3.f.

1109 [20] Y. H. Kerr, P. Waldteufel, P. Richaume, J. P. Wigneron, P. Ferrazzoli, 1110 A. Mahmoodi, A. Al Bitar, F. Cabot, C. Gruhier, D. Leroux, A. Mialon, 1111 and S. Delwart, "The SMOS soil moisture retrieval algorithm," IEEE Trans. Geosci. Remote Sens., 2011.

1113 [21] O. Merlin, C. Rüdiger, P. Richaume, A. Al Bitar, A. Mialon, J. P. Walker, 1114 1115 and Y. Kerr, Disaggregation as a top-down approach for evaluating $40 \mathrm{~km}$ resolution SMOS data using point-scale measurements: Application to AACES-1," in Proc. SPIE, Remote Sens. Agriculture, Ecosystems, Hydrol. XII, Toulouse, France, 2010, pp. 782 40I-1-78240I-8.

22] K. Nishida, R. R. Nemani, J. M. Glassy, and S. W. Running, "Development of an evapotranspiration index from Aqua/MODIS for monitoring surface moisture status," IEEE Trans. Geosci. Remote Sens., vol. 41, no. 2, pp. 493-501, Feb. 2003.

23] G. Gutman and A. Ignatov, "The derivation of the green vegetation fraction from NOAA/AVHRR data for use in numerical weather prediction models," Int. J. Remote Sens., vol. 19, pp. 1533-1543, 1998.

24] O. Merlin, B. Duchemin, O. Hagolle, F. Jacob, B. Coudert, G. Chehbouni, G. Dedieu, J. Garatuza, and Y. Kerr, "Disaggregation of MODIS surface temperature over an agricultural area using a time series of Formosat-2 images," Remote Sens. Environ., vol. 114, no. 11, pp. 2500-2512, Nov. 2010. doi:10.1016/j.rse.2010.05.025.

5] A. C. T. Pinheiro, J. Descloitres, J. L. Privette, J. Susskind, L. Iredell, and J. Schmaltz, "Near-real time retrievals of land surface temperature within the MODIS rapid response system," Remote Sens. Environ., vol. 106, no. 3, pp. 326-336, Feb. 2007. doi:10.1016/j.rse.2006.09.006.

26] J. Noilhan and S. Planton, "A simple parameterization of land surface processes for meteorological models," Monthly Weather Rev., vol. 117, no. 3, pp. 536-549, 1989.

[27] O. Merlin, J. P. Walker, A. Chehbouni, and Y. Kerr, "Towards deterministic downscaling of SMOS soil moisture using MODIS derived soil evaporative efficiency," Remote Sens. Environ., vol. 112, no. 10, pp. 39353946, Oct. 2008. doi:10.1016/j.rse.2008.06.012.

28] M. S. Moran, T. R. Clarke, Y. Inoue, and A. Vidal, "Estimating crop water deficit using the relation between surface-air temperature and spectral vegetation index," Remote Sens. Environ., vol. 49, no. 3, pp. 246-263, 1143 1994.

[29] T. N. Carlson, R. R. Gillies, and E. M. Perry, "A method to make use 1145 of thermal infrared temperature and NDVI measurements to infer soil 1146 water content and fractional vegetation cover," Remote Sens. Rev., vol. 52, 1147 pp. 45-49, 1994.

1148

[30] O. Merlin, G. Chehbouni, J. P. Walker, R. Panciera, and Y. Kerr, "A 1149 simple method to disaggregate passive microwave based soil moisture," 1150 IEEE Trans. Geosci. Remote Sens.-SMOS Special Issue, vol. 46, no. 3, 1151 pp. 786-796, Mar. 2008. doi:10.1109/TGRS.2007.914807.

[31] W. P. Kustas and J. M. Norman, "Evaluation of soil and vegetation heat 1153 flux predictions using a simple two-source model with radiometric tem- 1154 peratures for partial canopy cover," Agricultural Forest Meteorol., vol. 94, 1155 no. 1, pp. 13-29, 1999.

1156

[32] M. C. Anderson, J. M. Norman, G. R. Diak, W. P. Kustas, and 1157 J. R. Mecikalski, "A two-source time-integrated model for estimating sur- 1158 face fluxes using thermal infrared remote sensing," Remote Sens. Environ., 1159 vol. 60, no. 2, pp. 195-216, May 1997.

[33] O. Merlin and G. Chehbouni, "Different approaches in estimating heat 1161 flux using dual angle observations of radiative surface temperature," Int. 1162 J. Remote Sens., vol. 25, no. 1, pp. 275-289, 2004.

[34] T. J. Lee and R. A. Pielke, "Estimating the soil surface specific humidity," 1164 J. Appl. Meteorol., vol. 31, no. 5, pp. 480-484, 1992.

1165

[35] T. S. Komatsu, "Towards a robust phenomenological expression of evapo- 1166 ration efficiency for unsaturated soil surfaces," J. Appl. Meteorol., vol. 42, 1167 no. 9 , pp. $1330-1334$, Sep. 2003.

[36] O. Merlin, J. P. Walker, J. D. Kalma, E. J. Kim, J. Hacker, 1169 R. Panciera, R. Young, G. Summerell, J. Hornbuckle, M. Hafeez, and 1170 T. J. Jackson, “The NAFE'06 data set: Towards soil moisture retrieval 1171 at intermediate resolution," Adv. Water Resour., vol. 31, pp. 1444-1455, 1172 2008. doi:10.1016/j.advwatres.2008.01.018.

[37] Z. Wan and J. Dozier, "A generalized split-window algorithm for retriev- 1174 ing land-surface temperature from space," IEEE Trans. Geosci. Remote 1175 Sens., vol. 34, no. 4, pp. 892-905, Jul. 1996.

1176

[38] O. Merlin, A. Al Bitar, V. Rivalland, P. Béziat, E. Ceschia, and G. Dedieu, 1177 "An analytical model of evaporation efficiency for unsaturated soil sur- 1178 faces with an arbitrary thickness," J. Appl. Meteorol. Climatol., vol. 50, 1179 no. 2, pp. 457-471, Feb. 2011. doi:10.1175/2010JAMC2418.1.

[39] N. Agam, W. P. Kustas, M. C. Anderson, F. Li, and C. M. U. Neale, 1181 "A vegetation index based technique for spatial sharpening of thermal 1182 imagery," Remote Sens. Environ., vol. 107, no. 4, pp. 545-558, 2007.

[40] E. E. Small and S. A. Kurc, "Tight coupling between soil moisture and the 1184 surface radiation budget in semiarid environments: Implications for land- 1185 atmosphere interactions," Water Resour. Res., vol. 39, no. 10, p. 1278, 1186 Oct. 2003. doi:10.1029/2002WR001297.

1187

[41] C. Rüdiger, J. P. Walker, and Y. H. Kerr, "On the airborne spatial coverage 1188 requirement for microwave satellite validation," IEEE Geosci. Remote 1189 Sens. Lett., vol. 8, no. 4, pp. 824-828, Jul. 2011.

[42] R. Young, J. Walker, N. Yeoh, A. Smith, K. Ellett, O. Merlin, and 1191 A. Western, Soil Moisture and Meteorological Observations from the 1192 Murrumbidgee Catchment. Melbourne, Australia: Dept. Civil Environ. 1193 Eng., Univ. Melbourne, 2008.

1194

[43] A. J. Teuling, R. Uijlenhoet, R. Hurkmans, O. Merlin, R. Panciera, 1195 J. Walker, and P. A. Troch, "Dry-end surface soil moisture variability 1196 during NAFE'06," Geophys. Res. Lett., vol. 34, no. L17402, Sep. 2007. 1197

[44] W. T. Crow and E. F. Wood, "The assimilation of remotely sensed soil 1198 brightness temperature imagery into a land surface model using Ensemble 1199 Kalman filtering: A case study based on ESTAR measurements during 1200 SGP97," Adv. Water Resour., vol. 26, pp. 137-149, 2003.

[45] Q. K. Hassan, C. P.-A. Bourque, F.-R. Meng, and R. M. Cox, “A wetness 1202 index using terrain-corrected surface temperature and normalized differ- 1203 ence vegetation index derived from standard MODIS products: An eval- 1204 uation of its use in a humid forest-dominated region of eastern Canada," 1205 Sensors, vol. 7, no. 10, pp. 2028-2048, 2007.

Olivier Merlin, photograph and biography not available at the time of 1207 publication.

Christoph Rüdiger, photograph and biography not available at the time of 1209 publication. 
1211 Ahmad Al Bitar, photograph and biography not available at the time of 1212 publication.

1213 Philippe Richaume, photograph and biography not available at the time of 1214 publication.
Jeffrey P. Walker, photograph and biography not available at the time of 1215 publication.

Yann H. Kerr, photograph and biography not available at the time of 1217 publication. 


\section{AUTHOR QUERIES}

\section{AUTHOR PLEASE ANSWER ALL QUERIES}

Please be aware that the authors are required to pay overlength page charges ( $\$ 200$ per page) if the paper is longer than 6 pages. If you cannot pay any or all of these charges please let us know.

AQ1 = Please provide publication update in Ref. [8].

AQ2 = Please provide volume. issue number, page range and month of publication in [20].

\section{END OF ALL QUERIES}




\title{
Disaggregation of SMOS Soil Moisture in Southeastern Australia
}

\author{
3 Olivier Merlin, Christoph Rüdiger, Ahmad Al Bitar, Philippe Richaume, Jeffrey P. Walker, and Yann H. Kerr
}

4 Abstract-Disaggregation based on Physical And Theoretical 5 scale Change (DisPATCh) is an algorithm dedicated to the dis6 aggregation of soil moisture observations using high-resolution 7 soil temperature data. DisPATCh converts soil temperature fields 8 into soil moisture fields given a semi-empirical soil evaporative 9 efficiency model and a first-order Taylor series expansion around 10 the field-mean soil moisture. In this study, the disaggregation 11 approach is applied to soil moisture and ocean salinity (SMOS) 12 data over the $500 \mathrm{~km}$ by $100 \mathrm{~km}$ AACES (Australian Airborne 13 Calibration/validation Experiments for SMOS) area. The $40-\mathbf{k m}$ 14 resolution SMOS surface soil moisture pixels are disaggregated 15 at $\mathbf{1 - k m}$ resolution using the soil skin temperature derived from 16 moderate resolution imaging spectroradiometer (MODIS) data, 17 and subsequently compared with the AACES intensive ground 18 measurements aggregated at $\mathbf{1 - k m}$ resolution. The objective is to 19 test DisPATCh under various surface and atmospheric conditions. 20 It is found that the accuracy of disaggregation products varies 21 greatly according to season: while the correlation coefficient be22 tween disaggregated and in situ soil moisture is about 0.7 during 23 the summer AACES, it is approximately zero during the winter 24 AACES, consistent with a weaker coupling between evaporation 25 and surface soil moisture in temperate than in semi-arid climate. 26 Moreover, during the summer AACES, the correlation coefficient 27 between disaggregated and in situ soil moisture is increased from 280.70 to 0.85 , by separating the $1-\mathrm{km}$ pixels where MODIS temper29 ature is mainly controlled by soil evaporation, from those where 30 MODIS temperature is controlled by both soil evaporation and

31 vegetation transpiration. It is also found that the $5-\mathrm{km}$ resolution 32 atmospheric correction of the official MODIS temperature data 33 has a significant impact on DisPATCh output. An alternative at34 mospheric correction at $\mathbf{4 0}-\mathbf{k m}$ resolution increases the correlation 35 coefficient between disaggregated and in situ soil moisture from 360.72 to 0.82 during the summer AACES. Results indicate that

Manuscript received March 31, 2011; revised September 1, 2011; accepted October 30, 2011. The AACES participants are gratefully acknowledged for their participation in collecting this extensive data set. The Australian Airborne Calibration/validation Experiments for SMOS have been made possible through infrastructure (LE0453434) and research (DP0879212) funding from the Australian Research Council, and the collaboration of a large number of scientists from throughout Australia, United States and Europe. Initial setup and maintenance of the study catchments was funded by two research Grants (DP0343778, DP0557543) from the Australian Research Council and by the CRC for Catchment Hydrology. This work was funded by the CNES TOSCA (Terre solide, Océan, Surfaces Continentales et Atmosphère) program and the Centre National de la Recherche Scientifique.

O. Merlin is with the Centre d'Etudes Spatiales de la Biosphère (CESBIO), 31401 Toulouse, France (e-mail: olivier.merlin@ cesbio.cnes.fr).

C. Rüdiger (e-mail: chris.rudiger@monash.edu)

A. Al Bitar (e-mail: ahmad.albitar@cesbio.cnes.fr).

P. Richaume (e-mail: philippe.richaume@cesbio.cnes.fr).

J. P. Walker (e-mail: jeff.walker@monash.edu).

Y. H. Kerr (e-mail: yann.kerr@cesbio.cnes.fr).

Color versions of one or more of the figures in this paper are available online at http://ieeexplore.ieee.org.

Digital Object Identifier 10.1109/TGRS.2011.2175000
DisPATCh has a strong potential in low-vegetated semi-arid areas 37 where it can be used as a tool to evaluate SMOS data (by reducing 38 the mismatch in spatial extent between SMOS observations and 39 localized in situ measurements), and as a further step, to derive 40 a $1-\mathbf{k m}$ resolution soil moisture product adapted for large-scale 41 hydrological studies.

Index Terms-AACES, calibration/validation, disaggregation, 43 Disaggregation based on Physical And Theoretical scale Change 44 (DisPATCh), field campaign, moderate resolution imaging spectro- 45 radiometer (MODIS), soil moisture and ocean salinity (SMOS). 46

\section{INTRODUCTION}

$\mathbf{P}$ ASSIVE MICROWAVE remote sensing has the capability 48 to provide key elements of the terrestrial hydrological 49 cycle such as surface soil moisture [1], [2] and overland pre- 50 cipitation [3], [4]. Nevertheless, due to the large discrepancy 51 between the observation scale (several tens of $\mathrm{km}$ ) and the scale 52 of physical interactions with the land surface (one wavelength 53 or several $\mathrm{cm}$ ), the radiative transfer models applied to passive 54 microwave remote sensing data are only semiphysically based. 55 Consequently, the retrieval process of land surface parameters 56 from microwave brightness temperatures requires ancillary data 57 for calibration and validation purposes [5]. It also requires a 58 strategy to use such ancillary data since ground-based sampling 59 is often made over a small area/point, which constrasts with 60 the large integrated extent of spaceborne passive microwave 61 observations.

The soil moisture and ocean salinity (SMOS), [6]) satellite 63 was launched on November 2, 2009. Over land, the SMOS 64 mission aims at providing $\sim 5 \mathrm{~cm}$ surface soil moisture data 65 at a spatial resolution better than $50 \mathrm{~km}$ and a repeat cycle of 66 less than 3 days. The payload is a 2-D interferometer equipped 67 with 69 individual L-band antennas regularly spaced along Y- 68 shaped arms. This new concept allows observing all pixels in 69 the $1000 \mathrm{~km}$ wide field of view at a range of incidence angles. 70 It also allows reconstructing brightness temperatures on a fixed 71 sampling grid [7].

Since the SMOS launch, various field experiments (the 73 HOBE site in Denmark [8], the Mali site in Western Africa 74 [9], the SMOSMANIA site in Southwestern France [10] just 75 to name a few) have been undertaken to validate SMOS recon- 76 structed brightness temperatures and soil moisture retrievals. 77 The AACES (Australian Airborne Calibration/validation 78 Experiment for SMOS, [11]) is one of the most compre- 79 hensive campaigns worldwide dedicated to SMOS calibra- 80 tion/validation. A series of two experiments were undertaken 81 in 2010, AACES-1 in January-February (Austral summer) and 82 
83 AACES-2 in September (Austral winter). The data collected 84 in AACES include 1-km resolution airborne L-band brightness 85 temperature mapped over a $500 \mathrm{~km}$ by $100 \mathrm{~km}$ area, 20 days 86 of very intensive ground measurements and $205 \mathrm{~km}$ by $2 \mathrm{~km}$ 87 ground sampling areas.

88 Even though the AACES ground measurements are very 89 extensive, it is not feasible to cover the whole extent of a 90 SMOS pixel by ground sampling alone. This is the reason why 91 most validation strategies of spaceborne passive microwave 92 data using in situ measurements have been based on the as93 sumption that local observations are representative of a much 94 larger spatial extent (i.e., the size of a microwave pixel). In the 95 heterogeneous case where this assumption does not hold, up96 scaling approaches [12], [13] have been developed to relate the 97 available ground observations to satellite scale soil moisture. 98 Such approaches are very useful over sites which have been 99 monitored for a long time and where extensive measurements 100 have been made over a range of spatial scales. However, aggre101 gation rules are difficult to build over sites which have been set 102 up recently, or where no extensive field campaigns have been 103 undertaken.

104 This study develops a methodology to facilitate the cali105 bration and validation of SMOS data using localized ground 106 measurements, such as those collected during AACES. The 107 methodology combines upscaling (aggregation) and downscal108 ing (disaggregation) approaches to make remote sensing and 109 in situ observations match at an intermediate spatial resolution 110 of $1 \mathrm{~km}$. The key step in the procedure is a disaggregation 111 algorithm of passive microwave soil moisture using kilometric 112 optical data [14]-[16]. Disaggregating SMOS soil moisture can 113 solve the disparity of spatial scales between satellite and in situ 114 observations. However, the validation of spaceborne data by 115 means of a disaggregation approach requires the uncertainties 116 and potential error sources in downscaled data to be assessed. 117 Generally speaking, disaggregation is a compromise between 118 downscaling resolution and accuracy. The higher downscaling 119 resolution, the more disaggregated values are spatially repre120 sentative of ground observations, but typically have a lower 121 accuracy and vice versa [17]. In this context, a disaggrega122 tion algorithm named Disaggregation based on Physical And 123 Theoretical scale Change (DisPATCh) is applied to $40-\mathrm{km}$ 124 resolution SMOS soil moisture over the AACES area using 1$125 \mathrm{~km}$ resolution Moderate resolution Imaging Spectroradiometer 126 (MODIS) data. The objective is to test DisPATCh under various 127 surface and atmospheric conditions. Specifically, the impact 128 of climatic (evaporative demand), meteorologic (presence of 129 clouds), and vegetation (cover and water status) conditions on $1301-\mathrm{km}$ resolution disaggregated soil moisture is evaluated both 131 qualitatively by visual assessment of disaggregation images and 132 quantitatively by comparing DisPATCh output with AACES 133 intensive ground measurements.

134 The AACES, SMOS, and MODIS data used in this study 135 are first described. Next, the disaggregation methodology is 136 presented followed by a step-by-step description of the Dis137 PATCh algorithm. Results of the comparison between disag138 gregated SMOS soil moisture and in situ measurements are 139 then reported. To test DisPATCh under various surface and 140 atmospheric conditions, the algorithm is run during AACES-1 and AACES-2 in different modes, by including (or not) a 141 correction for vegetation and atmospheric effects. Finally, some 142 perspectives in the use of DisPATCh for validating SMOS data 143 using ground-based sampling are given.

\section{Data Collection And PReprocessing}

The AACES experiments were planned to provide ground 146 and airborne soil moisture data over an area of approximately 147 $500 \mathrm{~km}$ by $100 \mathrm{~km}$ during the two main seasons in the 148 Murrumbidgee river catchment, in southeastern Australia. The 149 first AACES campaign (AACES-1) was undertaken in summer 150 2010 from January 18 to February 21, and the second campaign 151 (AACES-2) was undertaken in the following Austral winter 152 from September 11 to September 24 [11]. Fig. 1 presents the 153 study area including the $205 \mathrm{~km}$ by $2 \mathrm{~km}$ ground sampling 154 focus areas. The background image is the MODIS 250-m res- 155 olution 16-day normalized difference vegetation index (NDVI) 156 product of February 2, 2010. The climate of the Murrumbidgee 157 catchment area ranges from semi-arid in the west to alpine in 158 the east, with a strong rainfall and potential evapotranspiration 159 gradient in the west-east direction. Land use is extensive graz- 160 ing in the west, cropping in the center, and mostly grazing/forest 161 in the east (refer to [11] for a detailed account of AACES). 162

\section{A. $H D A S$}

163

During both AACES-1 and AACES-2, a spatially enabled 164 platform (Hydraprobe Data Acquisition System, HDAS) was 165 used to collect extensive measurements of near-surface soil 166 moisture. HDAS is a handheld system combining a soil dielec- 167 tric sensor (Hydraprobe) and a pocket PC with GPS receiver, 168 allowing for direct storage of location and measurement within 169 the GIS software. HDAS measurements were calibrated using 170 the approach presented in [18] with a root mean square error 171 of point estimate of about $0.03 \mathrm{~m}^{3} / \mathrm{m}^{3}$. The sampling coverage 172 was two $5 \mathrm{~km}$ by $2 \mathrm{~km}$ farms per day during AACES- 1 and one 173 $5 \mathrm{~km}$ by $2 \mathrm{~km}$ farm per day during AACES-2. Within each farm, 174 a total of six adjacent $5 \mathrm{~km}$ long transects separated by $330 \mathrm{~m} 175$ were walked to cover each area of $10 \mathrm{~km}^{2}$, and three separate 176 HDAS measurements were made along transects every $50 \mathrm{~m} . \quad 177$

In this study, HDAS soil moisture data are aggregated at 178 $1-\mathrm{km}$ resolution by averaging all measurements made within 179 each pixel of the MODIS resolution grid. Out of concern for 180 spatial representativeness of in situ observations, only the 1-km 181 pixels whose ground sampling covers more than two third of 182 its surface area are kept for comparison with disaggregation 183 results. The 1-km average of HDAS measurements is denoted 184 $\left\langle\mathrm{SM}_{\mathrm{HDAS}}\right\rangle$ and the standard deviation of in situ measurements 185 (denoted $\sigma_{\mathrm{HDAS}}$ ) computed to estimate the subpixel variability 186 at $1-\mathrm{km}$ resolution.

\section{B. SMOS}

The version-4 SMOS level-2 soil moisture product is used. 189 This product (released on March 24, 2011) was produced from 190 the reprocessed level 1C data, and the version-4 level-2 soil 191 moisture algorithm. SMOS has a 6 am (ascending) and 6 pm 192 


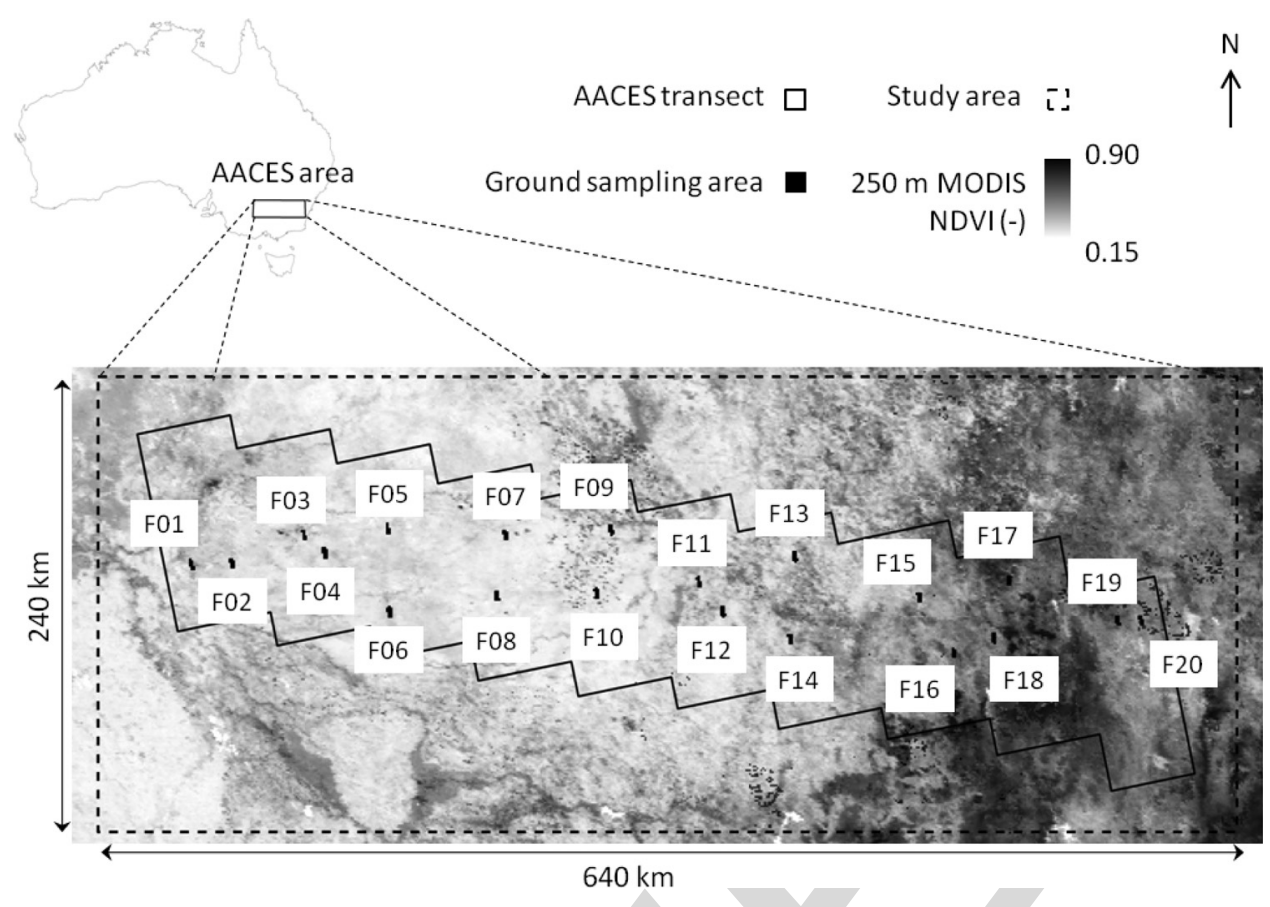

Fig. 1. Overview of the study area. During AACES, ten $100 \mathrm{~km}$ by $50 \mathrm{~km}$ patches were overflown by an airborne L-band radiometer. Within each patch, two $5 \mathrm{~km}$ by $2 \mathrm{~km}$ subareas were sampled to collect spatial soil moisture measurements. In this study, DisPATCh is run over a $640 \mathrm{by} 240 \mathrm{~km}$ area including the whole AACES area, and disaggregation results are evaluated over the ground sampling areas.

193 (descending) equator crossing time. The sampling grid of the 194 SMOS level-2 soil moisture product is called DGG or discrete 195 global grid [19], [20] and has a node separation of about $19615 \mathrm{~km}$. The DGG provides a discretization that is higher than 197 the SMOS natural pixel size, which is $40 \mathrm{~km}$ on average, 198 ranging from $30 \mathrm{~km}$ at boresight to $90 \mathrm{~km}$ at high incidence 199 angles. In this study, the disaggregation procedure takes advan200 tage of the oversampling of SMOS data to potentially reduce 201 (and provide an estimate of) random errors in disaggregated 202 SMOS data. Instead of using a single snapshot SMOS im203 age, DisPATCh uses four (overlapping) independent snapshots, 204 which are generated by: 1) sliding a 40-km resolution grid; and 2052 ) extracting the DGG nodes approximately centered on each $20640 \mathrm{~km}$ pixel. The extraction of SMOS DGG nodes is presented 207 in [21]. The DGG node(s) that fall(s) near the center of the $20840-\mathrm{km}$ resolution pixels with a $+/-10-\mathrm{km}$ tolerance are se209 lected. If more than one DGG is selected, the associated soil 210 moisture values are averaged to produce a single value for each $21140-\mathrm{km}$ resolution pixel. The $40-\mathrm{km}$ resolution grid that fits the 212 study area corresponds to what is termed here Resampling 1. 213 Similarly, Resampling 2, 3, and 4 are performed by sliding the 214 40-km resolution grid to coordinates $(+20 \mathrm{~km}, 0),(0,-20 \mathrm{~km})$, 215 and $(+20 \mathrm{~km},-20 \mathrm{~km})$, respectively. The four $40-\mathrm{km}$ resolu216 tion SMOS data sets are then used independently as input to 217 DisPATCh.

\section{C. MODIS}

The MODIS data used in this paper are composed of:

- Version-5 MODIS/Terra land surface temperature and emissivity daily level-3 global 1-km grid product (MOD11A1) and version-5 MODIS/Aqua land surface temperature and emissivity daily level-3 global 1-km grid 223 product (MYD11A1). The land surface temperature data 224 set is the main component of DisPATCh. It is used to 225 estimate $1-\mathrm{km}$ resolution soil evaporative efficiency at 226 $10 \mathrm{am}$ (Terra data) and $1 \mathrm{pm}$ (Aqua data) [22].

- Version-5 MODIS/Terra vegetation indices 16-day level-3 228 global 1-km grid product (MOD13A2). The NDVI data set 229 is used in DisPATCh to estimate the fractional vegetation 230 cover at 1-km resolution [23].

- Version-5 MODIS/Terra+Aqua albedo 16-day level-3 232 global 1-km grid product (MCD43B3). The surface albedo 233 data set is used in DisPATCh to estimate the vegetation 234 temperature at maximum water stress from the space land 235 surface temperature albedo [24]. The MCD43B3 product 236 provides $1-\mathrm{km}$ data describing both directional hemispher- 237 ical reflectance (black-sky albedo) at local solar noon 238 and bihemispherical reflectance (white-sky albedo). In this 239 study, surface albedo refers to the MODIS shortwave white 240 sky albedo.

- MODIS/Terra level-1B calibrated radiances swath 1-km 242 grid product (MOD021KM) and MODIS/Aqua level- 243 1B calibrated radiances swath $1-\mathrm{km}$ grid product 244 (MYD021KM). The radiance data set is used to derive 245 a land surface temperature data set that differs from the 246 official MOD11A1 and MYD11A1 products with respect 247 to atmospheric correction.

Products MOD11A1, MYD11A1, MOD13A2, and 249 MCD43B3 were downloaded through the NASA Warehouse 250 Inventory Search Tool (WIST http://wist.echo.nasa.gov/) and 251 products MOD021KM and MYD021KM were downloaded 252 through the NASA Level 1 and Atmosphere Archive and Dis- 253 tribution System (LAADS http://ladsweb.nascom.nasa.gov). 254 
TABLE I

Scale And OfFset VAlues Used to CONVERT TERra (AND AQUa) MODIS RADIANCE DATA TO PHYSICAL RADIANCE VALUES OVER THE AACES AREA

\begin{tabular}{|c||c|c|}
\hline Thermal band & Scale $\left(\mathrm{W} \mathrm{m}^{-2} \mathrm{sr}^{-1}\right)$ & Offset (-) \\
\hline \hline 31 & $8.4002 \cdot 10^{-4}\left(6.5081 \cdot 10^{-4}\right)$ & $1577(2036)$ \\
32 & $7.2970 \cdot 10^{-4}\left(5.7100 \cdot 10^{-4}\right)$ & $1658(2119)$ \\
\hline
\end{tabular}

255 All products were projected in UTM 55 South with a sampling 256 interval of $1000 \mathrm{~m}$ using the MODIS reprojection tool.

257 The level-1B calibrated radiance data $\left(R_{31}\right.$ and $R_{32}$ for bands 25831 and 32, respectively) were converted from digital number 259 (DN) to radiance in $\mathrm{W} \mathrm{m}^{-2} \mathrm{sr}^{-1}$ using the radiance scales and 260 offsets provided with each MODIS granule as listed in Table I

$$
R_{\lambda}=\text { Scale }_{\lambda} \times\left(\mathrm{DN}_{\lambda}-\text { Offset }_{\lambda}\right)
$$

261 The radiance values were then converted to brightness temper262 ature in $\mathrm{K}$ using the inverse of the Planck function [25]

$$
T b_{\lambda}=\frac{c_{2}}{\lambda \ln \left(1+\frac{c_{1}}{R_{\lambda} \lambda^{5}}\right)}
$$

263 with $c_{1}=1.19107 \times 10^{8} \quad \mu \mathrm{m}^{5} \quad \mathrm{~W} \mathrm{~m}^{-2} \quad \mathrm{sr}^{-1} \quad$ and $\quad c_{2}=$ $2641.43883 \times 10^{4} \mu \mathrm{m} \mathrm{K}$, for center wavelength of the given band 265 (11.0186 $\mu \mathrm{m}$ and $12.0325 \mu \mathrm{m}$ for 31 and 32 band, respectively).

\section{D. Overlapping HDAS, SMOS, and MODIS Data and}

\section{Generating an Input Data Set}

268 As indicated in Table II, HDAS soil moisture, SMOS soil 269 moisture, and cloud-free MODIS land surface temperature data 270 have overlapped on five days during AACES-1 (on January 27128 and 30 and February 15, 18, and 20) and on five days 272 during AACES-2 (on September 11, 13, 21, 22, and 24). On 273 each sampling day, two farms were sampled during AACES-1 274 (except on February 18 when three farms were sampled), and 275 one farm was sampled during AACES-2, so that disaggregation 276 results can be evaluated for ten date-farm units during AACES2771 and five date-farm units during AACES-2.

278 DisPATCh is applied to an input ensemble composed of the 279 different combinations of available SMOS (ascending orbit at $2806 \mathrm{am}$ and/or descending orbit at $6 \mathrm{pm}$ ) and MODIS (onboard 281 Terra platform at $10 \mathrm{am}$ and/or Aqua platform at $1 \mathrm{pm}$ ) data. To 282 increase the quantity of input data sets, the MODIS data col283 lected on the day before and the day after the SMOS overpass 284 date are also included. For SMOS data on day of year (DoY) 285 51, the clear sky MODIS data collected on DoY 54 are used. 286 Note that one implicitly assumes that no rainfall occurs between 287 MODIS and SMOS overpasses, and that the spatial variability 288 captured by MODIS is relatively similar to the actual variabil289 ity of surface soil moisture at the time of SMOS overpass. 290 Moreover, the SMOS data oversampling is used to generate 291 four (overlapping) 40-km resolution SMOS grids on which 292 DisPATCh is run independently, thus increasing the number 293 of downscaled data that could be used in the validation. It is 294 reminded that the spacing (about $15 \mathrm{~km}$ ) between neighboring 295 SMOS DGG nodes is smaller than the SMOS resolution (about
$40 \mathrm{~km}$ ). By combining the four SMOS grids, the two potential 296 SMOS data sets (two orbits in one day) and the six potential 297 MODIS data sets (three days including two overpasses each), 298 the maximum number of input data sets is 48 . The generation 299 of input data sets is shown in Fig. 2 and the number of daily 300 input data sets is indicated for each date-farm unit in Table II. 301

\section{Disagggregation Algorithm}

DisPATCh converts 1-km resolution MODIS-derived soil 303 temperature fields into $1-\mathrm{km}$ resolution surface soil moisture 304 fields given a semi-empirical soil evaporative efficiency model 305 [26] and a first-order Taylor series expansion around the 306 $40-\mathrm{km}$ resolution SMOS observation. DisPATCh is an im- 307 proved version of the algorithms in [16] and [27], and mainly 308 differs with regard to the representation of the vegetation water 309 status. In previous versions [16], [27], the soil temperature was 310 derived from MODIS land surface temperature by assuming 311 that vegetation was unstressed so that vegetation temperature 312 was uniformly set to the minimum surface temperature ob- 313 served within the SMOS pixel. In this study, the approach in 314 [28] is implemented to take into account vegetation water status 315 in the estimation of soil temperature.

\section{A. Disaggregation Methodology}

The disaggregation procedure decouples the soil evaporation 318 from the $0-5 \mathrm{~cm}$ soil layer and the vegetation transpiration 319 from the root-zone soil layer by separating MODIS surface 320 temperature into its soil and vegetation components as in the 321 triangle or trapezoidal method [28], [29]. MODIS-derived soil 322 temperature is then used to estimate soil evaporative efficiency, 323 which is known to be relatively constant during the day on clear 324 sky conditions. MODIS-derived soil evaporative efficiency is 325 finally used as a proxy for surface $(0-5 \mathrm{~cm})$ soil moisture 326 variability within the SMOS pixel. The link between surface 327 soil moisture and soil evaporative efficiency at different scales 328 is ensured by a downscaling relationship and a soil evapo- 329 rative efficiency model, as described below in more detail. 330 The originality of DisPATCh relies on a dynamical land cover 331 classification (based on the hourglass approach in [28]) that 332 takes into account the subpixel variability of the sensitivity of 333 soil evaporative efficiency to surface soil moisture.

1) Downscaling Relationship: The downscaling relation- 335 ship can be written as

$$
\begin{aligned}
\mathbf{S M}_{1 \mathrm{~km}}= & \mathbf{S M}_{\mathbf{S M O S}}+\frac{\partial \mathbf{S M}_{\mathbf{m o d}}}{\partial \mathbf{S E E}} \\
& \times\left(\mathrm{SEE}_{\text {MODIS }, 1 \mathrm{~km}}-\left\langle\mathrm{SEE}_{\text {MODIS }, 1 \mathrm{~km}}\right\rangle_{\mathbf{4 0} \mathrm{km}}\right)
\end{aligned}
$$

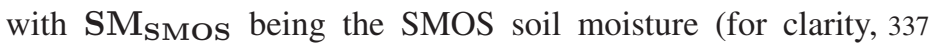
the variables defined at SMOS scale are written in bold), 338 SEE MODIS the MODIS-derived soil evaporative efficiency (ra- 339 tio of actual to potential evaporation), $\left\langle\mathrm{SEE}_{\mathrm{MODIS}}\right\rangle_{40} \mathrm{~km}$ its 340 average within a SMOS pixel and $\partial \mathbf{S} \mathbf{M}_{\text {mod }} / \partial \mathbf{S E E}$ the partial 341 derivative evaluated at SMOS scale of soil moisture with re- 342 spect to soil evaporative efficiency. Note that the linearity of (3) 343 implies that a possible bias in SMOS data would produce the 344 
TABLE II

List of OVERLAPPING HDAS, SMOS, AND MODIS (MOD11A1 AND MYD11A1) DATA DURING AACES-1 AND AACES-2. ONLY THE SMOS DATA Collected on the Same Day as Ground Sampling Have Been Considered. The MODIS Data Considered as InPut to DisPatCh Have Been Collected Within Plus or Minus One Day Either Side the Ground Sampling (and SMOS Overpass) Date. On Each Sampling Date, the Resultant Number of InPut Data Sets to DisPatCh Is Also Indicated

\begin{tabular}{|c|c|c|c|c|c|c|}
\hline Experiment & $\begin{array}{l}\text { Sampling } \\
\text { date }\end{array}$ & DoY & Farm & $\begin{array}{c}\text { SMOS } \\
\text { overpass time }\end{array}$ & $\begin{array}{c}\text { Cloud free } \\
\text { MODIS data (DoY) }\end{array}$ & $\begin{array}{c}\text { Number of input } \\
\text { data sets to DisPATCh }\end{array}$ \\
\hline \multirow[t]{10}{*}{ AACES-1 } & 28 January & 28 & F05 & $6 \mathrm{am}$ & Terra $(27,29) \&$ Aqua $(29)$ & 3 \\
\hline & 30 January & 30 & F07 & $6 \mathrm{am}$ & Terra $(29,30) \&$ Aqua $(29)$ & 12 \\
\hline & , & , & F08 & $6 \mathrm{am}$ & Terra $(29,30) \&$ Aqua $(29)$ & $9-12$ \\
\hline & 15 February & 46 & F15 & $6 \mathrm{am} \& 6 \mathrm{pm}$ & Terra (46) \& Aqua (47) & $8-14$ \\
\hline & , & , & F16 & $6 \mathrm{am} \& 6 \mathrm{pm}$ & Terra (46) \& Aqua (47) & $8-10$ \\
\hline & 18 February & 49 & F17 & 6 am \& $6 \mathrm{pm}$ & Terra $(48,50) \&$ Aqua $(48,49,50)$ & $30-38$ \\
\hline & , & , & F18 & $6 \mathrm{am} \& 6 \mathrm{pm}$ & Terra $(48,50) \&$ Aqua $(48,49,50)$ & $24-30$ \\
\hline & , & , & $\mathrm{F} 20$ & 6 am \& $6 \mathrm{pm}$ & Terra $(48,50) \&$ Aqua $(48,49,50)$ & $34-40$ \\
\hline & 20 February & 51 & F19 & $6 \mathrm{am} \& 6 \mathrm{pm}$ & Terra (54) \& Aqua (54) & $6-8$ \\
\hline & , & , & $\mathrm{F} 20$ & $6 \mathrm{am} \& 6 \mathrm{pm}$ & Terra (54) \& Aqua (54) & 16 \\
\hline \multirow[t]{5}{*}{ AACES-2 } & 11 September & 254 & F09 & $6 \mathrm{am} \& 6 \mathrm{pm}$ & Terra $(253,254) \&$ Aqua $(254)$ & $6-14$ \\
\hline & 13 September & 256 & F07 & 6 am \& $6 \mathrm{pm}$ & Terra (256) & 8 \\
\hline & 21 September & 264 & F13 & 6 am \& 6 pm & Terra (263) \& Aqua (264) & 16 \\
\hline & 22 September & 265 & F15 & 6 am \& $6 \mathrm{pm}$ & Terra $(265) \&$ Aqua $(264,266)$ & 16 \\
\hline & 24 September & 267 & F09 & $6 \mathrm{am} \& 6 \mathrm{pm}$ & Terra $(267) \&$ Aqua $(266,267,268)$ & $24-32$ \\
\hline
\end{tabular}

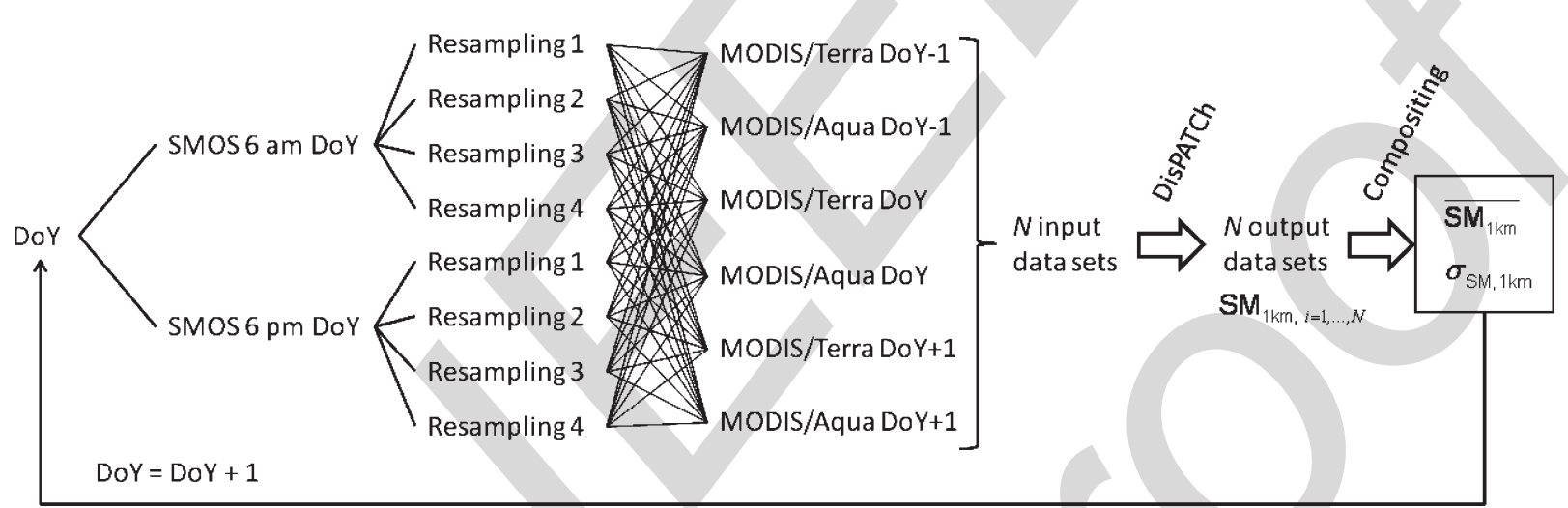

Fig. 2. Schematic diagram presenting the combination of SMOS and MODIS to generate an ensemble of input data to DisPATCh. The output data are composited at $1-\mathrm{km}$ resolution by computing the average $\left(\overline{\mathrm{SM}_{1} \mathrm{~km}}\right)$ and standard deviation $\left(\sigma_{\mathrm{SM}, 1 \mathrm{~km}}\right)$ of disaggregated SMOS soil moisture.

345 same bias in disaggregated data [30]. Consequently, although 346 the possible presence of a bias in SMOS data limits the accuracy 347 in the disaggregated soil moisture, it is not a limiting factor to 348 the applicability of DisPATCh. MODIS derived soil evaporative 349 efficiency is expressed as a linear function of soil temperature

$$
\mathrm{SEE}_{\mathrm{MODIS}, 1 \mathrm{~km}}=\frac{\mathbf{T}_{\mathbf{s}, \max }-T_{\mathrm{s}, 1 \mathrm{~km}}}{\mathbf{T}_{\mathbf{s}, \max }-\mathbf{T}_{\mathbf{s}, \min }}
$$

350 with $T_{\mathrm{S}}$ being the MODIS-derived soil skin temperature, $351 \mathbf{T}_{\mathbf{s}, \text { max }}$ the soil skin temperature at $\mathrm{SEE}=0$ and $\mathbf{T}_{\mathbf{s}, \text { min }}$ 352 the soil skin temperature at $\mathrm{SEE}=1$. The linearity of the 353 relationship between soil evaporative efficiency and surface 354 soil temperature was verified using the physically based dual 355 source energy budget model in [31] using a synthetic data set 356 composed of a range of surface soil moisture values and differ357 ent atmospheric conditions (results not shown). End-members $358 \mathbf{T}_{\mathbf{s}, \text { min }}$ and $\mathbf{T}_{\mathbf{s}, \max }$ are estimated from the polygons obtained by plotting MODIS surface temperature against MODIS NDVI 359 and MODIS albedo as in [24]. Derivation of soil temperature is 360 based on a linear decomposition of the surface temperature into 361 its soil and vegetation components as a good approximation of 362 the relationship with fourth power for temperatures [32], [33] 363 and consistent with the triangle method. MODIS-derived soil 364 skin temperature is expressed as

$$
T_{\mathrm{s}, 1 \mathrm{~km}}=\frac{T_{\mathrm{MODIS}}-f_{\mathrm{v}, 1 \mathrm{~km}} T_{\mathrm{v}, 1 \mathrm{~km}}}{1-f_{\mathrm{v}, 1 \mathrm{~km}}}
$$

with $T_{\text {MODIS }}$ being the $1-\mathrm{km}$ resolution MODIS land sur- 366 face temperature, $f_{\mathrm{v}}$ the MODIS-derived fractional vegetation 367 cover, and $T_{\mathrm{v}}$ the vegetation temperature. In this study, vegeta- 368 tion temperature is estimated using the approach proposed by 369 [28]. In (5), fractional vegetation cover is written as

$$
f_{\mathrm{v}, 1 \mathrm{~km}}=\frac{\mathrm{NDVI}_{\text {MODIS }}-\mathbf{N D V I}_{\mathbf{s}}}{\mathbf{N D V I}_{\mathbf{v}}-\mathbf{N D V I}_{\mathbf{s}}}
$$


371 with NDVI $\mathrm{M}_{\text {MODIS }}$ being the 1-km resolution MODIS NDVI, $372 \mathbf{N D V I}_{\mathbf{s}}$ the NDVI corresponding to bare soil, and $\mathbf{N D V I}_{\mathbf{v}}$ the 373 NDVI corresponding to full-cover vegetation. Minimum and 374 maximum NDVI values are set to 0.15 and 0.90 , respectively.

375 In [16], the accuracy and robustness of the disaggregation 376 methodology were tested using three different formulations of 377 soil evaporative efficiency [26], [34], [35]. Results based on the 378 NAFE'06 data set [36], which was collected over a $60 \mathrm{~km}$ by $37940 \mathrm{~km}$ area in the AACES area, indicated that the model in 380 [26] was better adapted for conditions where soil properties are 381 unknown at high resolution. Consequently, the partial derivative 382 in (3) is computed using the soil evaporative efficiency model 383 in [26]

$$
\mathrm{SEE}_{\bmod }=\frac{1}{2}-\frac{1}{2} \cos \left(\pi \cdot \mathrm{SM} / \mathbf{S M}_{\mathbf{p}}\right)
$$

384 with $\mathbf{S M}_{\mathbf{p}}$ being a soil parameter (in soil moisture unit). In 385 [26], $\mathbf{S M}_{\mathbf{p}}$ was set to the soil moisture at field capacity. In 386 DisPATCh, $\mathbf{S M}_{\mathbf{p}}$ is retrieved at $40-\mathrm{km}$ resolution from SMOS 387 and aggregated MODIS data [16]. By inverting (7), one obtains

$$
\mathrm{SM}_{\text {mod }}=\frac{\mathbf{S M}_{\mathbf{p}}}{\pi} \cos ^{-1}(1-2 \mathrm{SEE})
$$

388 2) Vegetation Temperature: Vegetation temperature in (5) is 389 estimated at 1-km resolution with the "hourglass" approach in 390 [28]. By plotting the diagonals in the quadrilateral in Fig. 3, 391 four areas are distinguished in the space defined by surface 392 temperature and fractional vegetation cover. In zone A, land 393 surface temperature is mainly controlled by soil evaporation 394 leading to optimal sensitivity to surface soil moisture. In zone $395 \mathrm{D}$, land surface temperature is mainly controlled by vegetation 396 transpiration with no sensitivity to surface soil moisture. In 397 zones B and C, land surface temperature is controlled by both 398 soil evaporation and vegetation transpiration with intermediate 399 (average) sensitivity to surface soil moisture. Based on this un400 derstanding, vegetation temperature is estimated in a different 401 manner in each zone.

402 For a given data point located in Zone A, vegetation temper403 ature is

$$
T_{\mathrm{v}, 1 \mathrm{~km}}=\left(\mathbf{T}_{\mathbf{v}, \text { min }}+\mathbf{T}_{\mathbf{v}, \text { max }}\right) / 2
$$

404 with $\mathbf{T}_{\mathbf{v}, \text { min }}$ and $\mathbf{T}_{\mathbf{v}, \text { max }}$ being the vegetation temperature 405 at minimum and maximum water stress, respectively. End406 members $\mathbf{T}_{\mathbf{v}, \text { min }}$ and $\mathbf{T}_{\mathbf{v}, \text { max }}$ are estimated from the poly407 gons obtained by plotting MODIS surface temperature against 408 MODIS NDVI and MODIS albedo as in [24].

409 For a given data point located in Zone B, vegetation temper410 ature is

$$
T_{\mathrm{v}, 1 \mathrm{~km}}=\left(T_{\mathrm{v}, \min , 1 \mathrm{~km}}+\mathbf{T}_{\mathbf{v}, \max }\right) / 2
$$

411 with $T_{\mathrm{v}, \mathrm{min}, 1 \mathrm{~km}}$ being the vegetation temperature associated 412 with $\mathrm{SEE}=0\left(T_{\mathrm{s}}=\mathbf{T}_{\mathbf{s}, \max }\right)$.

413 For a given data point located in Zone $\mathrm{C}$, vegetation temper414 ature is

$$
T_{\mathrm{v}, 1 \mathrm{~km}}=\left(\mathbf{T}_{\mathbf{v}, \min }+T_{\mathrm{v}, \max , 1 \mathrm{~km}}\right) / 2
$$
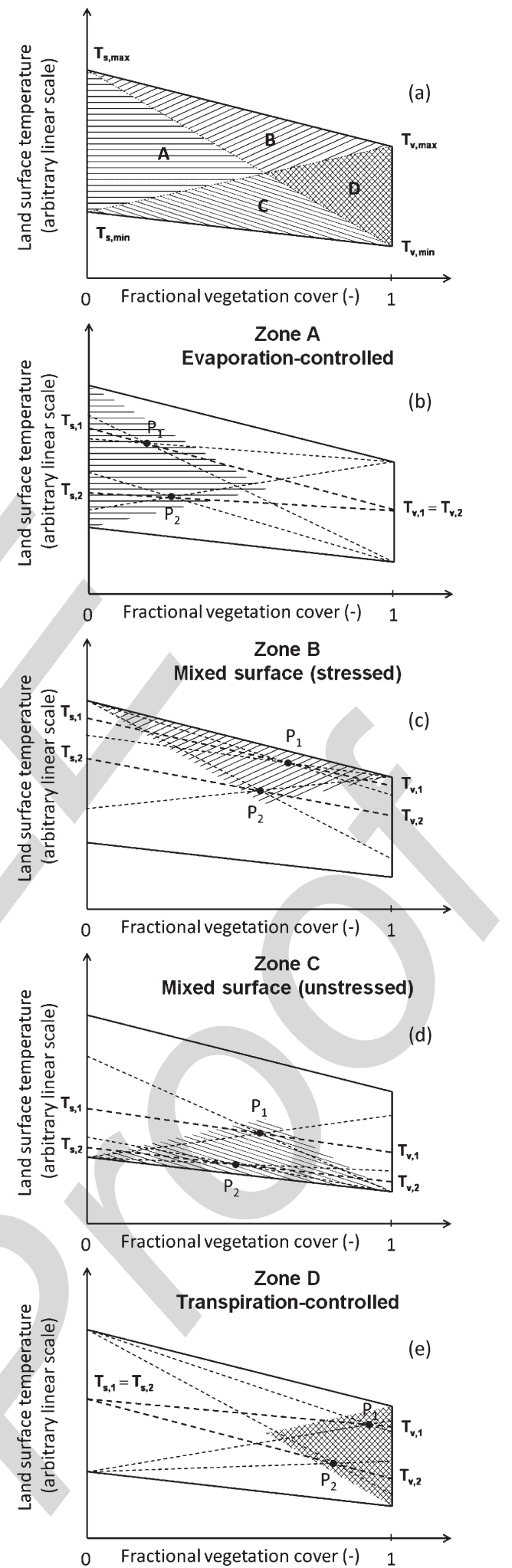

Fig. 3. Polygon defined in the land surface temperature-fractional vegetation cover space contains four distinct zones A, B, C, and D. In Zone A (soildominated area), the estimated vegetation temperature is constant leading to optimal sensitivity of estimated soil temperature to surface soil moisture. In Zone $\mathrm{D}$, the estimated soil temperature is constant with no sensitivity to surface soil moisture. In Zone B and C (mixed surface), surface temperature is both controlled by soil evaporation and vegetation transpiration with intermediate (average) sensitivity of estimated soil temperature to surface soil moisture. DisPATCh can be run in the Zone $\mathrm{A}+\mathrm{B}+\mathrm{C}$ mode or in the Zone A only mode. 

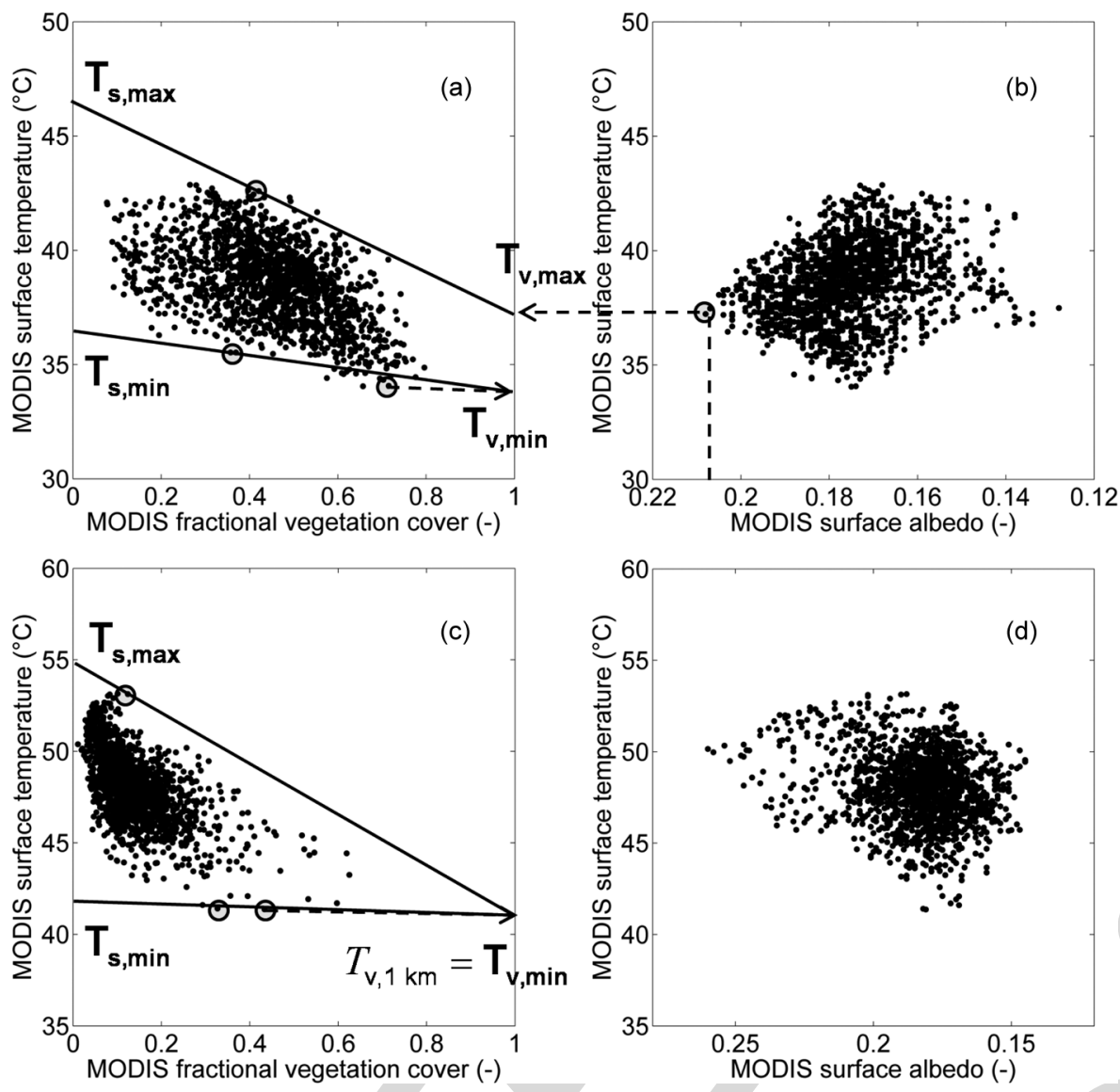

Fig. 4. Temperature end-members $\mathbf{T}_{\mathbf{s}, \mathbf{m i n}}, \mathbf{T}_{\mathbf{s}, \mathbf{m a x}}, \mathbf{T}_{\mathbf{v}, \mathbf{m i n}}$, and $\mathbf{T}_{\mathbf{v}, \mathbf{m a x}}$ are estimated from the surface temperature-fractional vegetation cover space and the surface temperature-surface albedo space within two given SMOS pixels. In (b), the pixel corresponding to the largest MODIS albedo has a fractional vegetation cover larger than 0.5 , so that $\mathbf{T}_{\mathbf{v} \text {, } \text { max }}$ is set to its surface temperature. In (d), the pixel corresponding to the largest MODIS albedo has a fractional vegetation cover lower than 0.5 , so that $\mathbf{T}_{\mathbf{v}, \max }$ is set to $\mathbf{T}_{\mathbf{v}, \text { min }}$.

415 with $T_{\mathrm{v}, \max , 1 \mathrm{~km}}$ being the vegetation temperature associated 416 with $\mathrm{SEE}=1\left(T_{\mathrm{S}}=\mathbf{T}_{\mathbf{s}, \mathbf{m i n}}\right)$.

417 For a given data point located in Zone D, vegetation temper418 ature is

$$
T_{\mathrm{v}, 1 \mathrm{~km}}=\left(T_{\mathrm{v}, \min , 1 \mathrm{~km}}+T_{\mathrm{s}, \max , 1 \mathrm{~km}}\right) / 2
$$

419 3) End-Members: End-members $\mathbf{T}_{\mathbf{s}, \min }, \mathbf{T}_{\mathbf{s}, \max }, \mathbf{T}_{\mathbf{v}, \min }$ 420 and $\mathbf{T}_{\mathbf{v} \text {, max }}$ are estimated by combining the spatial information 421 provided by the surface temperature-fractional vegetation cover 422 space and the surface temperature-albedo space plotted using 423 MODIS data collected in a 40-km resolution SMOS pixel. An 424 illustration is provided in Fig. 4 for two given SMOS pixels.
- $\mathbf{T}_{\mathbf{v}, \text { min }}$ : the vegetation temperature at minimum vegetation water stress is set to the minimum MODIS surface temperature in the SMOS pixel [see Fig. 4(a) and (c)].

- $\mathbf{T}_{\mathbf{v}, \text { max }}$ : the vegetation temperature at maximum vegetation water stress is set to the MODIS surface temperature of the pixel with the maximum value of MODIS albedo in the SMOS pixel [see Fig. 4(b)]. If the fractional vegetation cover of that pixel is lower than 0.5 [see Fig. 4(d)], the vegetation temperature at maximum vegetation water stress is alternatively set to $\mathbf{T}_{\mathbf{v}, \text { min }}$, meaning that vegetation is unstressed within the SMOS pixel. The condition based on fractional vegetation cover is lower than 0.5 aims to increase the robustness of the determination approach of
$\mathbf{T}_{\mathbf{v}, \text { max }}$, particularly in the SMOS pixels where all surface 438 conditions are not met.

- $\mathbf{T}_{\mathbf{s}, \text { min }}$ : the soil temperature at $\mathrm{SEE}=1$ is extrapolated 440 along the wet soil edge at $f_{\mathrm{v}}=0$. The wet soil edge 441 is defined as the line passing through $\left(1, \mathbf{T}_{\mathbf{v}, \text { min }}\right)$ and 442 through the data point such that all the data points with 443 $f_{\mathrm{v}}<0.5$ are located above the wet soil edge [see Fig. 4(a) 444 and (c)].

- $\mathbf{T}_{\mathbf{s}, \text { max }}$ : the soil temperature at $\mathrm{SEE}=0$ is extrapolated 446 along the dry soil edge at $f_{\mathrm{v}}=0$. The dry soil edge 447 is defined as the line passing through $\left(1, \mathbf{T}_{\mathbf{v}, \max }\right)$ and 448 through the data point such that all the data points with 449 $f_{\mathrm{v}}<0.5$ are located below the dry soil edge [see Fig. 4(a) 450 and (c)].

\section{B. Atmospheric Correction}

In MOD11A1 and MYD11A1 products, the land surface 453 temperature is derived from MODIS thermal radiances using 454 the split window algorithm [37]

$$
\begin{aligned}
T_{\text {MODIS }}= & C+\left(A_{1}+A_{2} \frac{1-\epsilon}{\epsilon}+A_{3} \frac{\Delta \epsilon}{\epsilon^{2}}\right) \frac{T b_{31}+T b_{32}}{2} \\
& +\left(B_{1}+B_{2} \frac{1-\epsilon}{\epsilon}+B_{3} \frac{\Delta \epsilon}{\epsilon^{2}}\right) \frac{T b_{31}-T b_{32}}{2}
\end{aligned}
$$


456 with $T b_{31}$ and $T b_{32}$ being the brightness temperatures mea457 sured in the MODIS bands 31 and 32, respectively, $\epsilon_{31}$ and $\epsilon_{32}$ 458 the surface emissivities estimated in the respective bands, and $459 A_{1}, A_{2}, A_{3}, B_{1}, B_{2}, B_{3}$, and $C$ regression coefficients. These 460 coefficients are available during algorithm execution via a look 461 up table stratified by subranges of near surface air temperature 462 and total column water vapor. These input field are obtained at 463 a 5-km resolution from the MODIS07_L2 product.

464 Given that regression coefficients in (13) are provided at $4655-\mathrm{km}$ resolution, the atmospheric corrections on the MODIS 466 land surface temperature product are actually made at 5-km 467 resolution. To test whether atmospheric corrections on MODIS 468 temperature have an impact on disaggregation results, a differ469 ent procedure is proposed to obtain another temperature data 470 set whose atmospheric corrections are operated at the scale 471 of a SMOS pixel, i.e., at $40-\mathrm{km}$ resolution (instead of $5-\mathrm{km}$ 472 resolution for the official MODIS temperature product). The 473 approach is to normalize the mean MODIS radiance-derived 474 brightness temperature at the SMOS resolution. Normalization 475 is done by adjusting the minimum and maximum mean MODIS 476 brightness temperature to the minimum and maximum value 477 of the official MODIS land surface temperature product within 478 the SMOS pixel, respectively. The new temperature noted $479 T_{\text {MODIS }}^{\text {unif. corr. (uniform atmospheric corrections) is written }}$

$$
\begin{aligned}
T_{\text {MODIS }}^{\text {unif. corr. }} & =T_{\text {MODIS,min }}+\left(T_{\text {MODIS,max }}-T_{\text {MODIS,min }}\right) \\
& \times \frac{T b_{31}+T b_{32}-\operatorname{Min}\left(T b_{31}+T b_{32}\right)}{\operatorname{Max}\left(T b_{31}+T b_{32}\right)-\operatorname{Min}\left(T b_{31}+T b_{32}\right)}
\end{aligned}
$$

480 with $T_{\text {MODIS, } m i n}$ and $T_{\text {MODIS, } m a x}$ being the minimum and 481 maximum MODIS land surface temperature within the SMOS 482 pixel, and $\operatorname{Min}()$ and $\operatorname{Max}()$ the function that returns the mini483 mum and maximum value within the SMOS pixel, respectively. 484 Note that the underlying assumptions of (14) are:

485 - near surface air temperature and column water vapor vary 486 at scales larger than $40 \mathrm{~km}$ (size of a SMOS pixel).

487 - surface emissivity is close to 1 .

\section{C. Algorithm}

489 The steps used in applying DisPATCh include: 1) select490 ing the SMOS pixels with at least 90\% (clear sky) MODIS491 retrieved land surface temperature coverage; 2) computing 492 soil evaporative efficiency over nominal MODIS pixels with 493 (4); 3) estimating soil evaporative efficiency over non-nominal 494 MODIS pixels; 4) retrieving parameter $\mathbf{S M}_{\mathbf{p}}$; 5) applying the 495 downscaling relationship of (3); 6) correcting disaggregated 496 soil moisture by the SMOS pixel weighting function; and 7) 497 compositing on a daily basis the disaggregation output en498 semble [21]. The input and output data and their link within 499 DisPATCh are summarized in Fig. 5.

500 1) Selecting Clear Sky SMOS Pixels: A threshold of $90 \%$ 501 cloud-free MODIS coverage is used to select the SMOS pix502 els to be disaggregated. In the official MODIS land surface 503 temperature product (MOD11A1 for Terra and MYD11A1 for 504 Aqua), the data affected by the presence of clouds are already 505 masked. Hence, selection of the $90 \%$ clear sky SMOS pixels is

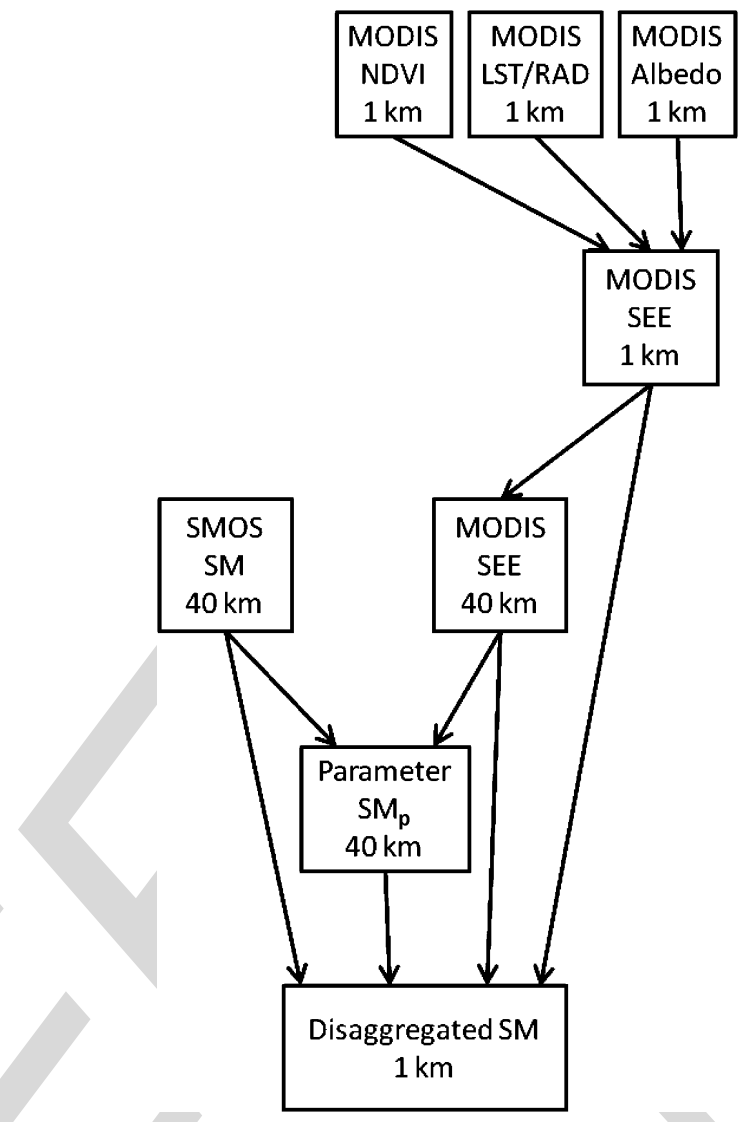

Fig. 5. Schematic diagram presenting the input and output data of DisPATCh.

directly based on the MODIS land surface temperature product 506 masking.

2) Non-Nominal Pixels: Nominal MODIS pixels are de- 508 fined as the $1-\mathrm{km}$ resolution pixels that do not include open 509 water and where land surface temperature is actually retrieved. 510 Open water pixels are flagged in the algorithm when MODIS 511 NDVI retrievals yield negative values. The soil evaporative 512 efficiency of open water pixels is set to 1 . The emerged pixels 513 where land surface temperature is not retrieved (due to the 514 presence of some clouds within the SMOS pixel) are processed 515 as pixels with mean surface conditions. In practice, the soil 516 evaporative efficiency of cloudy pixels (which represent less 517 than $10 \%$ of the surface area within the SMOS pixel) is set to 518 the mean soil evaporative efficiency calculated over the clear 519 sky MODIS pixels. Allocating a soil evaporative efficiency 520 value to non-nominal pixels allows DisPATCh to be run over a 521 wider range of SMOS pixels, including those partially covered 522 by clouds. However, non-nominal 1-km resolution pixels are 523 flagged and discarded from the disaggregation output ensemble. 524

3) Forested Areas: In this study, DisPATCh is applied to all 525 the SMOS pixels where the soil moisture retrieval is successful, 526 even those including forest class, as long as the $1 \mathrm{~km}$ MODIS 527 pixels are in Zone A, B or C (see Fig. 3). This choice is 528 relevant here because the AACES extensive data were almost 529 exclusively collected in agricultural areas (cropping/grazing), 530 so forests for this study are not an issue. In the case of a 531 mixed SMOS pixel including a significant fraction of forest, 532 DisPATCh should be applied to the surface area of the dominant 533 
534 class, thus excluding the surface area of the minority land cover 535 classes.

536 4) Calibration: The soil moisture parameter $\mathbf{S M}_{\mathbf{p}}$ used to 537 compute $\partial \mathbf{S} \mathbf{M}_{\mathbf{m o d}} / \partial \mathbf{S E E}$ in (3) is estimated by inverting the $538 \mathrm{SEE}$ model in (7) at SMOS resolution

$$
\mathbf{S M}_{\mathbf{p}}=\frac{\pi \cdot \mathbf{S M}_{\mathbf{S M O S}}}{\cos ^{-1}\left(1-2\left\langle\mathrm{SEE}_{\mathrm{MODIS}, 1 \mathrm{~km}}\right\rangle_{40 \mathrm{~km}}\right)}
$$

539 A value of $\mathbf{S M}_{\mathbf{p}}$ is obtained for each SMOS pixel and each 540 input data set. Note that the main assumption limiting validity 541 of the calibration approach is the soil evaporative efficiency 542 model [26] itself. The soil evaporative efficiency model in [26] 543 was chosen for its simplicity (one parameter) and its ability 544 to represent the general behavior of soil evaporative efficiency 545 over the full range of soil moisture: particularly the null deriva546 tive at zero and at maximum soil moisture, and an inflexion 547 point in between [38]. However, it has some inconsistencies. 548 In particular, [38] have indicated that 1) potential evaporation 549 is physically reached at soil saturation and not at field capac550 ity; therefore the model in [26] should be (strictly speaking) 551 parameterized by the soil moisture at saturation and not by the 552 soil moisture at field capacity, and 2) soil evaporative efficiency 553 varies with potential evaporation, meaning that the soil moisture 554 parameter (set to the soil moisture at field capacity in [26]) 555 should theoretically vary in time with atmospheric evaporative 556 demand. Consequently, the $\mathbf{S M}_{\mathbf{p}}$ retrieved from SMOS and 557 MODIS data using the model in [26] is definitely not the soil 558 moisture at field capacity as in [26], although it could be in part 559 related to it. In this study, $\mathbf{S M}_{\mathbf{p}}$ is therefore considered to be a 560 fitting parameter self-estimated by DisPATCh.

561 5) Weighting Function: A SMOS pixel WEighting Function 562 (WEF) is used to take into account the impact of soil mois563 ture distribution on the SMOS scale soil moisture as seen by 564 SMOS radiometer. A centrosymmetric analytical approxima565 tion MEAN_WEF is provided in [19], [20]

$$
\operatorname{MEAN} \_\operatorname{WEF}(\rho)=C_{\mathrm{MWEF} 2}+\mathrm{WEF}_{\mathrm{A}}\left(\frac{\rho}{C_{\mathrm{MWEF} 1}} \cdot \frac{\pi}{C_{\mathrm{WEF} 1}}\right)
$$

566 with $\rho$ being the distance from the SMOS pixel center, and $567 C_{\mathrm{MWEF} 1}=40 \mathrm{~km}, C_{\mathrm{MWEF} 2}=0.027, C_{\mathrm{WEF} 1}=73.30$ and

$$
\mathrm{WEF}_{\mathrm{A}}\left(\rho^{\prime}\right)=\frac{\left[\operatorname{sinc}\left(C_{\mathrm{WEF} 1} \cdot \rho^{\prime}\right)\right]^{C_{\mathrm{WEF} 2}}}{1+C_{\mathrm{WEF} 3} \cdot \rho^{\prime} C_{\mathrm{WEF} 4}}
$$

568 with $\rho^{\prime}$ being the distance in the director cosines coordinates, $569 \operatorname{sinc}(x)=\sin (x) / x$, and $C_{\mathrm{WEF} 2}=1.4936, C_{\mathrm{WEF} 3}=524.5$ 570 and $C_{\mathrm{WEF} 4}=2.103$.

571 A correction is applied to disaggregated soil moisture in (3)

$$
\underset{\mathrm{SM}_{1 \mathrm{~km}}^{\text {wef corr. }}=\mathrm{SM}_{1 \mathrm{~km}}+\frac{\sum \operatorname{MEAN} \_\mathrm{WEF}(\rho) \cdot \mathrm{SM}_{1 \mathrm{~km}}(\rho)}{\sum \operatorname{MEAN}_{-} \mathbf{W E F}(\rho)}}{-\mathbf{S M}_{\mathbf{S M O S}}}
$$

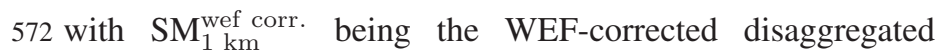
573 soil moisture. Mathematically speaking, one should replace $574 \mathbf{S M}_{\text {SMos }}$ with $\sum$ MEAN_WEF $\cdot \mathrm{SM}_{1 \mathrm{~km}} / \sum \mathrm{MEAN}$ _WEF 575 in (3) and (15) and run an iteration loop until convergence of $\mathrm{SM}_{1 \mathrm{~km}}^{\text {wef corr. }}$ values. However, the impact of the WEF on 576 disaggregated soil moisture is expected to be low so that the 577 simple correction in (18) is considered to be sufficient for the 578 purpose of the study.

6) Disaggregation Output: The downscaling relationship in 580 (3) is applied to each input data set, and the disaggregated soil 581 moisture data ensemble is averaged on each $1-\mathrm{km}$ resolution 582 pixel within the study area. Averaging is a way to reduce 583 random uncertainties in the disaggregation output. In [17], [27], 584 disaggregated soil moisture was averaged in space (aggregated) 585 at the expense of downscaling resolution. Herein, temporal 586 averaging [30] is preferred to keep an optimal downscaling 587 resolution. Note that a condition to average disaggregated soil 588 moisture in time is the availability of thermal infrared data 589 at high temporal frequency. Another significant advantage of 590 applying DisPATCh to an input ensemble is to provide an 591 estimate of the uncertainty in 1-km resolution disaggregated 592 soil moisture, e.g., by computing the standard deviation within 593 the output ensemble.

\section{ApPlication}

To test DisPATCh under various surface and atmospheric 596 conditions, the algorithm is run during AACES-1 and AACES- 597 2 in different modes, by including (or not) a correction for 598 vegetation and atmospheric effects. In each case, disaggregated 599 SMOS soil moisture and HDAS measurements are compared 600 at $1-\mathrm{km}$ resolution for all date-farm units with overlapping 601 HDAS/SMOS/MODIS data.

\section{A. Null Hypothesis}

In this study, the null hypothesis is defined as the application 604 of DisPATCh with parameter $\mathbf{S M}_{\mathbf{p}}$ set to zero in (8). Hence, 605 the downscaling relationship in (3) becomes

$$
\mathrm{SM}_{1 \mathrm{~km}}=\mathrm{SM}_{\mathrm{SMOS}}
$$

meaning that no 1-km information is used. Defining a null 607 hypothesis is useful to test whether DisPATCh is able to re- 608 produce the subpixel variability within the $\sim 10 \mathrm{~km}^{2}$ sam- 609 pling farms with better skill than simply assuming a uniform 610 moisture condition. Statistical results in terms of root mean 611 square difference, mean difference, correlation coefficient, and 612 slope of the linear regression between the SMOS soil moisture 613 disaggregated with (19) and in situ measurements are listed in 614 Table III. One observes that the root mean square difference 615 is generally explained by a (negative) bias in SMOS data and 616 that none of the correlations evaluated at $1-\mathrm{km}$ resolution for 617 each farm separately is statistically significant (all calculated p- 618 values are larger than 0.10). Thus, the rationale for developing 619 DisPATCh is to improve the correlation at fine scale between 620 SMOS and ground soil moisture and to reduce the bias in 621 disaggregated SMOS data in the specific case where the bias 622 in SMOS data at the farm scale is due to the heterogeneity of 623 soil moisture within the SMOS pixel. 
TABLE III

DisPatch Is Run With No 1-km Information ( $\mathbf{S M}_{\mathbf{p}}$ Set to Zero) and Statistical Results Are Listed in Terms of Root Mean SQuare

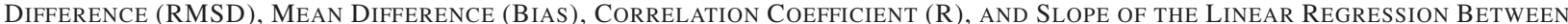
1-km Resolution Disaggregated SMOS Soll Moisture and 1-km Aggregated In Situ Measurements. The Mean

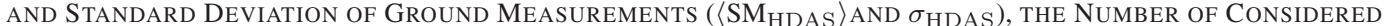
1-km Pixels, and Statistical Significance (p-Value) ARe Also Listed for Each Date-Farm Unit

\begin{tabular}{|c|c|c|c|c|c|c|c|c|}
\hline DoY/Farm & $\begin{array}{c}\left\langle\mathrm{SM}_{\mathrm{HDAS}}\right\rangle \\
\left(\mathrm{m}^{3} / \mathrm{m}^{3}\right)\end{array}$ & $\begin{array}{c}\sigma_{\mathrm{HDAS}} \\
\left(\mathrm{m}^{3} / \mathrm{m}^{3}\right)\end{array}$ & $\begin{array}{l}\text { Number of } \\
1 \mathrm{~km} \text { pixels }\end{array}$ & $\begin{array}{l}\text { RMSD } \\
\left(\mathrm{m}^{3} / \mathrm{m}^{3}\right)\end{array}$ & $\begin{array}{c}\text { Bias } \\
\left(\mathrm{m}^{3} / \mathrm{m}^{3}\right)\end{array}$ & $\begin{array}{l}\mathrm{R}^{\dagger} \\
(-)\end{array}$ & $\begin{array}{c}\text { Slope }^{\dagger} \\
(-)\end{array}$ & $\begin{array}{c}\text { p-value } \\
(-)\end{array}$ \\
\hline 28/F05 & 0.04 & 0.02 & 7 & 0.04 & -0.04 & - & - & 1.0 \\
\hline 30/F07 & 0.02 & 0.03 & 8 & 0.02 & -0.02 & - & - & 1.0 \\
\hline 30/F08 & 0.03 & 0.02 & 7 & 0.02 & -0.02 & - & - & 0.69 \\
\hline 46/F15 & 0.29 & 0.05 & 8 & 0.04 & 0.03 & - & - & 0.91 \\
\hline 46/F16 & 0.34 & 0.06 & 8 & 0.09 & -0.08 & - & - & 1.0 \\
\hline 49/F 17 & 0.21 & 0.06 & 8 & 0.04 & -0.04 & - & - & 0.66 \\
\hline 49/F18 & 0.25 & 0.07 & 6 & 0.08 & -0.08 & - & - & 0.42 \\
\hline $49 / \mathrm{F} 20$ & 0.20 & 0.09 & 4 & 0.02 & -0.007 & - & - & 0.87 \\
\hline $51 / \mathrm{F} 19$ & 0.24 & 0.08 & 6 & 0.13 & -0.13 & - & - & 0.77 \\
\hline $51 / \mathrm{F} 20$ & 0.20 & 0.10 & 6 & 0.09 & -0.08 & - & - & 0.79 \\
\hline AACES- 1 mean $\ddagger$ & - & - & - & - & - & - & - & $>0.10$ \\
\hline 254/F09 & 0.33 & 0.07 & 9 & 0.13 & -0.13 & - & - & 0.13 \\
\hline 256/F07 & 0.36 & 0.10 & 8 & 0.19 & -0.18 & - & - & 0.15 \\
\hline 264/F13 & 0.30 & 0.07 & 8 & 0.18 & -0.17 & - & - & 1.0 \\
\hline $265 / \mathrm{F} 15$ & 0.25 & 0.06 & 7 & 0.05 & -0.05 & - & - & 1.0 \\
\hline 267/F09 & 0.21 & 0.07 & 9 & 0.14 & -0.14 & - & - & 0.43 \\
\hline AACES- 2 mean & - & - & - & - & - & - & - & $>0.10$ \\
\hline
\end{tabular}

\section{B. Visual Assessment of Disaggregation Images}

626 As an example, DisPATCh is applied on DoY 49 over a 120 $627 \mathrm{~km}$ by $80 \mathrm{~km}$ subarea including the farms F16, F17, F18, F19, 628 and F20. The images of 1-km resolution disaggregated SMOS 629 soil moisture are presented in Fig. 6. DisPATCh is run with $630 \mathbf{S M}_{\mathbf{p}}$ set to zero (null hypothesis) and in four distinct modes 631 corresponding to the combinations of the "LST" (the official 632 MODIS land surface temperature product is used) and "RAD" 633 [the land surface temperature is derived from MODIS radiances 634 using (14)] modes and the "Zone $A+B+C$ " (the vegetation635 transpiration dominated $1-\mathrm{km}$ pixels are discarded) and "Zone 636 A only" (only the soil evaporation-dominated 1-km pixels are 637 selected) modes.

638 In Fig. 6, the SMOS DGG nodes where level-2 soil moisture 639 is successfully retrieved are overlaid on the image correspond640 ing to the null hypothesis (resampled SMOS data with no 1-km 641 information) for 6 am and 6 pm overpass times separately. The 642 gaps in SMOS data in the lower middle part of the images 643 are due to topography flagging over the Australian Alps. In 644 the version-4 SMOS level-2 processor, soil moisture is not 645 retrieved at the DGG nodes where the topography effects on 646 simulated brightness temperatures exceed a certain threshold, 647 so as to prevent large errors in soil moisture values. The appar648 ent resolution of the null hypothesis image is $20 \mathrm{~km}$ because 649 it is generated from the composition of four $40-\mathrm{km}$ resolution 650 resampled SMOS snapshot images, whose resampling grids are separated by $20 \mathrm{~km}$ (the SMOS level-2 data resampling strategy 651 was described in Section II-B.).

Note that the disaggregation products in the Zone $\mathrm{A}+\mathrm{B}+\mathrm{C} 653$ mode cover an area larger than the area sampled by SMOS 654 data, because the SMOS resolution (about $40 \mathrm{~km}$ ) is larger 655 than the SMOS product sampling length (about $15 \mathrm{~km}$ ), but 656 does not provide disaggregated values at a distance larger than 657 $20 \mathrm{~km}$ from the successful retrieval nodes. Concerning the Zone 658 A only mode, disaggregation products do not cover an area 659 larger than the SMOS sampling area because the Australian 660 Alps are surrounded by forests where the fraction of bare soil is 661 less than elsewhere in the area, and which correspond to Zone 662 $\mathrm{B}$ or $\mathrm{C}$ in the hourglass in Fig. 3.

When looking at the images obtained in the Zone $A+B+C 664$ mode in Fig. 6, one observes that the spatial structures of 665 1-km disaggregated SMOS soil moisture encompass, but does 666 not seem to be correlated with, the SMOS data sampling 667 length. However, a "boxy artifact" is still apparent at 20-km 668 resolution, which is the separation length of the SMOS data 669 resampling grids as explained in Section II-B. The notion of 670 "boxy artifact" was introduced by [39] to analyze the quality of 671 a disaggregation approach. The less apparent the low-resolution 672 boxes, the better the disaggregation skill of the algorithm to 673 spatially connect high-resolution disaggregated values between 674 neighboring low-resolution pixels, and thus to derive a realistic 675 high-resolution soil moisture field. When comparing the images 676 obtained in the Zone $\mathrm{A}+\mathrm{B}+\mathrm{C}$ mode with those obtained in the 677 


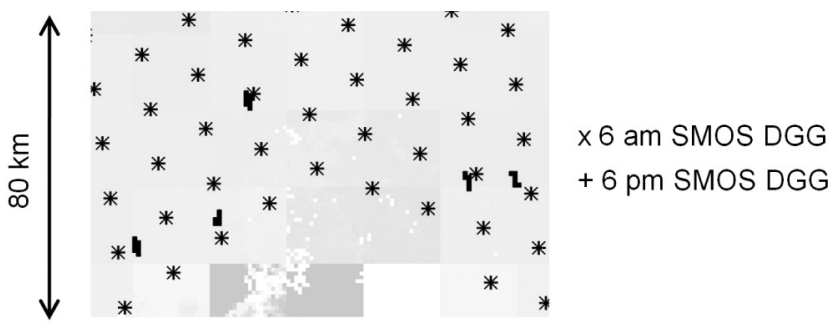

LST
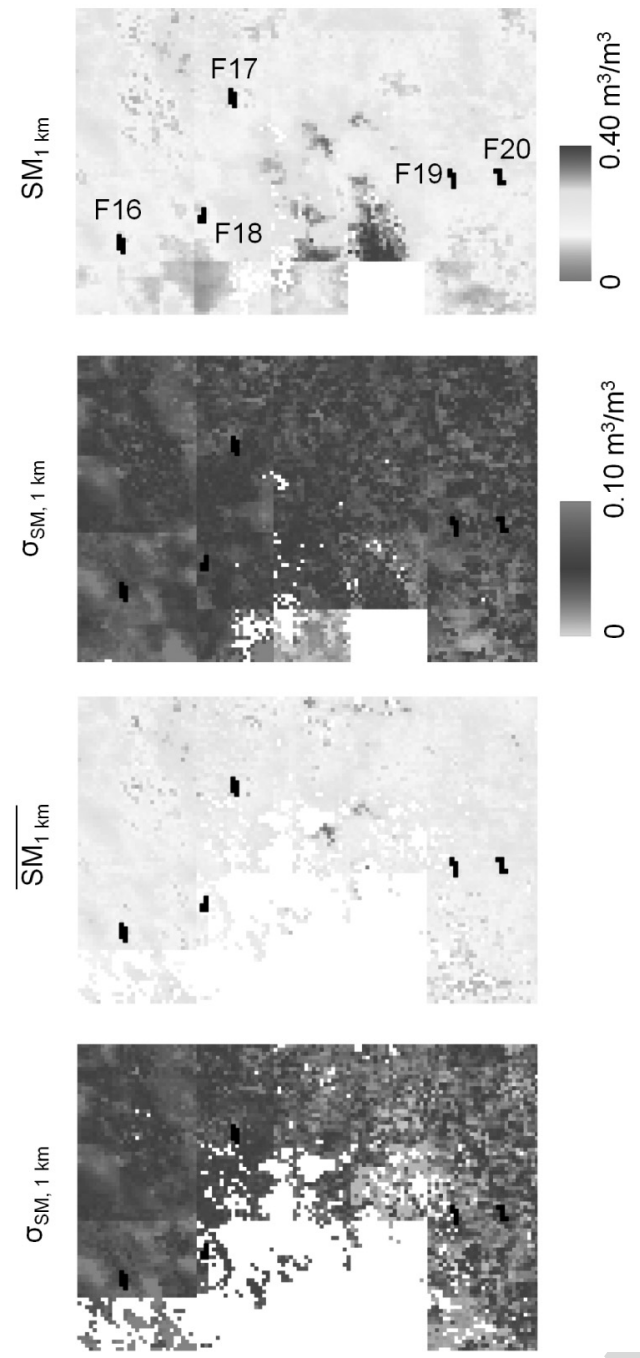

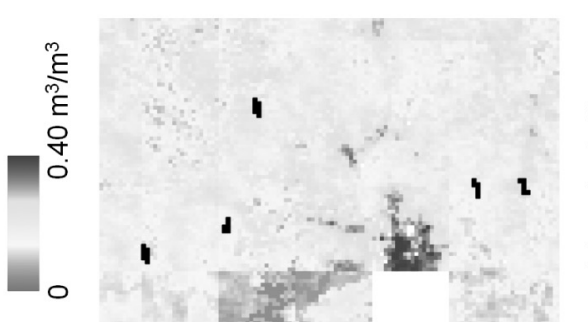

0
+
0
+
+
0
0
0
$N$

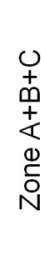

Fig. 6. Images of disaggregation results over a $120 \mathrm{~km}$ by $80 \mathrm{~km}$ subarea on DoY 49 . The disaggregated soil moisture $\left(\overline{\mathrm{SM}_{1} \mathrm{~km}}\right)$ and its estimated uncertainty $\left(\sigma_{\mathrm{SM}, 1 \mathrm{~km}}\right)$ are compared in the LST and RAD modes and in the Zone A+B+C and Zone A only modes. Sampling farms are overlaid on all images. SMOS DGG nodes are overlaid on the image corresponding to the null hypothesis (no 1-km resolution information) presented at top.

678 Zone A only mode, one observes that the 20-km resolution boxy 679 artifact is less apparent in the Zone A only mode, consistent 680 with the better sensitivity of MODIS-derived SEE with soil681 dominated pixels (Zone A) than with mixed-surface (Zone B 682 and C) pixels. In Fig. 6, the images obtained in the LST and 683 RAD mode highlight different spatial structures. In general, 684 there are less data gaps in the RAD than in the LST mode. 685 However, ground validation data are required to assess their 686 relative quality/accuracy.

687 As an assessment of the uncertainty in composited soil mois688 ture disaggregation, the standard deviation within the disaggre689 gation output ensemble is also reported for each disaggregation product in Fig. 6. The same observations can be made as with 690 the soil moisture images: spatial structures are more visible, and 691 the boxy artifact is less apparent in the RAD than in the LST 692 mode. In general, the estimated uncertainty in disaggregated 693 products is larger in the RAD than in the LST mode, regardless 694 of the Zone $(\mathrm{A}+\mathrm{B}+\mathrm{C}$ or $\mathrm{A}$ only) mode.

\section{SMOS Weighting Function}

To evaluate the impact of the SMOS instrument weighting 697 function on disaggregation results, DisPATCh is run with (and 698 without) the WEF correction in (18). The expected effect of the 699 


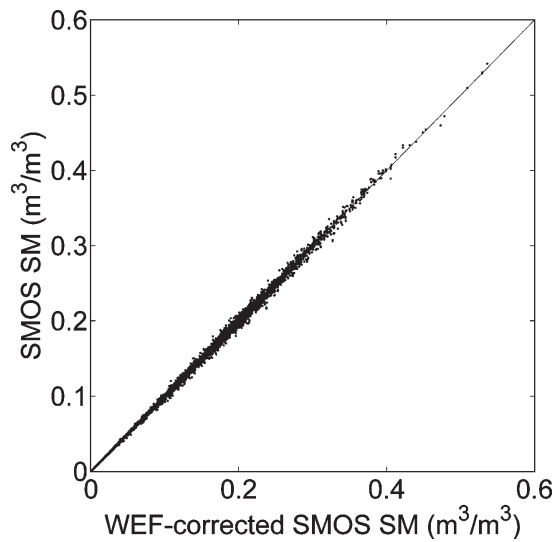

Fig. 7. Uncorrected versus WEF-corrected SMOS soil moisture for the entire data set.

$700 \mathrm{WEF}$ is a bias at $40 \mathrm{~km}$ resolution on disaggregated soil mois701 ture. Fig. 7 plots the uncorrected against WEF-corrected SMOS 702 soil moisture for the entire data set including both AACES-1 703 and AACES-2 experiments. The WEF correction has very 704 little impact on disaggregated soil moisture with a maximum 705 difference between uncorrected and WEF-corrected SMOS soil 706 moisture of $0.02 \mathrm{~m}^{3} / \mathrm{m}^{3}$, a mean difference of approximately 707 zero, and a standard deviation of $0.003 \mathrm{~m}^{3} / \mathrm{m}^{3}$. Although the 708 difference is small with this data set, WEF-corrected products 709 are expected to be more realistic. Therefore, the correction in 710 (18) is used in all the DisPATCh runs that follow.

\section{D. Quantitative Comparison With In Situ Measurements}

712 Fig. 8 presents the scatterplots of $1-\mathrm{km}$ resolution disaggre713 gated SMOS soil moisture versus 1-km resolution aggregated 714 in situ measurements for the ten date-farm units during 715 AACES-1. On each graph are plotted the soil moisture dis716 aggregated in the Zone $\mathrm{A}+\mathrm{B}+\mathrm{C}$ mode (empty squares) and 717 the soil moisture disaggregated in the Zone A only mode 718 (black squares). At the beginning of AACES-1, conditions are 719 very dry so that SMOS retrievals are close to zero and the 720 variability of in situ measurements is low (about $0.02 \mathrm{~m}^{3} / \mathrm{m}^{3}$ ). 721 In such conditions, no useful information is expected from the 722 application of DisPATCh, and the statistical results in terms of 723 spatial correlation are not meaningful for DoY 28/F05, DoY 724 30/F07 and DoY 30/F08. While wetter conditions occur after 725 DoY 30, cloud cover prevents DisPATCh to be run (MODIS 726 data are unavailable) until DoY 46. On DoY 46, the average 727 and standard deviation of in situ soil moisture measurements is $7280.32 \mathrm{~m}^{3} / \mathrm{m}^{3}$ and $0.06 \mathrm{~m}^{3} / \mathrm{m}^{3}$, respectively. The spatial variabil729 ity of $1-\mathrm{km}$ soil moisture is nicely captured by DisPATCh no730 tably in the RAD mode. On DoY 49, the disaggregated SMOS 731 soil moisture is still correlated with the in situ measurements 732 made in three farms (F17, F18, and F20). On the last ground 733 sampling day, disaggregation results are significantly correlated 734 with in situ measurements in F19, but not in F20. The poor 735 results obtained with DoY 51/F20 is probably due to the time 736 gap (3 days) between ground sampling date (DoY 51) and 737 MODIS overpass day (DoY 54).

738 Statistical results in terms of root mean square difference, 739 mean difference, correlation coefficient, and slope of the linear regression between the SMOS soil moisture disaggregated in 740 the Zone $\mathrm{A}+\mathrm{B}+\mathrm{C}$ mode and aggregated in situ measurements 741 are listed in Table IV. Statistical significance (p-value) is also 742 reported for each date-farm unit to select statistically significant 743 (p-value $<0.10$ ) results. Although the disaggregation of SMOS 744 data on extensively dry DoY 30 does not provide any additional 745 information (soil is uniformly dry), the observed correlation 746 between disaggregated (LST mode) and in situ soil moisture 747 is statistically significant, and the correlation coefficient value 748 is negative $(-0.70$ and -0.95 at F07 and F08, respectively). 749 One plausible explanation is the opposite effect of soil temper- 750 ature on HDAS soil moisture measurements and on MODIS- 751 derived soil evaporative efficiency: a slight undercorrection of 752 the temperature-corrected hydraprobe measurements at high 753 temperature [18] results in a slight increase of soil moisture 754 estimate with soil temperature, while an increase of soil temper- 755 ature makes soil evaporative efficiency decrease. Nevertheless, 756 the possible impact of soil temperature on HDAS measurements 757 is very low with a slope of the linear regression between 758 disaggregated SMOS and in situ soil moisture calculated as 759 -0.08 and -0.03 for F07 and F08, respectively. When selecting 760 statistically significant results $(\mathrm{p}$-value $<0.10$ ) and discarding 761 data for DoY 30, the mean correlation coefficient and slope in 762 RAD mode are 0.75 and 0.58 , respectively.

Fig. 9 presents the scatterplots of 1-km resolution disaggre- 764 gated SMOS soil moisture versus 1-km resolution aggregated in 765 situ measurements for the five date-farm units during AACES- 766 2. On each graph are plotted the soil moisture disaggregated in 767 the Zone $\mathrm{A}+\mathrm{B}+\mathrm{C}$ mode (empty squares) and the soil moisture 768 disaggregated in the Zone A only mode (black squares). The 769 surface conditions of AACES-2 were relatively wet with a mean 770 soil moisture value estimated as $0.29 \mathrm{~m}^{3} / \mathrm{m}^{3}$. The disaggre- 771 gated SMOS soil moisture does not correlate well with in situ 772 measurements with a p-value larger than 0.10 for all sampling 773 days, except for DoY 256/F07 in LST mode (see Table IV). The 774 negative correlation coefficient $(-0.73)$ obtained on DoY 256 is 775 discussed when comparing the Zone $\mathrm{A}+\mathrm{B}+\mathrm{C}$ and Zone A only 776 modes in Section IV-F. In general, statistical results in Table IV 777 indicate that DisPATCh does not succeed in representing the 778 variability of soil moisture at 1-km resolution during AACES- 779 2. In fact, DisPATCh is based on the tight coupling that occurs 780 between soil moisture and evaporation under high evaporative 781 demand conditions [40]. This coupling seems to be weak in 782 September over the study area so that the disaggregation results 783 at $1-\mathrm{km}$ resolution are not reliable.

784

For DoY 264/F13, however, an interesting feature is ob- 785 served on the graph corresponding to the RAD and Zone A 786 only modes. When removing the (three) black squares with 787 the largest errorbars, the correlation coefficient and the slope 788 of the linear regression between disaggregated and in situ 789 observations becomes 0.9 and 0.7 , respectively. This suggests 790 that: 1) the standard deviation within the disaggregation output 791 ensemble can be a good estimate of the uncertainty in the 792 composited disaggregation product; and 2) the applicability of 793 DisPATCh is greatly dependent on the quality of MODIS land 794 surface temperature. Note that in this study, a choice was made 795 to maximize the number of data points used in the comparison 796 with in situ measurements. Consequently, all the cloud-free 797 

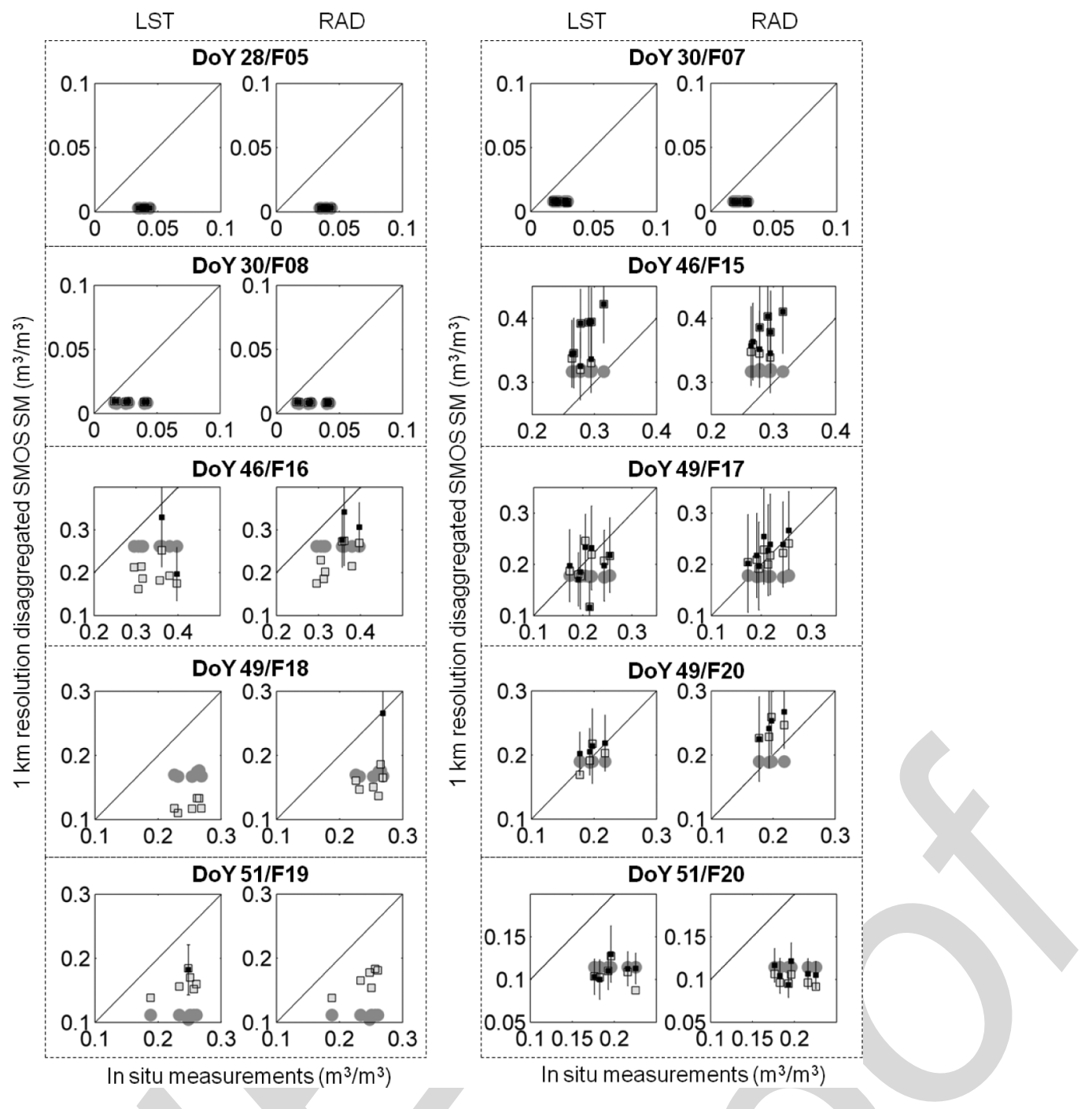

Fig. 8. Scatterplots of 1-km resolution disaggregated SMOS soil moisture versus 1-km resolution aggregated in situ measurements for each of the ten date-farm data sets during AACES-1. The filled circles correspond to disaggregation with no 1-km information, empty squares to Zone $\mathrm{A}+\mathrm{B}+\mathrm{C}$ mode and black squares to Zone A only mode. For the Zone A only mode, the uncertainty in disaggregated soil moisture is represented by vertical errorbars.

798 MODIS land surface temperature data were used regardless 799 of the MODIS land surface temperature quality index. Further 800 research should be conducted to assess whether selecting the 801 MODIS pixel with the best MODIS land surface temperature 802 quality index would improve the disaggregation results. This 803 would be possible using the AACES airborne data, which cover 804 a much larger area than in situ measurements.

\section{E. Atmospheric Corrections}

806 The impact of atmospheric corrections on DisPATCh output 807 is analyzed by comparing the disaggregation results obtained 808 in the LST and RAD mode. Quantitative comparison between 809 LST and RAD modes is provided in Table IV in terms of root 810 mean square difference, mean difference, correlation coeffi811 cient, and slope of the linear regression between disaggregated 812 SMOS soil moisture and aggregated in situ measurements. 813 Correlation coefficient and slope values are reported only if 814 the p-value (statistical significance) is lower than 0.10. It is 815 apparent that statistical results are better in the RAD than in the LST mode. When including all dates, the mean bias is 816 decreased from $-0.05 \mathrm{~m}^{3} / \mathrm{m}^{3}$ in LST mode to $-0.03 \mathrm{~m}^{3} / \mathrm{m}^{3} 817$ in RAD mode during AACES-1. When selecting statistically 818 significant results $(\mathrm{p}$-value $<0.10)$ and discarding data for 819 DoY 30, the mean correlation coefficient and slope is 0.75 and 820 0.58 in RAD mode, and 0.65 and 1.5 in LST mode, respectively. 821 Note that the improvement is very significant for DoY 46/F16 822 with a correlation coefficient and slope increasing from about 823 zero to 0.7 and 0.8 , respectively.

The fact that the results obtained in RAD mode are superior 825 to those obtained in LST mode indicates that the atmospheric 826 corrections of the official MODIS land surface temperature 827 add significant uncertainties in the disaggregation products. 828 One rationale may be that the information used in atmospheric 829 corrections (notably air temperature and water vapor profile 830 data) are subjected to large uncertainties at $5-\mathrm{km}$ resolution. 831 As DisPATCh is based on the spatial variations of MODIS 832 temperature relative to the $40 \mathrm{~km}$ scale mean, the atmospheric 833 corrections on the land surface temperature data are not nec- 834 essary at $5 \mathrm{~km}$ (as it is done in the MODIS temperature 835 
TABLE IV

DisPatCh Is Run in the Zone A+B+C Mode and Statistical Results Are Listed in Terms of Root Mean Square Difference (RMSD), Mean Difference (Bias), Correlation Coefficient (R), and Slope of the Linear Regression Between 1-km Resolution Disaggregated SMOS Soil Moisture and 1-km Aggregated IN Situ Measurements. The Results Obtained Using THE Radiance-Derived Land SuRface Temperature Data (RAD Mode) and Using The OfFicial MODIS LAND Surface Temperature Data (LSt Mode in Parenthesis) Are Compared. The Mean and Standard Deviation of Ground MEASUREMENTS ( $\langle$ SM HDAS $\rangle$ AND $\sigma$ HDAS $)$, THE NUMBER OF CONSIDERED 1-km PIXELS and Statistical Significance (P-Value) Are Also Listed for Each Date-Farm Unit

\begin{tabular}{|c|c|c|c|c|c|c|c|c|}
\hline DoY/Farm & $\begin{array}{c}\left\langle\mathrm{SM}_{\mathrm{HDAS}}\right\rangle \\
\left(\mathrm{m}^{3} / \mathrm{m}^{3}\right)\end{array}$ & $\begin{array}{c}\sigma_{\mathrm{HDAS}} \\
\left(\mathrm{m}^{3} / \mathrm{m}^{3}\right)\end{array}$ & $\begin{array}{l}\text { Number of } \\
1 \mathrm{~km} \text { pixels }\end{array}$ & $\begin{array}{l}\text { RMSD } \\
\left(\mathrm{m}^{3} / \mathrm{m}^{3}\right)\end{array}$ & $\begin{array}{c}\text { Bias } \\
\left(\mathrm{m}^{3} / \mathrm{m}^{3}\right)\end{array}$ & $\begin{array}{l}\mathrm{R}^{\dagger} \\
(-)\end{array}$ & $\begin{array}{c}\text { Slope }^{\dagger} \\
(-)\end{array}$ & $\begin{array}{c}\text { p-value } \\
(-)\end{array}$ \\
\hline 28/F05 & 0.04 & 0.02 & $7(7)$ & $0.04(0.04)$ & $-0.04(-0.04)$ & $-(-)$ & $-(-)$ & $0.72(0.80)$ \\
\hline 30/F07 & 0.02 & 0.03 & $8(8)$ & $0.02(0.02)$ & $-0.02(-0.02)$ & $-(-0.70)$ & $-(-0.08)$ & $0.20(0.05)$ \\
\hline $30 / \mathrm{F} 08$ & 0.03 & 0.02 & $7(7)$ & $0.02(0.02)$ & $-0.02(-0.02)$ & $-(-0.95)$ & $-(-0.03)$ & $0.11(0.001)$ \\
\hline $46 / \mathrm{F} 15$ & 0.29 & 0.05 & $8(8)$ & $0.09(0.09)$ & $0.09(0.08)$ & $-(0.65)$ & $-(1.5)$ & $0.12(0.08)$ \\
\hline $46 /$ F 16 & 0.34 & 0.06 & $8(8)$ & $0.12(0.15)$ & $-0.11(-0.14)$ & $0.72(-)$ & $0.76(-)$ & $0.04(0.95)$ \\
\hline 49/F17 & 0.21 & 0.06 & $8(8)$ & $0.02(0.04)$ & $0.00(-0.02)$ & $0.70(-)$ & $0.42(-)$ & $0.05(0.54)$ \\
\hline 49/F18 & 0.25 & 0.07 & $6(6)$ & $0.10(0.13)$ & $-0.09(-0.13)$ & $-(-)$ & $-(-)$ & $0.60(0.20)$ \\
\hline 49/F20 & 0.20 & 0.09 & $4(4)$ & $0.05(0.01)$ & $0.04(0.00)$ & $-(-)$ & $-(-)$ & $0.41(0.32)$ \\
\hline $51 /$ F19 & 0.24 & 0.08 & $6(6)$ & $0.07(0.08)$ & $-0.07(-0.08)$ & $0.84(-)$ & $0.56(-)$ & $0.04(0.19)$ \\
\hline $51 /$ F 20 & 0.20 & 0.10 & $6(6)$ & $0.10(0.09)$ & $-0.10(-0.09)$ & $-(-)$ & $-(-)$ & $0.17(0.51)$ \\
\hline AACES- 1 mean ${ }^{\ddagger}$ & $0.26(0.29)$ & $0.07(0.05)$ & $7(8)$ & $0.07(0.09)$ & $-0.06(-0.08)$ & $0.75(0.65)$ & $0.58(1.5)$ & $0.04(0.08)$ \\
\hline 254/F09 & 0.33 & 0.07 & $9(9)$ & $0.18(0.14)$ & $-0.16(-0.11)$ & $-(-)$ & $-(-)$ & $0.17(0.74)$ \\
\hline $256 / \mathrm{F} 07$ & 0.36 & 0.10 & $8(9)$ & $0.12(0.19)$ & $-0.10(-0.18)$ & $-(-0.73)$ & $-(-0.47)$ & $0.12(0.04)$ \\
\hline $264 / \mathrm{F} 13$ & 0.30 & 0.07 & $8(8)$ & $0.16(0.19)$ & $-0.14(-0.16)$ & $-(-)$ & $-(-$ & $0.59(0.47)$ \\
\hline $265 / \mathrm{F} 15$ & 0.25 & 0.06 & $7(7)$ & $0.16(0.18)$ & $0.01(0.03)$ & $-(-)$ & $-(-)$ & $0.32(0.34)$ \\
\hline 267/F09 & 0.21 & 0.07 & $9(9)$ & $0.16(0.15)$ & $-0.15(-0.15)$ & $-(-)$ & $-(-)$ & $0.90(0.86)$ \\
\hline AACES- 2 mean $\ddagger$ & 0.36 & 0.10 & $-(9)$ & $-(0.19)$ & $-(-0.18)$ & $-(-0.73)$ & $-(-0.47)$ & $>0.10(0.04)$ \\
\hline
\end{tabular}

$\ddagger$ the mean values computed for AACES-1 and AACES-2 include only statistically significant ( $\mathrm{p}$-value $<0.10)$ results and discard extensive dry days DoY 28-30.

836 algorithm). An atmospheric correction at $40-\mathrm{km}$ resolution is 837 sufficient and provides even better disaggregation results that 838 applying an atmospheric correction at $5-\mathrm{km}$ resolution.

\section{F. Vegetation Cover}

840 The impact of vegetation cover on DisPATCh output during 841 AACES-1 is analyzed by comparing the disaggregation results 842 obtained in the Zone $\mathrm{A}+\mathrm{B}+\mathrm{C}$ and Zone A only mode. Quan843 titative comparison between Zone $\mathrm{A}+\mathrm{B}+\mathrm{C}$ and Zone $\mathrm{A}$ only 844 modes is provided in Tables IV and $\mathrm{V}$ in terms of root mean 845 square difference, mean difference, correlation coefficient, and 846 slope of the linear regression between disaggregated SMOS soil 847 moisture and aggregated in situ measurements. It is apparent 848 that statistical results are generally better in the Zone A only 849 than in the Zone $\mathrm{A}+\mathrm{B}+\mathrm{C}$ mode for both LST and RAD modes. 850 In the RAD mode for instance, the mean correlation coefficient 851 is increased from 0.75 in the Zone $A+B+C$ mode (Table IV) to 8520.89 in the Zone A only mode (Table V). Also the mean slope 853 is closer to 1 as it switches from 0.58 in the Zone $A+B+C$ mode 854 (Table IV) to 0.91 in the Zone A only mode (Table V). Con855 sequently, results are consistent with the hourglass approach in 856 Fig. 3 that predicts a lower sensitivity of MODIS-derived soil 857 temperature to soil moisture in Zone B and C, Zone A having the highest potential for estimating soil moisture variability 858 from MODIS temperature.

On DoY 256, the negative correlation appearing in Zone 860 $\mathrm{A}+\mathrm{B}+\mathrm{C}$ mode (Table IV) is not significant in Zone A only mode 861 (Table V), suggesting that the contradictory result obtained on 862 DoY 256 is probably an artifact due to the small sample size. 863

Note that one drawback of the Zone A only mode is the larger 864 amount of data gaps in the soil moisture images. Therefore, 865 the use of both modes is a compromise between application 866 coverage and accuracy in the disaggregation output.

867

\section{G. Distinguishing Between SMOS and DisPATCh Errors}

868

By solving the extent mismatch between 40-km resolution 869 remote sensing observation and localized in situ measurements, 870 DisPATCh could be used as a tool to help improve the validation 871 strategies of SMOS data in low-vegetated semi-arid regions. It 872 also would reduce the coverage requirements identified by [41] 873 for airborne validation campaigns. However, such a validation 874 approach requires separating the different error sources that 875 may be attributed to SMOS soil moisture and to DisPATCh. 876 One solution is to estimate the errors attributed to DisPATCh 877 and then deduce the errors attributed to SMOS soil moisture. To 878 estimate the errors that are associated with the disaggregation 879 


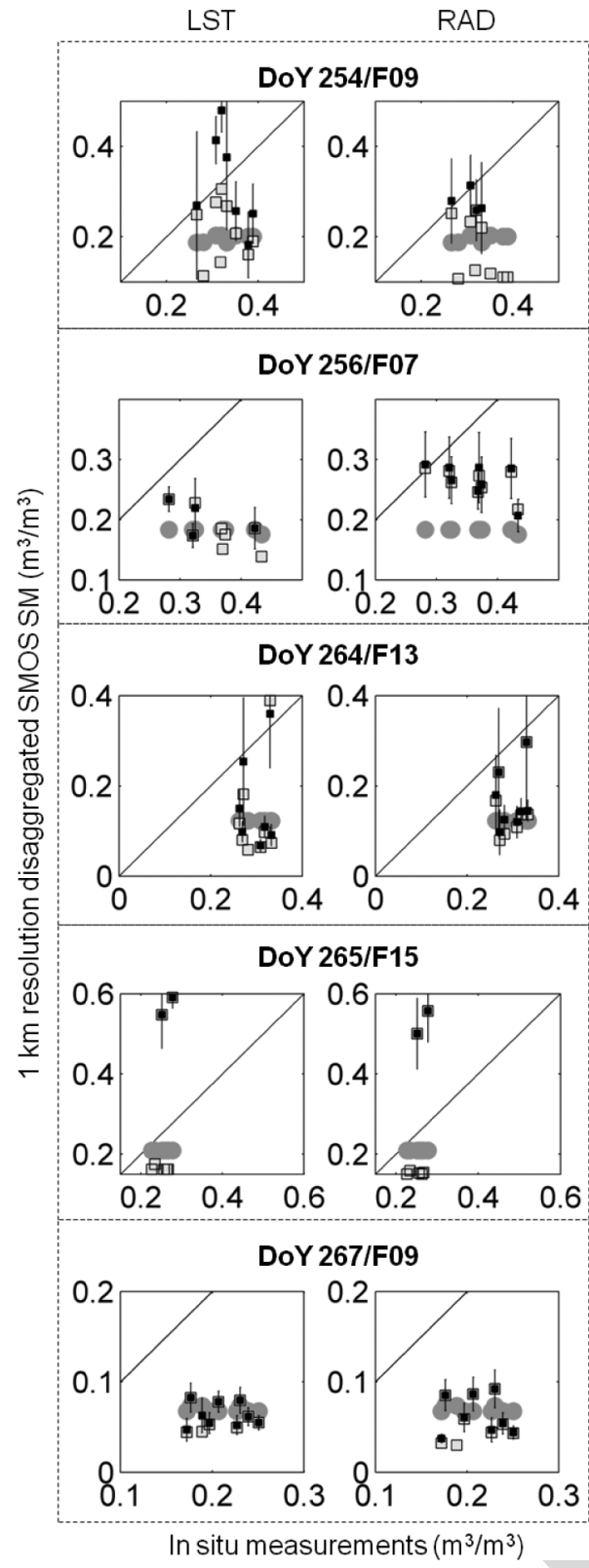

Fig. 9. Scatterplots of 1-km resolution disaggregated SMOS soil moisture versus 1-km resolution aggregated in situ measurements for each of the five datefarm data sets during AACES-2. The filled circles correspond to disaggregation with no $1-\mathrm{km}$ information, empty squares to Zone $\mathrm{A}+\mathrm{B}+\mathrm{C}$ mode and black squares to Zone A only mode. For the Zone A only mode, the uncertainty in disaggregated soil moisture is represented by vertical errorbars.

880 methodology, it is suggested to analyze the spatial correla881 tion between $1-\mathrm{km}$ disaggregated SMOS soil moisture and 882 in situ measurements. If the correlation is significant, then the 883 disaggregation product is likely to be sufficiently accurate for 884 validating SMOS data.

885 Note that the errors in DisPATCh are in part coupled with 886 the errors in SMOS soil moisture, particularly because SMOS 887 is an input to DisPATCh. However, any uncertainties in SMOS 888 soil moisture should not impact the disaggregation results at a 889 distance shorter than the SMOS data sampling length $(15 \mathrm{~km})$. 890 This is the reason why such a validation strategy should be 891 conducted with ground measurements made within a distance 892 radius of $15 \mathrm{~km}$.
In this study case, five date-farm units including DoY 893 46/F15, DoY 46/F16, DoY 49/F17, DoY 49/F18, and DoY 894 49/F20 indicate a significant correlation between disaggregated 895 SMOS soil moisture and in situ measurements. For these units, 896 the root mean square error in disaggregated SMOS soil mois- 897 ture is mainly explained by a bias in disaggregated soil moisture 898 (see Table IV). However, no conclusion can be drawn from 899 these data because: 1) the bias is sometimes positive (DoY 900 46/F15, DoY 49/F20), and sometimes negative (DoY 46/F16, 901 DoY 49/F17, DoY 49/F18); and 2) the comparison is made only 902 once for each farm, which does not allow analyzing the tempo- 903 ral behavior. Such a validation approach could be undertaken 904 in the near future using the OzNet (http://www.oznet.org.au/, 905 [42]) soil moisture monitoring network, providing continuous 906 measurements at 68 sites within the Murrumbidgee catchment 907 area.

\section{H. Subpixel Variability and Assimilation Perspectives}

DisPATCh is successively run in LST or RAD mode and in 910 Zone $\mathrm{A}+\mathrm{B}+\mathrm{C}$ or Zone A only mode during AACES-1. Fig. 10911 plots for each case the estimated uncertainty in disaggregated 912 soil moisture (computed as the standard deviation of the disag- 913 gregation output ensemble) against the subpixel variability of 914 $1-\mathrm{km}$ resolution in situ measurements (computed as the stan- 915 dard deviation of the in situ measurements made within 916 1-km pixels). The data corresponding to DoY 51 are plotted 917 separately because of the time gap between HDAS/SMOS 918 (DoY 51) and MODIS (DoY 54) collection time. It is interest- 919 ing to observe that the estimated uncertainty in disaggregated 920 soil moisture is closely related to the observed subpixel vari- 921 ability of in situ measurements. Hence, $\sigma_{\mathrm{SM}, 1 \mathrm{~km}}$ could be used 922 as a proxy for representing the soil moisture variability at scales 923 finer than 1-km resolution. Concerning the data on DoY 51, the 924 linear regression is clearly off the 1:1 line. This is consistent 925 with a decrease of the spatial variability in soil moisture during 926 a dry down period [43]. In particular, the spatial variability 927 in soil moisture is expected to be lower on DoY 54 than on 928 DoY 51.

The correlation between the estimated uncertainty in disag- 930 gregated soil moisture and the subpixel soil moisture variability 931 makes an additional link between DisPATCh output and assim- 932 ilation schemes into hydrological models. A number of optimal 933 assimilation methodologies have been developed to combine 934 model predictions with remote sensing observations. However, 935 any so-called optimal assimilation technique stops being opti- 936 mal if the uncertainty in remotely sensed data is unknown or 937 estimated with a large uncertainty. In the perspective of assim- 938 ilating disaggregated SMOS data into land surface models, one 939 should keep in mind that the error information on observable 940 variables is as crucial as the observations themselves, e.g., [44]. 941

\section{Summary AND CONCLUSION}

DisPATCh is an algorithm dedicated to the disaggregation of 943 soil moisture observations using high-resolution soil tempera- 944 ture data. It converts soil temperature fields into soil moisture 945 fields given a semi-empirical soil evaporative efficiency model 946 
TABLE V

DispatCh Is Run in the Zone A Only Mode, and Statistical Results Are Listed in Terms of Root Mean SQuare Difference (RMSD), Mean Difference (Bias), Correlation Coefficient (R), and Slope of the Linear Regression Between 1-km Resolution Disaggregated SMOS SoIl Moisture and 1-km AgGRegated IN Situ MEasurements. The Results ObTained Using the Radiance-Derived Land Surface Temperature Data (RAD Mode) and Using the OfFicial MODIS Land Surface Temperature Data (LSt Mode in Parenthesis) Are Compared. The Mean and Standard DeViation of Ground MEASUREMENTS ( $\left\langle\mathrm{SM}_{\text {HDAS }}\right\rangle$ AND $\sigma$ HDAS $)$, THE NUMBER OF CONSIDERED 1-km PiXels and Statistical Significance (P-VAlue) Are Also Listed for Each Date-Farm Unit

\begin{tabular}{|c|c|c|c|c|c|c|c|c|}
\hline DoY/Farm & $\begin{array}{c}\left\langle\mathrm{SM}_{\mathrm{HDAS}}\right\rangle \\
\left(\mathrm{m}^{3} / \mathrm{m}^{3}\right)\end{array}$ & $\begin{array}{c}\sigma_{\mathrm{HDAS}} \\
\left(\mathrm{m}^{3} / \mathrm{m}^{3}\right)\end{array}$ & $\begin{array}{l}\text { Number of } \\
1 \mathrm{~km} \text { pixels }\end{array}$ & $\begin{array}{l}\text { RMSD* } \\
\left(\mathrm{m}^{3} / \mathrm{m}^{3}\right)\end{array}$ & $\begin{array}{c}\text { Bias* } \\
\left(\mathrm{m}^{3} / \mathrm{m}^{3}\right)\end{array}$ & $\begin{array}{l}\mathrm{R}^{\dagger} \\
(-)\end{array}$ & $\begin{array}{c}\text { Slope }^{\dagger} \\
(-)\end{array}$ & $\begin{array}{c}\text { p-value } \\
(-)\end{array}$ \\
\hline $28 / \mathrm{F} 05$ & 0.04 & 0.02 & $7(7)$ & $0.04(0.04)$ & $-0.04(-0.04)$ & $-(-)$ & $-(-)$ & $0.72(0.80)$ \\
\hline $30 / \mathrm{F} 07$ & 0.02 & 0.03 & $8(8)$ & $0.02(0.02)$ & $-0.02(-0.02)$ & $-(-0.70)$ & $-(-0.08)$ & $0.20(0.05)$ \\
\hline $30 / \mathrm{F} 08$ & 0.03 & 0.02 & $7(7)$ & $0.02(0.02)$ & $-0.02(-0.02)$ & $-(-0.95)$ & $-(-0.03)$ & $0.11(0.001)$ \\
\hline $46 / F 15$ & 0.29 & 0.05 & $8(8)$ & $0.09(0.09)$ & $0.09(0.08)$ & $-(0.66)$ & - (1.4) & $0.13(0.07)$ \\
\hline $46 / \mathrm{F} 16$ & 0.34 & 0.06 & $3(2)$ & $0.07(0.14)$ & $-0.06(-0.12)$ & $-(-)$ & $-(-)$ & $0.96(-)$ \\
\hline 49/F17 & 0.21 & 0.06 & $8(8)$ & $0.02(0.04)$ & $0.02(-0.02)$ & $0.79(-)$ & $0.71(-)$ & $0.02(0.64)$ \\
\hline 49/F18 & 0.25 & 0.07 & $1(0)$ & $-(-)$ & $-(-)$ & $-(-)$ & $-(-)$ & $0.20(0.20)$ \\
\hline $49 / \mathrm{F} 20$ & 0.20 & 0.09 & $4(4)$ & $0.05(0.02)$ & $0.05(0.01)$ & $0.98(0.92)$ & $1.1(0.42)$ & $0.02(0.08)$ \\
\hline $51 / \mathrm{F} 19$ & 0.24 & 0.08 & $0(1)$ & $-(-)$ & $-(-)$ & $-(-)$ & $-(-)$ & $0.19(0.19)$ \\
\hline $51 /$ F 20 & 0.20 & 0.10 & $6(6)$ & $0.09(0.09)$ & $-0.09(-0.09)$ & $-(-)$ & $-(-)$ & $0.70(0.45)$ \\
\hline AACES-1 mean & $0.21(0.25)$ & $0.08(0.07)$ & $6(6)$ & $0.04(0.06)$ & $0.04(0.05)$ & $0.89(0.79)$ & $0.91(0.91)$ & $0.02(0.08)$ \\
\hline 254/F09 & 0.33 & 0.07 & $4(7)$ & $0.05(0.12)$ & $-0.03(-0.02)$ & $-(-)$ & $-(-)$ & $0.70(0.30)$ \\
\hline $256 / \mathrm{F} 07$ & 0.36 & 0.10 & $8(4)$ & $0.12(0.15)$ & $-0.10(-0.13)$ & $-(-)$ & $-(-)$ & $0.13(0.43)$ \\
\hline 264/F13 & 0.30 & 0.07 & $8(7)$ & $0.14(0.17)$ & $-0.13(-0.14)$ & $-(-)$ & $-(-)$ & $0.64(0.86)$ \\
\hline $265 / \mathrm{F} 15$ & 0.25 & 0.06 & $2(2)$ & $0.26(0.30)$ & $0.26(0.30)$ & $-(-)$ & $-(-)$ & $-(-)$ \\
\hline 267/F09 & 0.21 & 0.07 & $8(9)$ & $0.15(0.15)$ & $-0.15(-0.15)$ & $-(-)$ & $-(-)$ & $0.77(0.85)$ \\
\hline AACES- 2 mean & - & - & $-(-)$ & $-(-)$ & $-(-)$ & $-(-)$ & $-(-)$ & $>0.10(>0.10)$ \\
\hline
\end{tabular}

$\ddagger$ the mean values computed for AACES- 1 and AACES-2 include only statistically significant $(p$-value $<0.10)$ results and discard extensive dry days DoY 28-30.

947 and a first-order Taylor series expansion around the field-mean 948 soil moisture. In this study, the disaggregation approach is ap949 plied to 40-km resolution version-4 SMOS level-2 soil moisture 950 using 1-km resolution MODIS data. The objective is to test 951 DisPATCh under different surface and atmospheric conditions 952 using the very intensive ground measurements collected in 953 southeastern Australia during the 2010 summer and winter 954 AACES campaigns. Those measurements are aggregated at 955 the downscaling resolution $(1 \mathrm{~km})$ and subsequently compared 956 to the disaggregated SMOS soil moisture. Over the study 957 area, climatic (evaporative demand), meteorologic (presence 958 of clouds), and vegetation (cover and water status) conditions 959 are strong constraints on disaggregation results. The quality 960 of disaggregation products varies greatly according to season: 961 while the correlation coefficient between disaggregated and 962 in situ soil moisture is 0.7 during the summer AACES, it 963 is about zero during the winter AACES, consistent with a 964 weaker coupling between evaporation and surface moisture 965 in temperate than in semi-arid climate. Moreover, vegetation 966 cover prevents the soil temperature to be retrieved from thermal 967 infrared data and the vegetation water stress may increase the 968 remotely sensed land surface temperature independent of near969 surface soil moisture. By separating the 1-km pixels where 970 MODIS temperature is mainly controlled by soil evaporation, from those where MODIS temperature is controlled by both 971 soil evaporation and vegetation transpiration, the correlation 972 coefficient between disaggregated and in situ soil moisture is 973 increased from 0.70 to 0.85 during the summer AACES cam- 974 paign. Also, cloud cover totally obscures the surface during rain 975 events, and on clear sky days, the water vapor in the atmosphere 976 significantly affects the quality of land surface temperature 977 data. It is found that the 5-km resolution atmospheric correction 978 of the official MODIS temperature data has significant impact 979 on DisPATCh output. An alternative atmospheric correction at 980 40-km resolution increases the correlation coefficient between 981 disaggregated and in situ soil moisture from 0.72 to 0.82 during 982 the summer AACES.

983

The above limitations must be kept in mind when using 984 DisPATCh as a tool for validating SMOS soil moisture. Over 985 semi-arid areas, disaggregation can solve the extent mismatch 986 between the 40-km resolution SMOS data and localized in situ 987 measurements. However, the validation of SMOS using Dis- 988 PATCh requires separation of the errors associated with SMOS 989 data and the errors associated with DisPATCh. As SMOS data 990 are an input to DisPATCh, the errors in DisPATCh are also 991 linked to the uncertainty in SMOS soil moisture. Nevertheless, 992 one way to identify the error sources specifically attributed 993 to DisPATCh is to analyze the spatial correlation between 994 


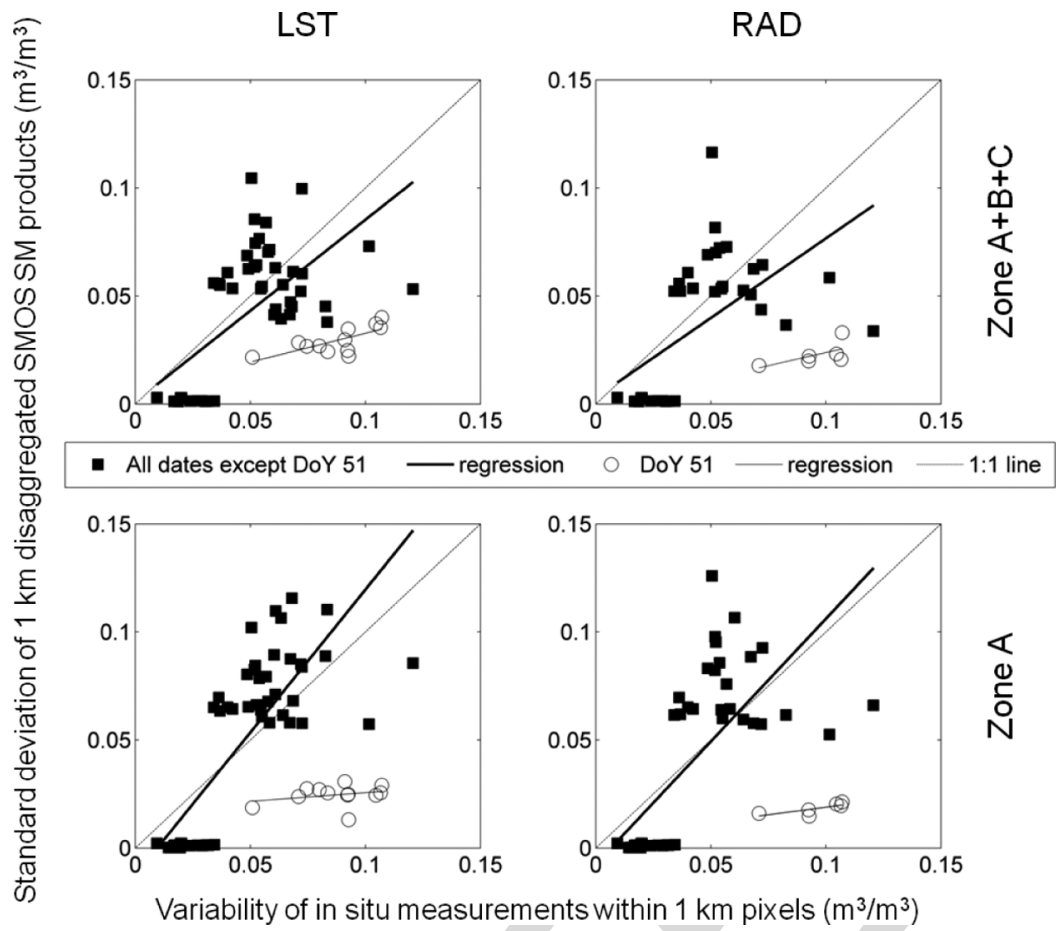

Fig. 10. Estimated uncertainty in disaggregated soil moisture $\left(\sigma_{\mathrm{SM}}, 1 \mathrm{~km}\right)$ versus subpixel variability of $1 \mathrm{~km}$ resolution in situ measurements for DisPATCh run in LST or RAD mode and Zone $\mathrm{A}+\mathrm{B}+\mathrm{C}$ or Zone A only mode.

995 disaggregated SMOS data and the in situ measurements made 996 at a distance larger than the downscaling resolution $(1 \mathrm{~km}$ with 997 MODIS data) and smaller than the SMOS data sampling length $998(15 \mathrm{~km})$.

999 Based on the results obtained using the AACES in situ 1000 measurements, several improvements of DisPATCh can be 1001 suggested:

1002

1003

1004

1005

1006

1007

1008

1009

1010

1011

1012

1013

1014

1015

1016

1017

1018

1019

1020

1021

1022

1023

1024

1025

1026
- Use of the MODIS land surface temperature quality index to select the SMOS pixels with the highest MODIS data quality.

- Correcting the MODIS land surface temperature for topography and illumination effects [45]. Within a 40-km SMOS resolution pixel, the elevation range may be very significant and thus induce a variability in land surface temperature that is not attributed to surface soil moisture.

- Use of ancillary air temperature data to constrain the estimation of end-members. The unstressed vegetation temperature $\mathbf{T}_{\mathbf{v}, \text { min }}$ could be set to the air temperature instead of the minimum MODIS land surface temperature. This would make the estimation of $\mathbf{T}_{\mathbf{v}, \mathbf{m i n}}$ less dependent on the representativeness of the surface conditions met within the SMOS pixel [24].

- Accounting for the dependency of soil evaporative efficiency to potential evaporation, by replacing the model in [26] with the model in [38].

- Estimating an optimal downscaling resolution for each season: as the sensitivity of soil evaporative efficiency to soil moisture is lower in the winter months than in the summer months, aggregating DisPATCh output may improve the quality of disaggregation products at the expense of spatial resolution [17].
A robust disaggregation methodology of SMOS soil moisture 1027 at $1-\mathrm{km}$ resolution, which would provide both disaggregated 1028 soil moisture and its uncertainty at $1-\mathrm{km}$ resolution is a crucial 1029 step toward the application of SMOS data to hydrological 1030 studies.

\section{REFERENCES}

[1] E. G. Njoku and L. Li, "Retrieval of land surface parameters using passive 1033 microwave measurements at 6-18 GHz," IEEE Trans. Geosci. Remote 1034 Sens., vol. 37, no. 1, pp. 79-93, Jan. 1999.

1035

[2] C. S. Draper, J. P. Walker, P. J. Steinle, R. A. M. D. Jeu, and 1036 T. R. H. Holmes, "An evaluation of AMSR-E derived soil moisture 1037 over Australia," Remote Sens. Environ., vol. 113, no. 4, pp. 703-710, 1038 Apr. 2009. doi:10.1016/j.rse.2008.11.011.

1039

[3] C. Kummerow, W. S. Olson, and L. Giglio, "A simplified scheme for 1040 obtaining precipitation and vertical hydrometeor profiles from passive 1041 microwave sensors," IEEE Trans. Geosci. Remote Sens., vol. 34, no. 5, 1042 pp. 1213-1232, Sep. 1996.

1043

[4] M. Grecu and E. N. Anagnostou, "Overland precipitation estimation from 1044 TRMM passive microwave observations," J. Appl. Meteor., vol. 40, no. 8, 1045 pp. 1367-1380, Aug. 2001.

1046

[5] T. J. Jackson, M. H. Cosh, R. Bindlish, P. J. Starks, D. D. Bosch, 1047 M. Seyfried, D. C. Goodrich, M. S. Moran, and J. Du, "Validation of 1048 advanced microwave scanning radiometer soil moisture products," IEEE 1049 Trans. Geosci. Remote Sens., vol. 48, no. 12, pp. 4256-4272, Dec. 2010. 1050 doi:10.1109/TGRS.2010.2051035.

1051

[6] Y. H. Kerr, P. Waldteufel, J.-P. Wigneron, S. Delwart, F. Cabot, 1052 J. Boutin, M. J. Escorihuela, J. Font, N. Reul, C. Gruhier, S. E. Juglea, 1053 M. R. Drinkwater, A. Hahne, M. Martin-Neira, and S. Mecklenburg, 1054 "The SMOS mission: New tool for monitoring key elements of the 1055 global water cycle," Proc. IEEE, vol. 98, no. 5, pp. 666-687, May 2010. 1056 doi:10.1109/JPROC.2010.2043032.

1057

[7] P. Matos, A. Gutiérrez, and F. Moreira, SMOS L1 Processor Discrete 1058 Global Grids Document, vol. SMOS-DMS-TN-5200. Lisboa, Portugal: 1059 DEIMOS Engenharia, 2004, V1.4.

1060

[8] S. Bircher, J. E. Balling, N. Skou, and Y. Kerr, "SMOS validation by 1061 means of an airborne campaign in the Skjern river catchment, Western 1062 Denmark," IEEE Trans. Geosci. Remote Sens., 2011, to be published. 1063 AQ1

[9] C. Gruhier, P. de Rosnay, S. Hasenauer, T. Holmes, R. de Jeu, 1064 Y. Kerr, E. Mougin, E. Njoku, F. Timouk, W. Wagner, and M. Zribi 1065 
1066 (2010, Jan.). Soil moisture active and passive microwave products: 1067 Intercomparison and evaluation over a Sahelian site. Hydrol. Earth Syst. 1068 Sci. [Online]. 14(1), pp. 141-156. Available: www.hydrol-earth-syst1069 sci.net/14/141/2010/

1070 [10] J.-C. Calvet, N. Fritz, F. Froissard, D. Suquia, A. Petitpa, and B. Piguet, 1071 "In situ soil moisture observations for the CAL/VAL of SMOS: The 1072 SMOSMANIA network," in Proc. IGARSS, Barcelona, Spain, 2007, 1073 pp. 1196-1199.

1074 [11] S. Peischl, J. P. Walker, M. Allahmoradi, D. Barrett, R. Gurney, Y. Kerr, 1075 E. Kim, J. Le Marshall, C. Rüdiger, D. Ryu, and N. Ye, "Towards vali1076 dation of SMOS using airborne and ground data over the Murrumbidgee 1077 catchment," in Proc. MODSIM, Cairns, Australia, 2009, pp. 3733-3739.

1078 [12] M. H. Cosh, T. J. Jackson, S. M. Moran, and R. Bindlish, "Temporal 1079 persistence and stability of surface soil moisture in a semi-arid water1080 shed," Remote Sens. Environ., vol. 112, no. 2, pp. 304-313, Feb. 2008. 1081 doi:10.1016/j.rse.2007.07.001.

1082 [13] P. de Rosnay, C. Gruhier, F. Timouk, F. Baup, E. Mougin, P. Hiernaux, 1083 L. Kergoat, and V. Le Dantec, "Multi-scale soil moisture measurements 1084 at the Gourma meso-scale site in Mali," J. Hydrol., vol. 375, no. 1/2, 1085 pp. 241-252, Aug. 2009. doi:10.1016/j.jhydrol.2009.01.015.

1086 [14] N. S. Chauhan, S. Miller, and P. Ardanuy, "Spaceborne soil moisture esti1087 mation at high resolution: A microwave-optical/IR synergistic approach," 1088 Int. J. Remote Sens., vol. 24, no. 22, pp. 4599-4622, Nov. 2003.

1089 [15] M. Piles, A. Camps, M. Vall-llossera, I. Corbella, R. Panciera, C. Rüdiger, 1090 Y. H. Kerr, and J. P. Walker, "Downscaling SMOS-derived soil moisture 1091 using MODIS visible/infrared data," IEEE Trans. Geosci. Remote Sens., 1092 vol. 49, no. 9, pp. 3156-3166, Sep. 2011

1093 [16] O. Merlin, A. Al Bitar, J. P. Walker, and Y. Kerr, "An improved algorithm 1094 for disaggregating microwave-derived soil moisture based on red, near1095 infrared and thermal-infrared data," Remote Sens. Environ., vol. 114, 1096 no. 10, pp. 2305-2316, Oct. 2010. doi:10.1016/j.rse.2010.05.007.

1097 [17] O. Merlin, A. Al Bitar, J. P. Walker, and Y. Kerr, "A sequential model 1098 for disaggregating near-surface soil moisture observations using multi1099 resolution thermal sensors," Remote Sens. Environ., vol. 113, no. 10, 1100 pp. 2275-2284, Oct. 2009. doi:10.1016/j.rse.2009.06.012.

1101 [18] O. Merlin, J. Walker, R. Panciera, R. Young, J. Kalma, and 1102 E. Kim, "Soil moisture measurement in heterogeneous terrain," in Proc. 1103 MODSIM-International Congress Modelling Simulation Modelling 1104 Simulation Society Australia New Zealand, Dec. 2007, pp. 2604-2610.

1105 [19] Y. H. Kerr, P. Waldteufel, P. Richaume, P. Ferrazzoli, and J.-P. Wigneron, 1106 SMOS Level 2 Processor Soil Moisture Algorithm Theoretical Basis 1107 Document (ATBD), vol. SO-TN-ESL-SM-GS-0001. Toulouse, France: 1108 CESBIO, May 2011, V3.f.

1109 [20] Y. H. Kerr, P. Waldteufel, P. Richaume, J. P. Wigneron, P. Ferrazzoli, 1110 A. Mahmoodi, A. Al Bitar, F. Cabot, C. Gruhier, D. Leroux, A. Mialon, 1111 and S. Delwart, "The SMOS soil moisture retrieval algorithm," IEEE Trans. Geosci. Remote Sens., 2011.

1113 [21] O. Merlin, C. Rüdiger, P. Richaume, A. Al Bitar, A. Mialon, J. P. Walker, 1114 1115 and Y. Kerr, Disaggregation as a top-down approach for evaluating $40 \mathrm{~km}$ resolution SMOS data using point-scale measurements: Application to AACES-1," in Proc. SPIE, Remote Sens. Agriculture, Ecosystems, Hydrol. XII, Toulouse, France, 2010, pp. 782 40I-1-78240I-8.

22] K. Nishida, R. R. Nemani, J. M. Glassy, and S. W. Running, "Development of an evapotranspiration index from Aqua/MODIS for monitoring surface moisture status," IEEE Trans. Geosci. Remote Sens., vol. 41, no. 2, pp. 493-501, Feb. 2003.

23] G. Gutman and A. Ignatov, "The derivation of the green vegetation fraction from NOAA/AVHRR data for use in numerical weather prediction models," Int. J. Remote Sens., vol. 19, pp. 1533-1543, 1998.

24] O. Merlin, B. Duchemin, O. Hagolle, F. Jacob, B. Coudert, G. Chehbouni, G. Dedieu, J. Garatuza, and Y. Kerr, "Disaggregation of MODIS surface temperature over an agricultural area using a time series of Formosat-2 images," Remote Sens. Environ., vol. 114, no. 11, pp. 2500-2512, Nov. 2010. doi:10.1016/j.rse.2010.05.025.

5] A. C. T. Pinheiro, J. Descloitres, J. L. Privette, J. Susskind, L. Iredell, and J. Schmaltz, "Near-real time retrievals of land surface temperature within the MODIS rapid response system," Remote Sens. Environ., vol. 106, no. 3, pp. 326-336, Feb. 2007. doi:10.1016/j.rse.2006.09.006.

26] J. Noilhan and S. Planton, "A simple parameterization of land surface processes for meteorological models," Monthly Weather Rev., vol. 117, no. 3, pp. 536-549, 1989.

[27] O. Merlin, J. P. Walker, A. Chehbouni, and Y. Kerr, "Towards deterministic downscaling of SMOS soil moisture using MODIS derived soil evaporative efficiency," Remote Sens. Environ., vol. 112, no. 10, pp. 39353946, Oct. 2008. doi:10.1016/j.rse.2008.06.012.

28] M. S. Moran, T. R. Clarke, Y. Inoue, and A. Vidal, "Estimating crop water deficit using the relation between surface-air temperature and spectral vegetation index," Remote Sens. Environ., vol. 49, no. 3, pp. 246-263, 1143 1994.

[29] T. N. Carlson, R. R. Gillies, and E. M. Perry, "A method to make use 1145 of thermal infrared temperature and NDVI measurements to infer soil 1146 water content and fractional vegetation cover," Remote Sens. Rev., vol. 52, 1147 pp. 45-49, 1994.

1148

[30] O. Merlin, G. Chehbouni, J. P. Walker, R. Panciera, and Y. Kerr, "A 1149 simple method to disaggregate passive microwave based soil moisture," 1150 IEEE Trans. Geosci. Remote Sens.-SMOS Special Issue, vol. 46, no. 3, 1151 pp. 786-796, Mar. 2008. doi:10.1109/TGRS.2007.914807.

[31] W. P. Kustas and J. M. Norman, "Evaluation of soil and vegetation heat 1153 flux predictions using a simple two-source model with radiometric tem- 1154 peratures for partial canopy cover," Agricultural Forest Meteorol., vol. 94, 1155 no. 1, pp. 13-29, 1999.

1156

[32] M. C. Anderson, J. M. Norman, G. R. Diak, W. P. Kustas, and 1157 J. R. Mecikalski, "A two-source time-integrated model for estimating sur- 1158 face fluxes using thermal infrared remote sensing," Remote Sens. Environ., 1159 vol. 60, no. 2, pp. 195-216, May 1997.

[33] O. Merlin and G. Chehbouni, "Different approaches in estimating heat 1161 flux using dual angle observations of radiative surface temperature," Int. 1162 J. Remote Sens., vol. 25, no. 1, pp. 275-289, 2004.

[34] T. J. Lee and R. A. Pielke, "Estimating the soil surface specific humidity," 1164 J. Appl. Meteorol., vol. 31, no. 5, pp. 480-484, 1992.

1165

[35] T. S. Komatsu, "Towards a robust phenomenological expression of evapo- 1166 ration efficiency for unsaturated soil surfaces," J. Appl. Meteorol., vol. 42, 1167 no. 9 , pp. $1330-1334$, Sep. 2003.

[36] O. Merlin, J. P. Walker, J. D. Kalma, E. J. Kim, J. Hacker, 1169 R. Panciera, R. Young, G. Summerell, J. Hornbuckle, M. Hafeez, and 1170 T. J. Jackson, “The NAFE'06 data set: Towards soil moisture retrieval 1171 at intermediate resolution," Adv. Water Resour., vol. 31, pp. 1444-1455, 1172 2008. doi:10.1016/j.advwatres.2008.01.018.

[37] Z. Wan and J. Dozier, "A generalized split-window algorithm for retriev- 1174 ing land-surface temperature from space," IEEE Trans. Geosci. Remote 1175 Sens., vol. 34, no. 4, pp. 892-905, Jul. 1996.

1176

[38] O. Merlin, A. Al Bitar, V. Rivalland, P. Béziat, E. Ceschia, and G. Dedieu, 1177 "An analytical model of evaporation efficiency for unsaturated soil sur- 1178 faces with an arbitrary thickness," J. Appl. Meteorol. Climatol., vol. 50, 1179 no. 2, pp. 457-471, Feb. 2011. doi:10.1175/2010JAMC2418.1.

[39] N. Agam, W. P. Kustas, M. C. Anderson, F. Li, and C. M. U. Neale, 1181 "A vegetation index based technique for spatial sharpening of thermal 1182 imagery," Remote Sens. Environ., vol. 107, no. 4, pp. 545-558, 2007.

[40] E. E. Small and S. A. Kurc, "Tight coupling between soil moisture and the 1184 surface radiation budget in semiarid environments: Implications for land- 1185 atmosphere interactions," Water Resour. Res., vol. 39, no. 10, p. 1278, 1186 Oct. 2003. doi:10.1029/2002WR001297.

1187

[41] C. Rüdiger, J. P. Walker, and Y. H. Kerr, "On the airborne spatial coverage 1188 requirement for microwave satellite validation," IEEE Geosci. Remote 1189 Sens. Lett., vol. 8, no. 4, pp. 824-828, Jul. 2011.

[42] R. Young, J. Walker, N. Yeoh, A. Smith, K. Ellett, O. Merlin, and 1191 A. Western, Soil Moisture and Meteorological Observations from the 1192 Murrumbidgee Catchment. Melbourne, Australia: Dept. Civil Environ. 1193 Eng., Univ. Melbourne, 2008.

1194

[43] A. J. Teuling, R. Uijlenhoet, R. Hurkmans, O. Merlin, R. Panciera, 1195 J. Walker, and P. A. Troch, "Dry-end surface soil moisture variability 1196 during NAFE'06," Geophys. Res. Lett., vol. 34, no. L17402, Sep. 2007. 1197

[44] W. T. Crow and E. F. Wood, "The assimilation of remotely sensed soil 1198 brightness temperature imagery into a land surface model using Ensemble 1199 Kalman filtering: A case study based on ESTAR measurements during 1200 SGP97," Adv. Water Resour., vol. 26, pp. 137-149, 2003.

[45] Q. K. Hassan, C. P.-A. Bourque, F.-R. Meng, and R. M. Cox, “A wetness 1202 index using terrain-corrected surface temperature and normalized differ- 1203 ence vegetation index derived from standard MODIS products: An eval- 1204 uation of its use in a humid forest-dominated region of eastern Canada," 1205 Sensors, vol. 7, no. 10, pp. 2028-2048, 2007.

Olivier Merlin, photograph and biography not available at the time of 1207 publication.

Christoph Rüdiger, photograph and biography not available at the time of 1209 publication. 
1211 Ahmad Al Bitar, photograph and biography not available at the time of 1212 publication.

1213 Philippe Richaume, photograph and biography not available at the time of 1214 publication.
Jeffrey P. Walker, photograph and biography not available at the time of 1215 publication.

Yann H. Kerr, photograph and biography not available at the time of 1217 publication. 


\section{AUTHOR QUERIES}

\section{AUTHOR PLEASE ANSWER ALL QUERIES}

Please be aware that the authors are required to pay overlength page charges ( $\$ 200$ per page) if the paper is longer than 6 pages. If you cannot pay any or all of these charges please let us know.

AQ1 = Please provide publication update in Ref. [8].

AQ2 = Please provide volume. issue number, page range and month of publication in [20].

\section{END OF ALL QUERIES}

